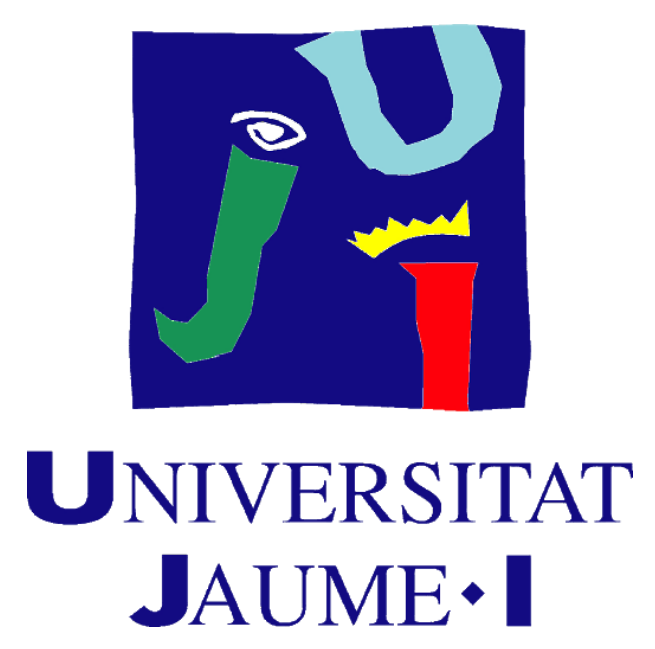

Doctoral programme in Economics and Business

Universitat Jaume I Doctoral School

\title{
Homo Geographicus and Homo Economicus: the role of territorialization in generating cooperation. The case of the Sibari Plain
}

Report submitted by Raffaella Rose in order to be eligible for a doctoral degree awarded by the Universitat Jaume 1

Author:

Raffaella ROSE
Supervisor:

Dr. Gabriele TEDESCHI 


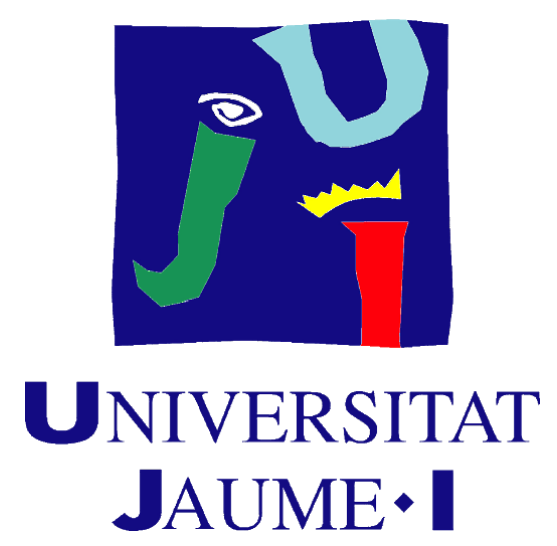

Programa de Doctorado en Economía y Empresa

Escuela de Doctorado de la Universitat Jaume I

\section{Homo Geographicus and Homo Economicus: the role of territorialization in generating cooperation. The case of the Sibari Plain}

Raffaella Rose

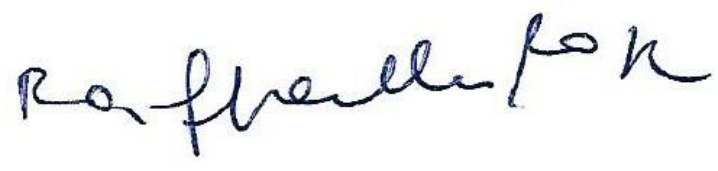

Dr Gabriele Tedeschi

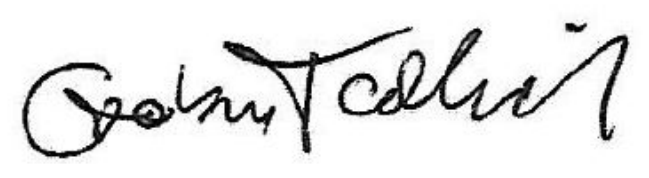




\section{Contents}

Abstract

Introduction

1. The unit of investigation: the territorial system of the Sibari Plain 5

$\begin{array}{ll}1.1 \text { A note on methodology } & 6\end{array}$

$\begin{array}{lr}\text { 2. Social capital } & 8\end{array}$

3. The territorial dimension of the 'Ndrangheta and its influence on the available social capital 11

4. Geographic framework and settlement processes 16

5. Territorialization: the constraints and the possibilities 20

6. Water control and its role in the building of territorial social capital 21

7. Reclamation and irrigation in the Sibari Plain 24

8. Structures and pathways of the agricultural economy of Calabria 25

$\begin{array}{ll}\text { 8.1 The role of agriculture today } & 28\end{array}$

$\begin{array}{lr}\text { 9. The citriculture } & 29\end{array}$

9.1 Citrus as a commodity and the birth of the mafia, a hypothesis 30

$\begin{array}{lr}9.2 \text { Current citriculture } & 30\end{array}$

9.3 The turn to the organic production $\quad 35$

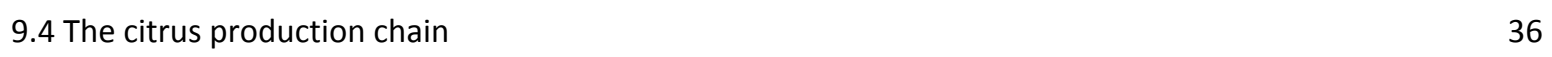

10. Citrus growing and irrigation in the Sibari Plain, an inseparable duo 36

11. The "unspoken" of the Sibari Plain $\quad 39$

12. Producer enterprises $\quad 42$

$\begin{array}{ll}\text { 13. The commercialization } & 44\end{array}$

14. Selling to wholesale traders $\quad 46$

15. The players of private intermediation $\quad 46$

$\begin{array}{lr}\text { 16. The Cooperatives } & 49\end{array}$

16.1 Introduction to cooperativism in Calabria $\quad 49$

16.2 Concentration of supply: cooperatives for the marketing of citrus fruits 51

16.3 Associated cooperativism: Producer Organizations (POs) 54

17. Field interviews with various operators $\quad 56$ 
18.1 The results

19. Interviews and questionnaire: the "something" in the cooperating 65

20. The role of available social capital

21. Social Network Analysis (SNA)

21.1 Results

21.2 Discussion of results from network analysis 76

Conclusions 78

References 



\section{Abstract}

Thanks to its pedoclimatic pre-conditions and the great anthropogenic modification of the natural environment of the coastal plain - due to the integral bonification (1930-1950) - the territory of the Sibari Plain (Calabria Region, southern Italy), within a few decades, has turned from a marshy and malarial land into one of the most valuable areas of citrus production.

The Sibari Plain accounts for $50 \%$ of the total production of clementines in Italy (Ismea, 2016). Clementine citrus fruit plays a primary role in the economy of the coastal plain, both as a quantity production as well as an added value. It turned out to be a successful endogenous development strategy especially when compared with industrial development strategies, which were implemented through top down policies during the second half of the 20th century.

One of the most significant features of Italian citrus production is the close link between citrus fruits and the territories in which they grow. The labels that certify their origin (Protected Designation of Origin and Protected Geographical Indication) provide an important added value to the product in phase of commercialization, and also guarantee the originality of citrus production in terms of biodiversity, value of cultivation practices, richness of landscapes and environmental protection.

Here, the study of the clementinization of the Sibari Plain provides an expedient way to understand how and to what extent the territorialization processes have been useful in building social capital in the long run. Furthermore, this study provides an insight into the nature and role played by the specific social capital in the citrus economy of the Plain, especially in building cooperative networks for citrus marketing.

\section{Introduction}

Territory $^{1}$ is one of the spatial geographical dimensions, a distinct dimension from the concept of space, environment and region. By the term territory, we mean a

\footnotetext{
${ }^{1}$ The territory is the result of an action conducted by a player on the space. By appropriating concretely or abstractly (for example, through representation) of a space, the player territorializes this space, constantly reorganizing the pre-existing conditions (C. Raffestin, p. 149, 1980).

The land becomes territory when it is a means of communications, when it is a means and object of work, production, exchanges, cooperation (G. Dematteis, p. 74, 1985)

Let us try to understand geography as the territorial form of social action. We call space an extension of the Earth's surface with mere physical attributes, while we call territory a space over which some human work has been carried out; the process through which this artefact is constituted and evolves is called territorialization (Turco, p.15, 1988).
} 
dynamic and complex geographical reality, produced (and continuously reproduced) by the interaction between physical-natural elements and anthropogenic processes. Complexity is a feature of systems which consist of many interacting entities, whose collective behavior cannot be explained as the sum of individual behaviors considered separately.

A territory can be delimited by administrative or physical boundaries and it can be considered as an organism which undergoes a specific evolutionary process. The territorialization process is a collective process which arises from man's effort to emancipate himself from the primordial constraints of nature, thus moving from deterministic relations to possibilistic relations (Turco A., 1988). Societies, observed in their territorial dimension, can be understood as dynamic systems of living beings which, by relating themselves, generate social networks through which they produce territory and create economies. These economies are therefore deeply embedded ${ }^{2}$ in the social and environmental dimension of the territories.

These are the dimensions that will be considered in what we can define as the clementine district, that is the current and characterizing form of the economic organization of the Sibari Plain - a coastal plain generated by the flooding of the downstream part of the hydrographic network corresponding to the hydrographic basin Crati-Coscile and other minor streams. The wide availability of superficial and deep waters allows the extensive and intensive cultivation of the citrus fruits typical of the Mediterranean regions. Given the characteristics of the climate of these regions, water resources represent an asset which should be managed efficiently.

The management of water for irrigation is a tangible expression of the

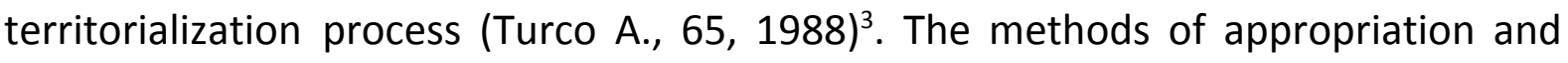
management are the result of social and cultural dimensions which in turn shape the social and environmental dimensions of the territories and communities (Bevilacqua, 2000).

When analysing development processes, neoclassical economics traditionally refers to a simplified geographical dimension, the spatial dimension: it is an undifferentiated and uniform geographical entity that can be treated by generalizing and universalist models (Governa F., 2001). In this economic dimension, the geographical reference element in which to embed economic phenomena appears as a simplified container provided with only a few measurable variables: a perfect scenario for the rational action of homo oeconomicus. It is a paradigmatic metaphor

\footnotetext{
2 By embeddedness I therefore mean that economic action as well as its outcomes and economic institutions are influenced by the personal relationships of the actors, and by the overall structure of the network of these relationships (M. Granovetter, p. 215, 1988)

${ }^{3}$ Continental hydrography is one of the major bricks on which territorialisation is built (Turco A., 65, 1988).
} 
endowed with an axiomatic rationality which pursues a single goal: the maximization of his individual interest by responding to the market signals.

Therefore, the spatial geographic dimension, characterised by a few simplified variables, presents itself as a suitable geographic dimension congenial to neoclassical economic analysis.

In this study I imagined an alternative metaphorical figure - the homo geographicus". A 'geographical man/woman' - or what I will call here homo geographicus - can behave very differently from the way they are supposed to behave according to economic orthodoxy (Sokol M. p. 25, 2011). An agent who acts with another type of rationality within a localized, multifactorial and diversified space. An actor who makes choices between the possibilities and constraints of the environment in which it is immersed. It is a social figure who transforms the relational space in which he is immersed.

One can imagine the homo geographicus as an economic agent acting within a framework of rationality that is much broader than that attributed to the homo oeconomicus. The homo geographicus considers social and environmental conveniences, and by acting collectively it territorializes and generates something we can call territorial social capital ${ }^{5}-$ an unused or underused resource of which there is little awareness (Flora A., p. 136, 2008). It territorializes and, by territorializing, transforms itself into a non-dualistic dimension. It is a non-dualistic vision of the environment and of man, which is far from the behavioral models attributed to homo oeconomicus.

\footnotetext{
${ }^{4}$ A particular social actor who, despite the multiplicity of roles that he plays, in some way or at some time: a) produces territory, b) uses territory, c) activates, develops and concludes relationships with other social actors through the territory (A. Turco, p. 52, 1988). The territorial action of homo geographicus is supported by three logics: eco-logical, bio-logical and socio-logical (Raffestin C. in Turco A., 1988).

${ }^{5}$ Due to its identification with a given territory, the social capital assumes the connotation of the territorial social capital (A. Flora, p. 173, 2008).
} 


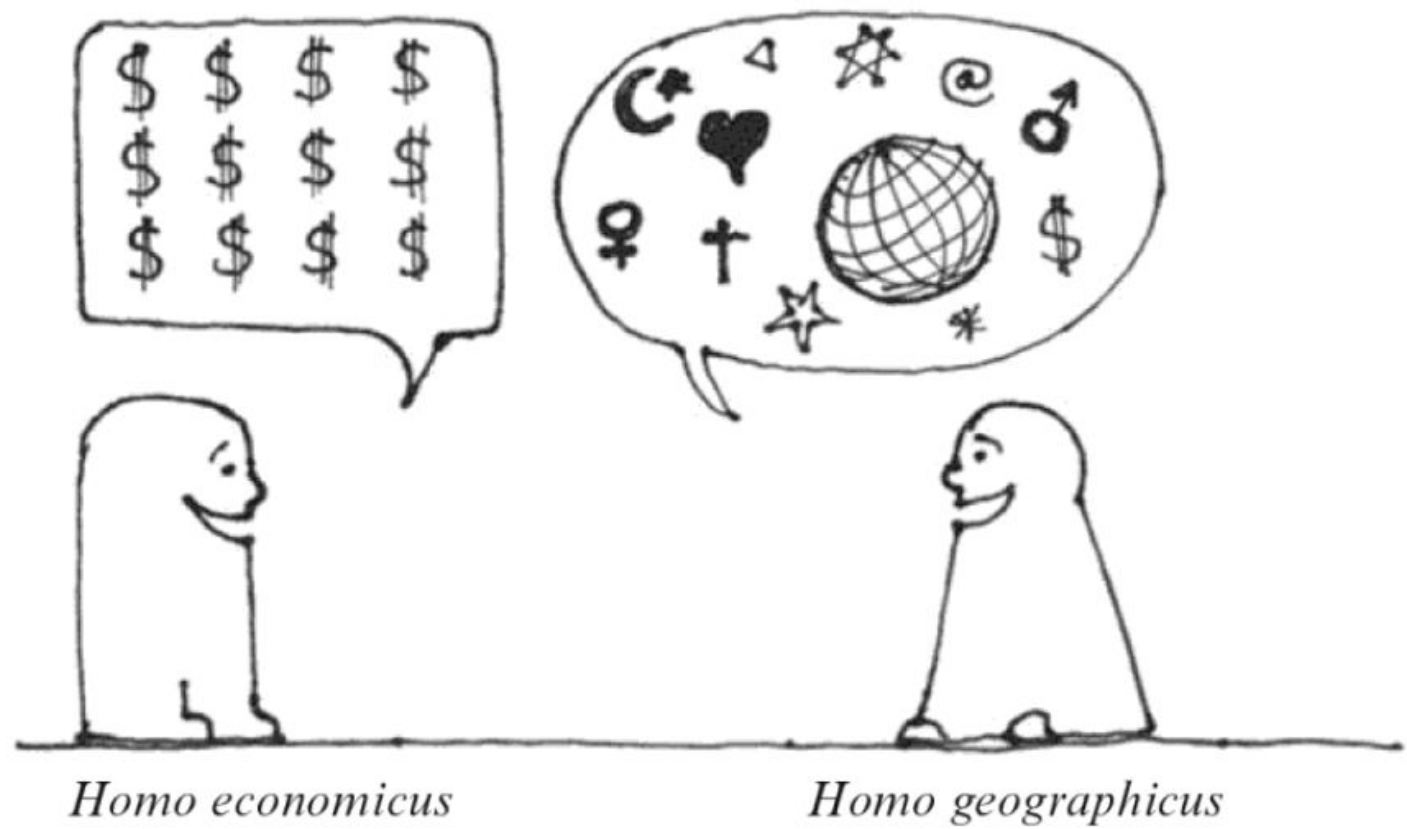

(C) M. Sokol, 2008

Figure 1 Homo economicus and Homo geographicus (Sokol M. p. 25, 2011).

The recognition of the existing relationships between economic development and the territorial dimension of the geographic space first emerged in economics with the Marshallian studies on industrial districts ${ }^{6}$ (1890). Later these relationships have been further investigated by economists, sociologists and geographers such as Bagnasco (1977) Becattini (1985), Dematteis (1985) through studies on the characteristics of the Italian economy. The replacement of the homogeneous and undifferentiated space of the neoclassical economy with a new complex, multidimensional and relational geographical entity such as the territory itself, has led to the overcoming of the geographical space intended as a passive support for activities and functions, or as a container of trivial resources available to the economic action.

The territory takes part in the economic dynamics in completely different ways. The local specificities and characteristics themselves derive from the development, in the historical period, of a complex order of relationships connecting a given social organization to a given geographical area. This produces synergies and externalities, thus defining the basis for the organization and the implementation of specific and localized development dynamics (F. Governa, p. 7, 2001)

\footnotetext{
${ }^{6}$ In The Principles of Economics Marshall describes industrial districts with special atmospheres which, in a broader sense, can coincide with the concept of milieu (Becattini, 1991).
} 
The territory, in its dimension of relational system with its own connotations, can be delimited by administrative or physical boundaries, but basically it can be considered as a system in which relations take place between the natural environment and living beings, and between human beings among themselves. It is a system which undergoes a specific evolutionary process and has an external environment. The territory as a generator and a container of dynamic and relational facts is therefore a complex system, outcome and condition of human action (Turco A., 1988). The territory generated by this co-evolution is consequently a highly complex living system, whose growth is nourished by non-deterministic but essential relationships between the physical environment, the built environment, the anthropic environment (Magnaghi A., p. 18, 2001). Having said that, let us consider the citrus economy of the Sibari Plain as the result and condition of a particular territorialization process. I have decided to opt for the geographical approach, both for the use of field research and for its scientific characteristics which allow us to grasp the complexity of the territories.

Geography, which is by definition multidisciplinary, prompts the dialogue between bio-physical and anthropogenic phenomena and processes.

This is the theoretical-geographical framework of reference in which we will study what can be defined as the clementine district ${ }^{7}$, that is the current and characterizing form of economic organization of the Sibari Plain.

\section{The unit of investigation: the territorial system of the Sibari Plain}

The selected territory has been identified as significant for the study of cooperativism in the marketing of citrus fruits, specifically the clementines. This territory accounts for $50 \%$ of the total production of clementines in Italy (Ismea, 2016).

The investigated territorial unit is defined by geographical and administrative boundaries and is characterised by a specific and original environmental and social dynamics, which are relevant for the purpose of this study.

With regard to this area, the emerging aspects pertaining the study of the economy of clementines are as follows:

\footnotetext{
7 The area of the plain can be defined as a rural district, due to the strong concentration and specialization of the plain in the production of clementines, the supply chain and the productive and commercial organization in the area, its typical landscape, the demographic density and the creation of the metropolitan city as a result of the union of Rossano and Corigliano.
} 
- the production area corresponds to a coastal plain generated by the flooding of the downstream part of the hydrographic network coinciding with the Crati-Coscile basin and other minor waterways. This hydrographic system has a particular geomorphology and water regime. The intensive cultivation of citrus fruits is made possible by the wide availability of surface and deep water for irrigation;

- a history of human settlement characterized by long cycles of abandonment and only two short periods of stable and flourishing settlement.

- long centuries of latifundia-based productive system and recent minifundia agriculture mainly characterised by citrus fruit cultivated with monoculture. The cooperative agricultural organization model was initially imposed and then stimulated with subsidies from top down policies in order to promote economic growth. However, it was not adopted as an effective strategy that could bring benefits through social and collaborative practices;

- in the entire region of Calabria there is a strong presence of the local mafia, the 'Ndrangheta, which while operating within global economic networks is characterized by a pervasive control of the territory in which it is rooted.

With reference to the clementines district, 14 municipalities $^{8}$ belongs to the Sibari plain: Villapiana, Cassano allo Ionio, Francavilla Marittima, San Lorenzo del Vallo, Spezzano Albanese, Terranova di Sibari, Trebisacce, Corigliano calabro, Altomonte, Castrovillari, Cerchiara di Calabria, Rossano, San Giorgio albanese, Vaccarizzo albanese (Cersosimo, 1996, Petrone, 1993, Viale, 1997).

\subsection{Note on methodology}

The work presented here fits into the methodological context of the geographical disciplines ${ }^{9}$. The studies on the agricultural sector referring to the area of connection between the physical-natural dimension and the anthropic-social dimension

\footnotetext{
8 In 2018 the municipalities of Corigliano calabro and Rossano merged into a single municipality called Corigliano-Rossano.

9 Among the various definitions, geography is understood here as the territorial form of social action (Turco,p.15, 1988)
} 
represent a strategic unit of investigation. As a matter of fact, these studies allow us to understand the interdependencies and outcomes of the relationship between human communities and ecosystems. Human beings are part of small-scale ecosystems where nature represents a second player. Nature, together with human activity, acts as an active partner in the process of producing wealth (Bevilacqua P., p. 10, 2000).

Field research, the typical method of investigation of the geographical disciplines, was used to carry out this multidisciplinary research. This consisted of 5 survey periods of study between 2016 and 2020. While working in the Sibari Plain, I have made contacts with some local producers and heads of cooperatives - whose activities I have followed over time - who provided me with data and information. A trust relationship has developed with some of these producers, allowing me to follow the evolution of their business over the years. Information was collected relating to the production process and price formation, the supply chain and the relational dynamics. These relationships are developed among producers who, in their turn, build relationships with other stakeholders and organizations to concentrate their citrus offer in the territorial context. My field research highlighted the strong discrepancy between the official Chamber of Commerce data referring to the conferment cooperatives active in the Sibaritide (the so called territory of Sibari Plain) and the actual data. Numerous interviews allowed me to discover the number of members for each first-degree active cooperative, and the relations of these with second-degree cooperatives. This information, which was not contained in official sources and which has been subject to major variations over the years, has been of the utmost importance for reconstructing the networks between producers and cooperatives.

In September 2020 I conducted an online and face-to-face citrus producers survey to try to understand the motivations which lay behind the cooperative and individualistic strategies during the commercialization of the citrus production. The distribution of the survey was scheduled for the end of the 2019-2020 citrus campaign, but due to the Covid-19 pandemic, I had to opt for a shorter period in September. This has prevented me from obtaining the expected number of answers. As for the database used for the Social Network Analysis, I used the Infocamere database, which contains the Chamber of Commerce official data and which records all the registered companies divided according to municipality, legal form and NACE. These data are disaggregated and nominal. This form of data dissemination has allowed the reconstruction of the networks between producers, cooperatives and the Producers' Organization (POs). This data set also contains others disaggregated 
information on the date of registration to the Chamber of Commerce, value of production, revenues, profits or losses and the latest balance sheet.

The Italian national lists of POs (Producer Organizations) and fruit and vegetables APOs (associations of producer organizations) recognized by the Ministry of Agricultural, Food and Forestry Policies (MIPAAF) was used with regards to second and third-level cooperative organizations.

\section{Social capital}

In the modern Western world, we think of life and the economy as being ordered by formal laws and property rights. Yet formal rules in even the most developed country make up a small (although very important) part of the sum of constraints that shape choices. In our daily interactions with others, whether within the family, in eternal social relations or in business activities, the governing structure is overwhelmingly defined by codes of conduct, norms of behavior, and conventions. (D. North, p. 36, 1990)

The phenomenon of the commercialization of clementines was analysed through the dimension of the specific social capital characterising the studied territory. We can argue that the economic actors and their networks represent both the expression and the cause of this social capital.

The territory meant as a system of interrelations between economic, socio-cultural and political factors which influence development. This also implies that the endogenous aspects, the responsiveness and adaptation capacities of the different local contexts, acquire more importance than external constraints and conditioning. Clearly, it is not a matter of neglecting exogenous constraints, but of trying to connect them to the endogenous components perhaps more extensively compared to the past. And it is precisely in this field, which involves more non-economic variables, that the contribution of a historical-sociological approach is particularly important (Trigilia, p. 170, 1988).

The concept of social capital, which emerged in the Sixties of last century in the sociological field (Jacobs, 1961; Bourdieu, 1980, 1986; Coleman, 1990; Granovetter, 1973, 1985), was first used in the Nineties to study economic and political phenomena.

There are basically two theoretical lines - one headed by Putnam (1993) and Fukuyama (1995) and the other headed by Coleman (1990). The first theoretical line identifies the matrices and consequences of social capital in trust, cooperation and 
norms of reciprocity, while according to the second one the matrix of the social capital is to be found in the networks of relationships.

The concept of social capital has been often criticized for its vagueness and imprecision, including the measurement difficulties which consequently arise. However, it is also true that the ambiguity, plurality and even contradictoriness of the forms it assumes [...] just embody the situational and dynamic aspect (F. Piselli, p.400, 1999). On the one hand, the situational aspect can be understood as relating to specific geographic contexts: an intangible relational heritage, the result and the condition of specific territorialization processes. On the other hand, this dimension is also dynamic because it is subject to change over time.

The purpose is to understand whether and how the geographically localized social capital, which will be defined as territorial social capital ${ }^{10}$ - an unused or underused resource of which there is little awareness (Flora, p. 136, 2008) - has played a role in associations for the marketing of citrus fruits. From this point of view, the hypothesis is that over time, in the Sibari Plain, a shared relational heritage has been produced and reproduced. This in turn has generated specific behaviors and behavioural models within which the economy of clementines and its networks are embedded.

While in the immediate term individual and collective behaviours seem in a certain way rational because they are advantageous for a single individual and for specific cliques, in the long term, however, they appear to be inefficient and unfavorable at a collective level for the territorial system as a whole.

Among the different definitions, interpretations and uses of social capital, the one proposed by J. Coleman, differently from other authors, is devoid of positive moral connotations in terms of the ability to cooperate "Social capital is defined by its function. It is not a single entity, but a variety of different entities having two characteristics in common: they all consist of some aspect of a social structure, and they facilitate certain actions of individuals who are within the structure. Like other forms of capital, social capital is productive, making possible the achievement of certain ends that in its absence would not be possible" (p. 302, 1990).

In this theoretical framework, social capital is not a generic attitude of trust and cooperation that underlies a shared local culture, as in Putnam (1993) and Fukuyama (1995), but it is, on the contrary, the product of a relational system that can improve,

\footnotetext{
10 To the best of my knowledge, this attribute of the social capital is mentioned for the first time in Flora A., $p$. 173, 2008 "Due to its identification in a specific territorial context, the social capital then assumes the connotation of territorial social capital. This is to underline not only the geographical limits within which relations operate, but also because it is the territory itself, as historically and anthropically understood, which produces such relations". Few authors provide geographical attributes to social capital geographical localized social capital in K. Laursen et al, 2012 and G. Giudici et al., 2013.
} 
but also hinder cooperation, trust, civic awareness, openness to innovation, local development (C. Trigilia, p. 419, 1999).

Social capital is not an attitude of trust. Trust is a by-product of interaction in social networks. So is distrust. Contra Putnam, interpersonal trust does not readily spill over into trust in formal organizations or political institutions. (Rose R., 2000).

In the case of societies characterized by organizational inefficiencies of state and market, and by the corruption of formal organizations, social capital existing into the lattices can be used to the advantage of illegal or informal networks linked to restricted cliques (Ibidem, 2000).

When state and market formal organizations fail, those who rely merely on formal organizations become socially excluded, as they have no other network. Therefore, one can, consciously or unconsciously, think of resorting to informal or illegal networks, as the result of investment strategies which can produce material and symbolic advantages to a single individual or for specific groups, but which cannot necessarily produce collective advantages. Concerning the italian Mezzogiorno (Southern Italy), it is also necessary to highlight the peculiarity of the role played by politics within the social and economic networks. In order to provide a better explanation for the insufficient growth of the Italian Mezzogiorno, we have to place a focus on the role played by politics in both hindering the development of social capital and in rendering inefficient the use of public transfers and public intervention. Politics in the South of Italy is characterized by clientelism ${ }^{11}$, a peculiar type of political system whereby consensus and political popularity is achieved through giving out advantages to particular families, economic groups, or local communities (Trigilia, p.143, 2012). Consequently, it may be considered that in societies characterized by the organizational inefficiency of modern state institutions the specific social capital, obtained via family and community connections, is used to favour specific circles in which the "exchange of favors" system is reproduced.

This can generate a "trap" effect within local markets (Laursen et al., 2012b) with negative effects in the creation of large networks.

\footnotetext{
11 Clientelism is a relationship between individuals with unequal status ("the boss" and his "clients") that entails the reciprocal exchange of goods and services based on a personal link that is generally perceived in terms of obligation. Clientelism is the exchange of goods and services for political support. It involves an asymmetric relationship between groups of political actors described as patrons, brokers, and clients.
} 


\section{The territorial dimension of the 'Ndrangheta and its influence on the available social capital}

When studying the territorial system of the Sibaritide, one must not ignore the presence of the specific and pervasive social and economic phenomenon of the 'Ndrangheta. The presence of the system of illegality in the socio-economic and political fabric, typical of areas with a strong mafia presence, is testified by the numerous criminal acts carried out by local bosses to the detriment of individuals and economic entities. In the Cosenza Province, however, this system of illegality is less visible and pervasive compared to other areas of Calabria. As far as the collusion between politics and the mafia is concerned, numerous judicial investigations have been carried out. In this regard, let us consider two significant events: the dissolution of the municipal councils of Corigliano calabro and Cassano ionico, in 2011 and in 2017 respectively, due to mafia infiltration. Unlike other countries' criminal organizations, the Italian mafia and, particularly, the Calabrian mafia, base their power on their strong presence within the relational networks (social, economic, political) of origin territories. The strong presence on the territorial level is the main difference from other types of organized crime (Sciarrone R., 1998). In addition to using the traditional organized crime tools, such as violence and extortion, the mafiosi have the great ability to manipulate and exploit social relations in order to accumulate resources placed in social networks. It is through the use of this social capital, made up of relational heritage, that the mafia for at least two centuries has managed to successfully reproduce itself and extend its networks first at a local micro-scale and, hence, at a transnational level.

Until recently the Calabrian Mafia had been perceived as a minor criminal organization, as an expression of a residual outdated society; hence, a modern analysis was not conducted, since it has been considered more "primitive" compared to the Sicilian and Neapolitan Mafia. This primitiveness is in direct opposition to the success that 'Ndrangheta has shown in the last decades, in particular with its capacity of territorial expansion along with its integration into transnational illegal activities (Sciarrone, 2014).

The reticular structure of the relational model of the 'Ndrangheta represents a successful model (Sciarrone, 2002). On the one hand, the internal networks in the origin territory are constituted by the close and stable parental and friendship ties - 
strong ties $^{12}$ - which are linked by the same system of values. On the outside, however, as we move away from the central territorial nucleus wherein the networks are established with other legal and illegal organizations, ties tend to become more fluid and weaker. The absolute internal cohesion of the 'Ndrangheta is highlighted by the very low number of collaborators of justice compared to the other Italian mafias. The strength of the weak ties in the most distant points of the networks is represented by the dynamism and economic robustness of the extension of mafia networks.

Whereas within the territory of origin the mafia families structure ties of the bonding type, on the outside they make use of bridging ties, which act as a bridge between distant circles and channel elements of novelty between otherwise disconnected circles. In most cases, the mafia members tend to exploit the 'structural holes' of the networks (R.S. Burt, Structural holes, 1992), that is the absence of relationships between distinct social circles (Sciarrone, 2015). The large amount of relational capital attributes to the mafia a role of "crucial" intermediary within the "structural holes" existing in the relations between social and institutional circles, distinct and distant (eg. between economic and political operators, citizens and bureaucracy, etc.).

By playing this linking role they preserve separation: they connect distant nodes and circles, but keep them separate. The separation of these circles represents a guarantee of their role as mediators of flows (information, money, etc.).

It is in the nodal points that they intercept wealth and exercise control over the network by increasing the specific social capital, in order to strengthen existing networks or create new ones (R. Sciarrone, 1998).

Consequently, the mafia groups, rather than producing wealth (not only economic, but also of knowledge) for their territory, appropriate the wealth. The purpose is partly to redistribute it among the various subjects within the local circles (D. Barazzetti, 1997). This redistributive aspect is however an investment to maintain the monopoly of functions and control over the territory.

Unlike the nomadic bandit, the settled one is concerned with redistributing part of his income in order to maintain the cohesion of the system.

The mafia family holding the monopoly of crime in a given community has a moderately inclusive interest due to the monopoly itself. By using coercive power, it

\footnotetext{
${ }^{12}$ According to Mark Granovetter (1973), strong ties tend to bind similar individuals to each other and to create close circles between them in which mutual bonds are strong. A high degree of fidelity is thus obtained in circles of this type, but there is little possibility of innovation. On the contrary, the weak ties are those allowing to create local bridges in order to reach external circles and widen the networks. It is through weak ties that local structures receive information from the outside, thus igniting the possibility of innovation. In this lies the strength of the weak ties.
} 
considers the community interest, as, in a certain way, it bets on the income of the community (Olson M., p 5, 2001).

In a certain sense, the redistributive propensity of the settled bandit, such as the mafioso, for the benefit of the territory, does not turn into a public good. Rather, we can speak of "club goods" or "positional goods", that is, goods which increase the prosperity of their domains. This happens only in order to optimize the net amount of its withdrawal to the detriment of the society itself (Olsom M. in Sciarrone, p. 58, 2002).

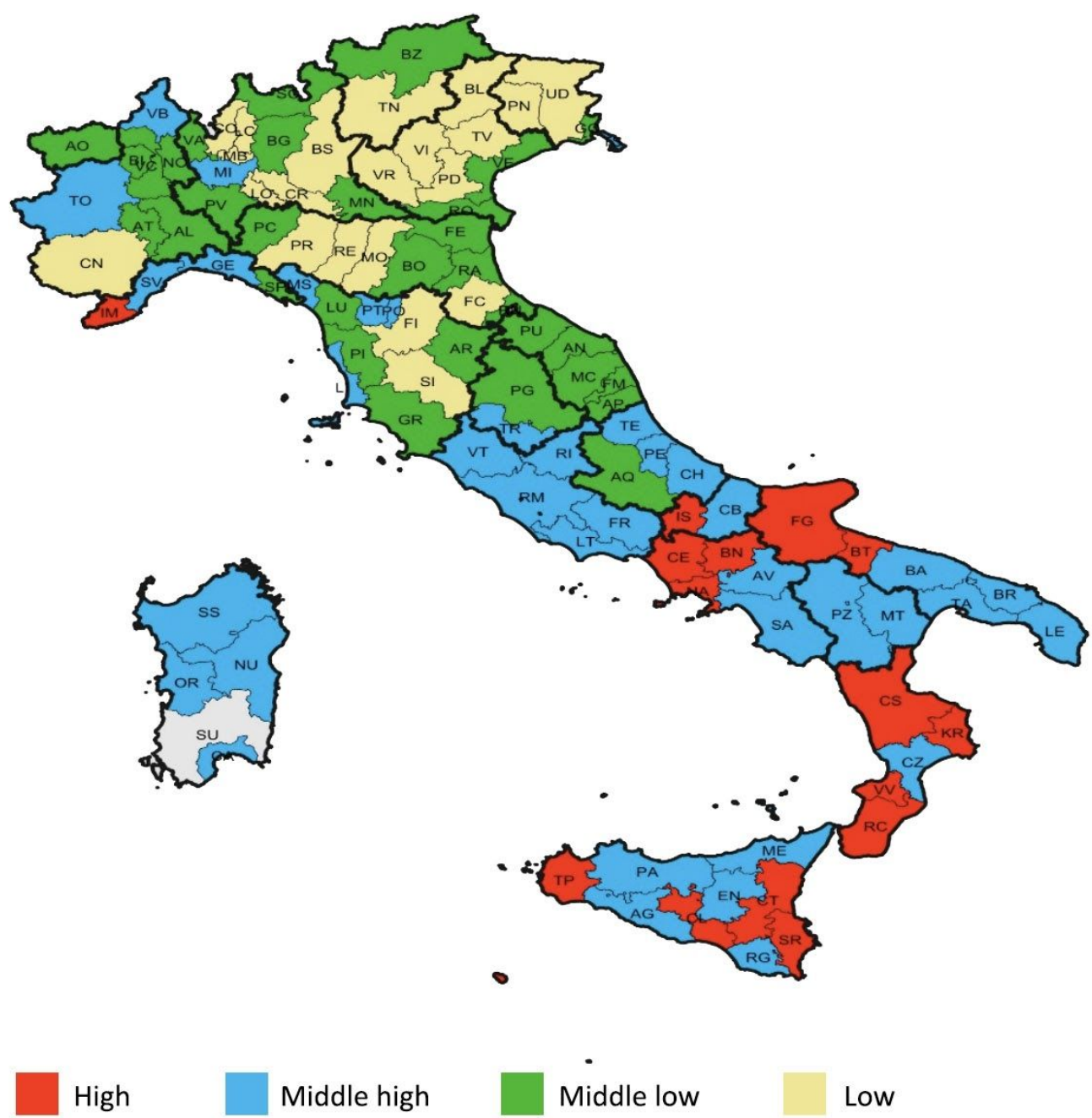

Figure 2 Organized Crime Permeability Index (OCPI) ${ }^{13}$, (Eurispes, p.8 2020).

\footnotetext{
${ }^{13}$ The IPCO is a composite index which allows us to summarize in a single measure a multidimensional and complex phenomenon such as that of the permeability of organized crime into territories. Not only does the index concern criminal phenomena, but also social and economic dimensions. 163 variables contribute to the index, the data of which come from official sources of several kinds. Among the variables considered is the quality of the institutions, in which the 5 Calabrian provinces appear in the first 6 positions due to the inadequacy of the institutions, with the province of Cosenza being the fourth. Therefore, the static analysis of the IPCO highlights: permeability levels concentrated throughout the national territory, a North-South polarization of the permeability level, and locally concentrated levels of permeability. The permeability of the South is mainly due to the social vulnerability (Eurispes, 2020).
} 

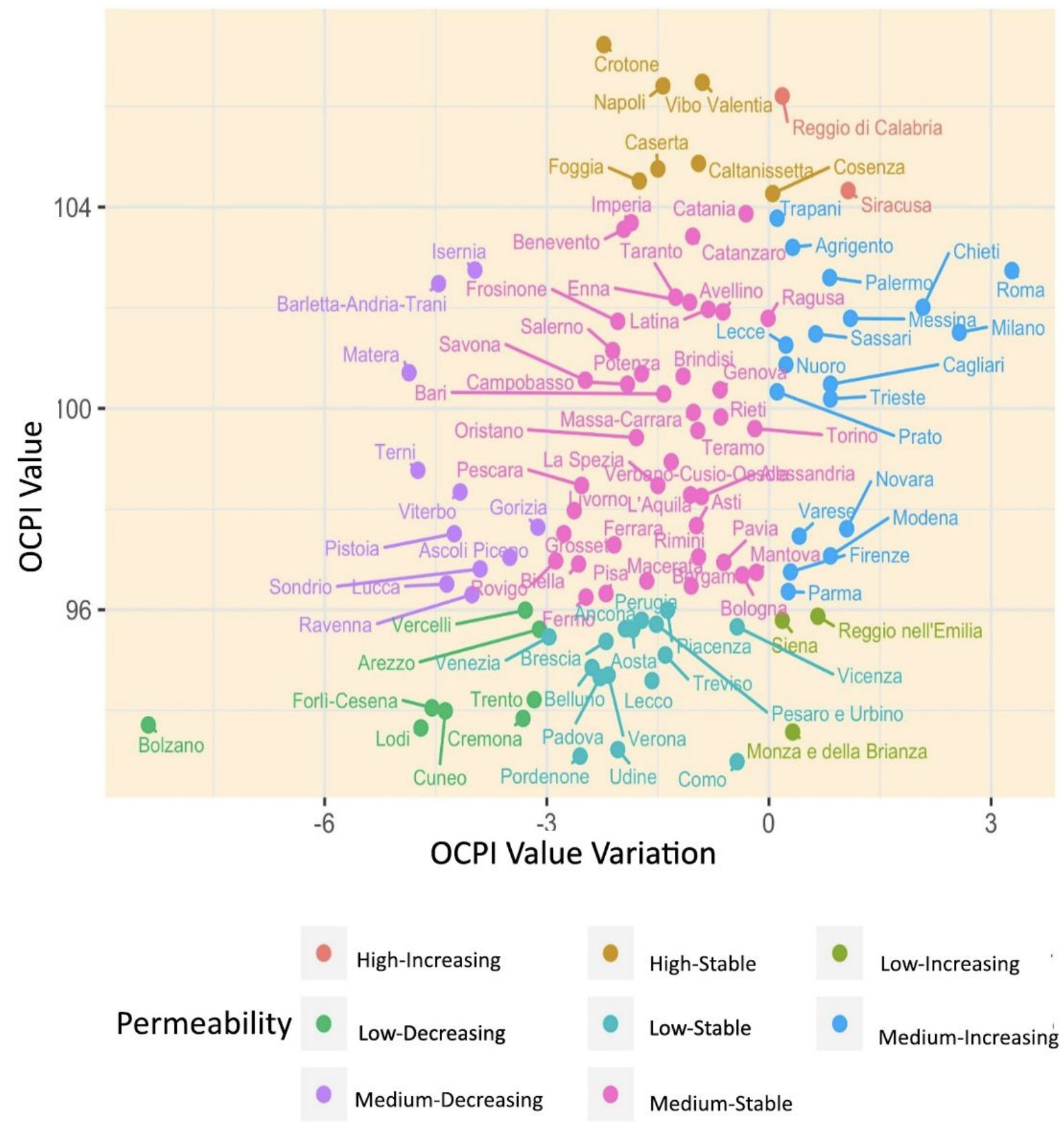

Figure 3 Dynamics of the Organized Crime Permeability Index (IPCO). Three-year average values (Eurispes, p. $15,2020$.

The judicial inquiries illustrate a unique organizational structure, and strong connections with the legal, economic, political, and government institutions ( $R$. Sciarrone, 2014). The 'Ndrangheta, as other Italian mafias, carries out functions of guarantee and control over the economic activities taking place on its territory. It also establishes links with politics, thus conditioning the functioning of the institutions. 
Because of the specificity of its network structure, in the traditional origin areas the mafia presents itself as an alternative but sometimes as the only supplier of services, which are normally offered in modern societies by the State or local public authorities, or by private organizations. In this way it contends with the State for control of the territory. This is the case of the protection service appropriation offered by the mafia in some geographical areas under a quasi-monopoly regime. In territories where insecurity reigns, the guarantee of protection becomes a scarce and desirable good (Gambetta D., 1992). However, mafia protection does not have those "non-rivalry" and "non-excludability" from consumption characteristics, which are typical of pure public good. On the contrary, the monopoly of protection is exercised only at the level of individual territories and applied to some specific sectors (Ibidem, p. 58). The mafia is a successful entrepreneur in the protection industry sector, not so much because of its profitability, but because of its ability to assume the monopoly by appropriating the public authorities' function. In this way, it strengthens and feeds its control and consensus at the territorial level.

As a matter of fact, the territorial domain is necessary for the functioning and reproduction of the organization itself. The typical combination of extortion and protection operated by the mafia is necessary to guarantee security on a large number of activities. Its functioning is activated by relational resources, and in turn it activates relational resources, which can be defined in terms of social capital (Sciarrone R., 2015).

The mafia presence is not only coercive, on the contrary, it activates a system of exchange and gratitude within the networks of local relations. Therefore, it is not easy to distinguish between coercion and will to join the system proposed by the mafia.

In addition to the protection service, the mafia offers a wide range of services related to economic activities, not necessarily illegal ones. It also intermediates with the bureaucratic sphere of public administrations and with politicians.

Confronted with organizational failure, individuals have a choice between a variety of alternatives. Informal networks can substitute for the failure of modern bureaucratic organizations. Additional tactics include trying to personalize relations with impersonal bureaucrats or using connections or bribery in an attempt to get bureaucrats to violate rules; or fatalistically accepting that nothing can be done (R. Rose, p. 19, 2000).

Here, the intention is not to create a deterministic and ineluctable vision of the mafia presence in social and economic relations in the areas affected by the presence of this settled organized crime. Rather, the purpose is, on the one hand, to highlight to what extent this ancient and successful social and economic phenomenon pervades 
the territorial fabric at different levels and, on the other hand, to what degree it is interested in feeding structural holes and opaque areas.

Exogenous interventions should not ignore the existence of this complex and ancient organizational system at the territorial level. Theoretically speaking, it also has rational connotations given the lack of alternatives in areas where the presence of the State is often uncertain as the result of a clientele system that makes it inefficient.

In this context, the hypothesis is that in the long term networks of relationships have been produced in the Sibari Plain; in the immediate term these have generated specific, rational and advantageous behaviors and behavioural models for individuals, which however in the long term proved to be inefficient and unfavorable for the territorial system as a whole.

In this regard, it is intended to demonstrate that the weakness of the territorial system emerges mainly in the management of collective resources and services. In reference to the case study, I believe that the presence of this opaque area emerges in the following key services which function as a precondition for the citrus fruit production and marketing:

- cooperativism in the post-harvest and marketing of citrus fruits

- water management for irrigation through the Reclamation Consortium

- public infrastructure resources (commercial port of Corigliano and railways)

\section{Geographic framework and settlement processes}

It is on the slender coastal plains that Calabria has seen flourish the only luminous phase of its history - the Greek era. And today on those same plains Calabria is beginning to glimpse this luminous rebirth (L. Gambi, p. 44, 1965).

The experience of Calabria shows that, when referring to agricultural contexts, it does not make much sense to contrast sociology with ecology and geography with history (G. Arrighi, F. Piselli, p. 680, 1987). 


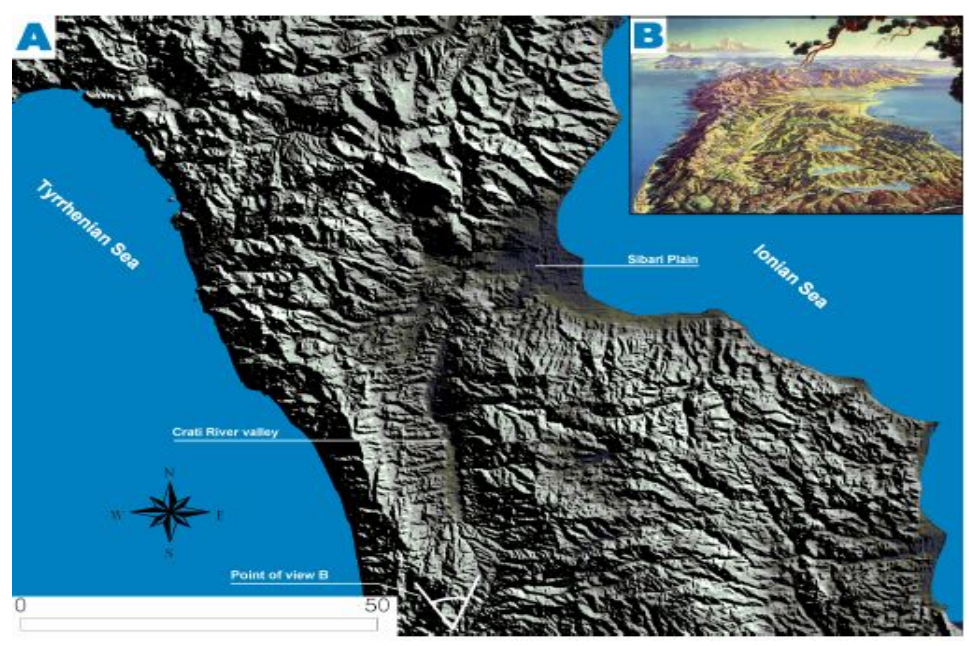

Figure 4 Global view of the study area and of the surrounding mountains. (A) hill shade map and approximate point of view of the image B; (B) artistic bird's eye view made by H. C. Berann (1915-1999) using cartographic techniques (approximate point of view on the view A) [in O. Petrucci e M. Polemio, 2007]

The Sibari Plain is located in the extreme northern arc of Ionian Calabria and covers an area of about $475 \mathrm{sq}$. $\mathrm{kms}$. In a $90 \%$ mountainous and hilly region, it is one of the very few and narrow coastal plains. The orography of the entire region is disordered and fractured, a continuous alternation of height differences which still make the distances between molecular and fragmented settlements endless.

Geologically, it is located between the extremity of the metamorphic massif of the Sila to the west and south, and those of the carbonate massif of the Pollino to the north. The coastal plain coincides with the downstreams of the rivers Crati (the largest in Calabria), Coscile and other 22 smaller watercourses. The peculiar geomorphology of the Crati Valley-Sibari Plain system makes the water regime fast and torrential, giving rise to the characteristic phenomenon of fiumare ${ }^{14}$.

The Sibari Plain is characterized by a long-term average annual rainfall of $913.7 \mathrm{~mm}$, more than two third concentrated from autumn to winter, and an average annual temperature of $17{ }^{\circ} \mathrm{C}$, with a maximum value of $26.8{ }^{\circ} \mathrm{C}$ occurring in August and a minimum value of $8.8^{\circ} \mathrm{C}$ in January.

The floods and the significant subsidence of the coastal part have produced the almost permanent swamping of the flat area, keeping it unhealthy because of malaria and unsuitable for stable human settlements.

Following the reclamation interventions (1911-1930 and 1951-1970) in accordance with specific national laws (Petrucci and Polemio, p. 367, 2007), this narrow coastal area, which is characterised by the fragile geological and ecological balance typical of

\footnotetext{
${ }^{14}$ Ephemeral watercourses inactive for most of the year, which, due to heavy and sudden rains, mainly in autumn and winter, are loaded with huge and destructive quantities of water and granite debris that are quickly discharged downstream.
} 
transition environments, plays a strategic role from the point of view of the agrarian economy, thanks to the fertility of the soils formed by the continuous flooding.

Such a dynamic physical environment is strongly affected by both seasonal weather variations and long-term climatic fluctuations. The environments on which the river basins insist are more likely to record major transformations during cool and humid climatic periods, especially when the flow of rivers increases and alluvial phenomena become more frequent (Bellotti et al, 2006).

The wetlands of the Italian Mediterranean coast - the plains of the Calabrian coast which are confined between the mouth of the Apennine valleys and the sea, in their natural state provided important ecosystem services and biodiversity, the regulation of pollutants and nutrients, water filtration, etc. Here, during the cold months, when malaria tended to occur less frequently, local communities created seasonal economies: they were mostly used as cattle pasture areas, small dry arable areas and fishing grounds.

However, the recently made hydraulic works - operated for the purpose of channelling the water and protecting the area - on the one hand have made a significant area of the territory available for agriculture and permanent settlements, and on the other hand, they have generated a mistaken sense of safety, which may lead to underestimate the risk factors of this area. Local people occupied cultivable lands along riverbanks, even in flood-prone areas. The effects of these works on the fragile equilibrium of basins were usually neglected. The reasons are both an overestimation of human capacity to control natural phenomena and the lack of specific knowledge of basin characteristics (O. Petrucci, M. Polemio, p. 362, 2007). The stable human presence in this area, characterised by a fragile hydrogeological balance, was only possible in periods during which the following two conditions were met: hot-dry climatic periods, along with the possibility of investing huge resources in the construction and maintenance of infrastructures for the security and control of the territory (P. Bellotti et al., 2006) $)^{15}$.

15 From the climatic point of view, between the $6^{\text {th }}$ and 4th century $B C$ there was such a significant deterioration that this period has come to be known as the "archaic ice age». As evidenced by literary sources along with archaeological and geological investigations, the river regime tends to escape human control - the population suffers heavy repercussions, so that it abandons the Sibari site. It can be assumed that the infrastructures built by the Greek colonists were affected by the ongoing changes. Unfortunately it would be too risky to argue that this population crisis is only due to climatic reasons only, or to affirm that the geomorphological changes have occurred due to the crisis of the Crathis Plain during that time. The analysis of historical events shows how the conflict with Crotone, which culminated with the destruction of Sibari and with the events related to the various attempts at its re-foundation, is crucial to understand the instability of the Sibari during that time. The geographical events must have been a contributing cause, making a new stable settlement difficult in the absence of organized and coordinated interventions, which were possible only with an Athenian action (Bellotti, et al., P. 93-94, 2006) 
This concomitance, for prolonged periods of time, occurs in two historical periods: first in the Magna Graecia settlement with the Sibari pòlis (730-720 BC - 510 BC), and then in the current climatic period, coinciding with the great transformation due to integral bonification (1930-1970) and the Agrarian Reform of 1950.

In both cases it was necessary to mobilize huge exogenous resources which gave the necessary input to the plain transformation. The recent reclamation works on the coastal plain which, on the one hand, by eradicating malaria, allowed settlements and economic uses, on the other hand, have drastically changed its hydrogeological and ecological balance (Petrucci and Polemio, 2007). The environmental transformations of the Sibaritide show how the long processes of geomorphological and human population evolution are strongly correlated.

In the very long interval between these two major changes of the territory, the coastal plain was sporadically inhabited.

From the mid-ninth century and for about the subsequent ten centuries, the coastal towns have been subject to raids and invasions by Saracens, then Maghrebis and Turks (Gambi, p. 139, 1965).

Starting from the dissolution of the Magna Graecia civilization, the migration to the most protected and healthy inland areas triggered processes of molecularization and isolation of the inhabited areas. The practice of extensive agriculture in the latifundia, accompanied by deforestation, caused further erosion. The huge sediments load from the rivers, which was favored by landslides and erosion phenomena increased by deforestation, created wide alluvial fans at the mouth of the rivers. The low slope of the plain slowed down the runoff and the stream flow, creating swamps where malaria began to spread (Petrucci and Polemio, p. 364, 2007). The first attempts to structurally prevent the hydrogeological disorder were undertaken during the Bourbon period (Kingdom of the Two Sicilies 1816-1861).

But it was only between 1950 and 1970 that the whole process of integral reclamation was completed. By reducing landslides and erosion upstream, it resulted in the channelling of the waters into the plain, making them healthy and available for irrigated crops (O. Petrucci, M. Polemio, 2007, p. 369).

This process, which was put forward together with land reforms, caused a counter-migration of populations from inland areas to the coastal plains. (Ibidem, 2007). Until recently, the urban centers had not had such a size or functions as to act as a propulsor towards the surrounding territorial system ( $P$. Bevilacqua, p. 337, 1985). The settlements of the whole region are still highly fragmented. It is a polycentric region, where the connections between the various centres are long and difficult to travel on. 
Out of the total 404 municipalities in Calabria, only 4 municipalities exceed 60,000 inhabitants in a region whose total population is 1,924,701 (Istat, 2019). The municipality of Corigliano-Rossano is the third largest municipality in Calabria by number of inhabitants: 77,096 (2019).

\section{Territorialization: the constraints and the possibilities}

[...] Excessive anarchy has been dominating for 15 centuries. So anaemic was the fabric of relations between its parts, so fragmented and dispersed were the human initiatives as to prevent the enucleation of those energies, which elsewhere they have generated evolved and supportive human creations (Gambi p. 451, 1965).

In the 15 centuries mentioned by Lucio Gambi, the social life of Calabria was affected by some conditions:

- the uninhabitability of coastal areas: during the summer season due both to malaria, and to the frequent raids by Saracens, then Maghrebis and Turks (L. Gambi, p. 139, 1965);

- the inexistence or precariousness of infrastructures within a region characterised by particularly disordered geomorphology. Still today, especially in winter, this results in very long and inaccessible journeys between inhabited centres, which are close to each other (as the crow flies). Also, the absence of important reachable markets, where to sell surpluses, and the extreme lack of infrastructures linking the region to the outside, which can be referred to the inefficiency and lack of infrastructure and services of the southern regions in general (see Viesti 2007, Asso and Trigilia 2010);

- the phenomenon of brigandage in the form of endemic social crime, making travel unsafe (Bevilacqua, p. 120, 1985).

Therefore, in this context social and economic relationships could only take place in very restricted geographical contexts. The rational adaptive strategy to that type of territorial and historical context was the agrarian system based on the latifundia ( $M$. Petrusewicz, 1989).

Here latifundia is understood not only as a large land property oriented to rent-seeking, but as a territorial organization related to an agricultural system with specific social, economic, political and even environmental characteristics. This type of property was peculiar of the latifundia, which were only characterised by large extensions, in which relationships within the specific social realities tended to 
organize themselves in rigidly hierarchical forms. It was a system with very low innovation and investments, inserted in particularly adverse environmental situations in the central and southern Italian regions, but which had, in its own way, an archaic rationality (Bevilacqua 1989). This form of organization and the extreme environmental adversities produced a collapse of social life, along with the peripheralization of the entire region (G. Arrighi, F. Piselli, p. 47, 1987).

\section{Water control and its role in the building of territorial social capital}

The soil of the vast plain between the rivers Lucino and Sarracino is clayey and almost all the rivers intersecting it carry limestone sand from the mountains; the Crathis, instead, carries also granite sand from the Sila mountains. In their overflows, having flooded the countryside adjacent to their respective courses, they deposited high layers of rouge mixed with the abovementioned sands. Consequently, they have made that clayey soil much more fertile. These natural beneficial floods could be artificially imitated by irrigating the fields with the murky rivers, before they were prepared for the new crop. By using these means - as a result of which that very fertile district, where the climate is so favourable to vegetation, turned healthy - the flourishing agriculture admired in the adventurous days of Sibari could resurrect. By making the steep slopes of the nearby mountains firm and wooded again, pastoralism would regain extensive natural pastures. Furthermore, during the snow season the artificial pastures of the sub-plains would provide subsistence for livestock (C. Afan de Rivera, 1833, vol. I, p.276). 


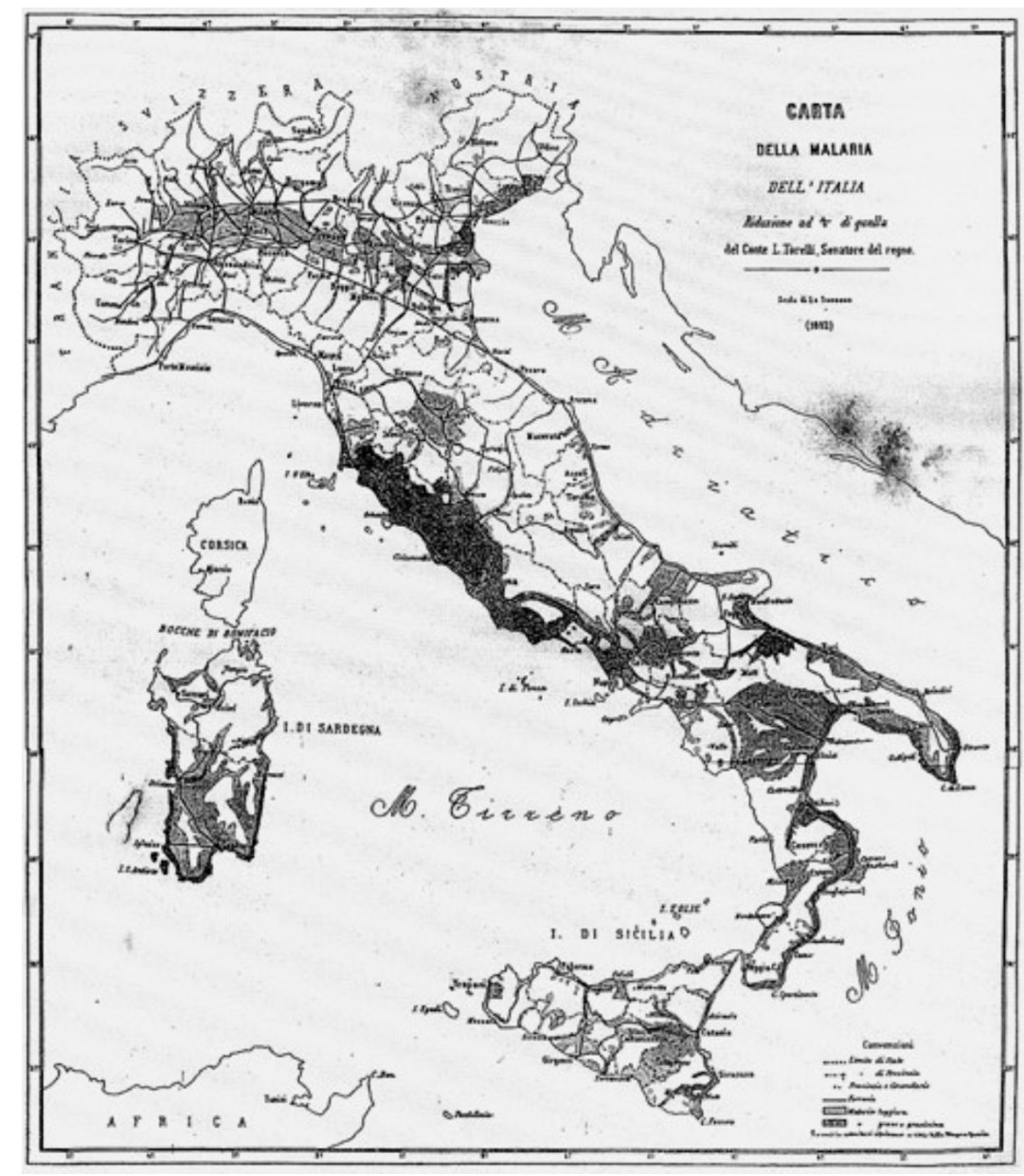

Figure 5 The marsh fever map of Italy, 1882.

In Italy, between the end of the 19th century and the first thirty years of the 20th, about 2-2.5 million hectares of swamps were reclaimed (Bevilacqua P. Rossi-Doria M., 1984). In addition to the availability of millions of hectares of arable land, it was the increase in the extension of irrigated areas in Mediterranean climate regions that marked the development of intensive agriculture in Southern Italy.

It is necessary to highlight that the methods of appropriation and management of water for irrigation use represent tangible expressions of the territorialization processes - they are the result of social and cultural dimensions, which in turn shape the social and environmental dimensions of territories and communities.

The social networks which developed over time through this practice of controlling natural resources and the territory can be considered as stock of social capital, which was crucial in facilitating the emergence of cooperative movements in rural areas (Beltrán Tapia FJ, 2012 ). 
It is through these networks of relationships, created for the management of water and other collective resources, that social codes, shared visions and institutions were built (F.J. Beltrán Tapia, 2012, P. Bevilacqua, 2000).

In the different territorial contexts analysed in Governing the commons, Elinor Ostrom notes that all successful collective irrigation water management systems are systems in which stakeholders must manage uncertain and complex ecosystems, where the construction of physical infrastructures to govern the waters reduces the level of uncertainty, but also increases the level of the territorial systems' complexity (p. 132, 2006).

Despite the uncertainty related to environmental factors, however, the populations of these localities have remained stable for a long time. Individuals have been sharing their past and now they are planning to share their future (Ibid, p. 132).

The huge reclamation works, which reshaped the Italian peninsula, not only converted large extensions of malarial territories into arable land, but they also represented a great social work. Consequently, political and civil apprenticeship was created, and human communities learned more or less collaborative relational practices. Through these practices, they introduced water management practices for irrigation and learned to regulate the resulting conflicts. This resulted in the creation of a wealth of codes and standards in order to manage water as a collective good (Bevilacqua P., 1996 and 2000).

The comparison between the different users was obligatory. As a matter of fact, according to the right to the irrigation water, the landowners shall let the water destined to the contiguous parcels flow through their own (Law of April 1, 1865). Furthermore, this water was regulated between the different users in order to fairly serve the funds.

The fights and conflicts in the appropriation of such a vital resource in agriculture be resolved individually, but required collective agreements and solutions. For this purpose, a wealth of codes, rules, sanctions and control systems was first produced at a local level and later resulted in the foundation of the Irrigation Consortia (Law of June 29, 1873). This heritage of shared codes, which could be considered as a part of the territorial social capital, deeply shaped local societies. This was due to the important role played by agriculture in pre-industrial societies or in those that were on their way to industrialization. However, the process of controlling the water had different results in different geographical contexts.

Bevilacqua points out that in the Po basin the water regime and the specific physical and settlement context made possible a collective water governance in the flood phases, and also their use for irrigation. This was not the case of other geographical areas, where the geomorphology, the water regime and the settlement molecularity 
made small rehabilitation interventions completely inadequate with respect to the vastness and intensity of hydrogeological phenomena (Bevilacqua P., 2000).

The latter case is typical of the many environmental contexts of the Mezzogiorno, including the Sibari Plain.

\section{Reclamation and irrigation in the Sibari Plain}

The first attempts to structurally reduce the hydrogeological disorder of the Sibari Plain started during the Bourbon period (Kingdom of the two Sicilies 1816-1861).

In such complex environmental contexts as these examined here, the modification of a watercourse beneficial to one landed property can actually cause damage to the contiguous properties. This may increase the hydrographic system disorder and provoke conflicts between owners.

In 1930, it was the Italian State that began the first works to reduce landslides and erosion, as the demanding and complex intervention to refurbish the entire river basins could not be operated by private individuals (Gambi, p. 455, 1965). These works ended in 1970 with the definitive eradication of malaria and the canalization of water for irrigation (O. Petrucci, M. Polemio, 2007, p. 369).

The management of irrigation water was assigned to the Consorzio di bonifica Piana di Sibari-Valle del Crati (Consortium of Reclamation), a "public economic institution subject to private entrepreneurship discipline", which from 1954 had been continuously put under the administration of external commissioners until its suppression in 2010.

The story of this institution shows how subtle networks of connivance can develop over time, thus turning a public service governance into an inextricable intertwining of private interests. This leads to a progressive dissipation of resources, the expiry of the provided services and, in this specific case, the collapse of the structure (Barazzetti D. p. 116 and 117 in Dolci Clementine, 1997).

Nowadays, the consortium water management institution is the Consorzio di bonifica integrale dei bacini dello Jonio cosentino. This consortium provides for an annual 
reclamation contribution ${ }^{16}$ and an irrigation contribution ${ }^{17}$ (Consortium website, 2020).

All the stakeholders whom I met expressed a great hostility towards the irrigation contribution, as well as a deep mistrust against the consortium. The irrigation contribution is mandatory regardless of whether the owner wants to use, or rather manages to use, these waters.

During the increasingly frequent periods of drought, the absence of a regular supply water service by the Consortium puts citrus fruit production at risk, thus requiring the individual solution of constructing wells to draw water from the deep aquifers. The use of wells is an evidence of the failure in the collective water management for the benefit of an obligatory and expensive individual solution. The most damaged by this erratic distribution are the small producers, who make investments for the construction of the wells.

Furthermore, the growing demand of water, due to climatic stress, along with the reduction of groundwater recharges, increase the risk of marine intrusion into near-coast aquifers, thus producing a qualitative and quantitative degradation of fresh groundwater.

\section{Structures and pathways of the agricultural economy of Calabria}

The rapid transformation of the Sibari Plain from a malarial swamp to an intensive citrus area must be part of the historical framework of agriculture in Calabria and in Southern Italy.

According to the model proposed by Manlio Rossi-Doria (1958), the Mezzogiorno of Italy could be divided into bare and planted with trees.

Ninety per cent of the agricultural land in the South was destined for cereals and pasture, while the remaining land was destined for tree crops. This was due to the strong environmental and geomorphological constraints, the distribution of land property and the abundance of low-cost labour force.

\footnotetext{
${ }^{16}$ The reclamation contribution is an annual contribution due by law by all owners of land and buildings located in the territory managed by a Reclamation Consortium. The reclamation contributions are duties on property which are due in accordance with the tax-collection rules. (Article 21 of the Royal Decree n.215 / 1933).

${ }^{17}$ Some areas of the district are subject not only to the reclamation contribution, but also to the irrigation contribution for the maintenance of the irrigation network, (irrigation systems, dewatering pumps, lifting stations, channels, small canals, etc.). The irrigation contribution is due based on the area in which the land is potentially irrigable, regardless of the actual use of water.
} 
This model is built on a clear separation between two worlds. On the one hand, there is the green world, which is a luxuriant and highly productive world based on the profit deriving from tree crops mainly located in the irrigated coastal areas, and on the other hand the barren world, which is desolate and based on the landowner rent in the inland areas of Southern Italy.

Unlike the Northern European regions, in the Mediterranean regions the typical forms of settlement appear to have a weak correlation with the surrounding agrarian systems. This would highlight the priority given by human communities to defensive needs (against sea invasions, malaria, hydrogeological risk, etc.) in relation to the economic functions of agricultural activity (Bevilacqua, p. 117,).

The reasons for the persistence of the latifundia model oriented to the extensive cultivation of cereals in Calabria until the 1950 land reform are listed as follows:

- a southern landlord class oriented towards income, and the absence of a significant entrepreneurial agricultural class,

- particularly in coastal plains areas, the strong environmental and climatic constraints which allowed to use marshy and malarial soil

- the lack of nearby markets, and the almost total isolation due to the lack of connecting infrastructure - between the regional centres, and between the region and the external world - which meant that it was not interesting to create surpluses to resell on the markets

- The choice for a very low-cost and abundant labour force, compared to expensive investments necessary to plant tree crops. Not to mention the lack of income with the first fructification happening after 5 years.

The latifundia system did not focus on technological innovations, but persisted with extensive agriculture and with the use of labour-intensive techniques (Arrighi G. and Piselli F. in La Calabria, p. 406, 1985), until its definitive dissolution with the Agrarian Reform of 1950.

The expropriations of the latifundia of the Napoleonic domain (1806-1815) established the legal foundations of the land private ownership in order to favour the birth of bourgeois landowners. However, they did not contribute to the development of small and medium-class landowners. Both as wage earners and as short-term tenants of small plots, the landless peasants continued to provide labour in large estates.

This new class of tenants was assigned small and poor plots, which were often far from inhabited centres. For this reason, they mostly continued to constitute a workforce for the large estates of emerging middle-class owners (Bevilacqua, 1988 
and Capano and Marini, 2005). The short rental period along with different types of contracts did not encourage the tenants to make investments, had they had the means to do so.

In this land property context, the relational system based on small cliques of relatives and neighbours undergoes an even major contraction. The increasingly frequent lack of work, food and land reduces even more the traditional relationship cliques of solidarity and reciprocity, upon which to rely on in case of need. After relying on neighbourhood first and then on family cliques, the only way to survive was to live at the expense of others by committing thefts etc. (Arrighi G. and Piselli F., in La Calabria, p. 410, 1985).

In some cases, the small subsistence peasant property coexisted with the large latifundia rented to the peasants. Cooperation, aimed at subsistence, took place within the relational context of small local cliques. These forms mostly coexisted with the capitalist large estates of great mercantile production. To a lesser extent, they developed also in the coastal areas, which were gradually reclaimed, with a system of small commercial production and marketing of citrus and olive products ${ }^{18}$.

The system of renting parcels with short-term contracts converted the peasants in rural and mobile proletariat, obliging them to sell labour force and to emigrate.

Landowners used the surplus either to strengthen the properties by purchasing new funds, or to give their children an education in liberal careers (Bevilacqua P., pp. 287-288, in La Calabria, 1985). Also, though to a minor extent, they used the surplus to develop the profitable economy of trees, citrus and olive trees as soon as conditions allowed it (Ibidem, p. 289).

The latifundia model is defined both by the paternalistic aspect of protecting the members of its system, and by the aspect of territorial control through the use violence - as well as the territorial monopoly, it assumes the monopoly of the land (Arrighi G. e Piselli F., p. 412, in La Calabria, 1985).

These monopolistic functions could be exercised only with the complacency of the public authorities. In order to maintain this monopoly, the landowners pursued a political activity, occupying positions of power at various local and state institutions.

\footnotetext{
18 The study of Arrighi e Piselli (1987) -- which represents a model of reference for a number of studies on the transformation processes of agricultural economy -- identifies three types of land structures, which derive from the crisis of the landownership system in three different geographical areas of Calabria. Until the middle of the 20th century, these three types of land structures correspond to three different types of social strategies of adaptation. The situational analysis of the three examined territories is as follows: people are immersed in a multiplicity of social networks within which they act according to different strategies, depending on the situation. The inhabitants of the investigated three geographical areas, corresponding to the three forms of economic structures, adopt different roles and have different interests; they act in their complex personal network of cross-relationships [...] In particular, they use their multiple ties of kinship, clientele, community to increase and defend their positions of power and prestige (G.Arrighi e F. Piselli In La Calabria, p. 377 e 378,1985 )
} 
Therefore, the people linked to these positions of power activated a system of exchange of favours and clientelism (Ibidem, p. 413).

With the emergence of a market economy and the 1950 Land Reform, the landowner model dissolved. The relationships of kinship, clientelism and community ${ }^{19}$, upon which the landowner social and economic model was based, persisted in the forms of the territorial organization which replaced it. The monopoly of violence passes to the mafia authority (Arrighi and Piselli highlight the case of the Crotone area, where the organized mafia presence in the feuding system is stronger. However, it is a system more or less replicated by the Calabrian 'Ndrangheta in other geographical areas).

After the dissolution of the latifundia system, the new entrepreneurs are driven by vertical pushes to social mobility, rather than by horizontal collaborative pushes. The mafia uses this type of "mentality" to ensure the turnover of power groups based on the model of kinship, clientele and community. Traditionally, the relational networks activated by the mafia are based on the "code of honor", although their interests are economic ones and related to the control of the territory.

\subsection{The role of agriculture today}

Currently, the agricultural sector assumes a significant weight in the economy of the Region in comparison with the Italian average. In 2019 Calabria had positive results in the agricultural sector both in terms of production volume and added value: + $10.6 \%$ and $+17 \%$ respectively.

About 15 percent of the employed are employed in this sector: the highest incidence among the Italian regions (Bank of Italy, p. 8, 2019)

Although the contribution of Calabria to the overall Italian agricultural production is significant, with $0.5 \%$ its contribution to export is very low (Istat, 2019)

The intensive and specialized agricultural production is mainly concentrated in the three Calabrian plains Sibari, Lamezia and Gioia Tauro with $61 \%$ of the area destined for agricultural use, producing $26 \%$ of employment in the sector and $16 \%$ of the total regional income.

\footnotetext{
${ }^{19}$ Relationship, clientele and community are not a simple way of organizing personal relationships, but they are part of a system of economic and political relations between groups [...] they play a fundamental role in the organization of the economy and political life (Arrighi and Piselli , p. 367, in La Calabria, 1985).
} 


\section{The citriculture}

After the intensive specialization of mulberry, olive and grapevine, citrus crops represent the last intensive specialization of the Mediterranean agriculture, which is stimulated by international demand, like the above-mentioned crops.

The citrus boom happened 50 years after the discovery of the properties of ascorbic acid contained in lemons and oranges as an antidote to scurvy. The discovery was made in 1747 by James Lind, a physician of the Royal Navy.

The strong demand for citrus fruits came from markets outside the production areas (northern Europe and the USA). Thanks also to its preservability, the citrus fruits consumption experienced an exceptional expansion, which was never met before. Rapidly, this led to the transformation of a great deal of barren Mediterranean agricultural landscapes into green citrus monocultures.

Citrus cultivation represented a successful strategy for the Mediterranean areas of southern Italy (Sicily and later Calabria, and Campania) and later for those of the southeast of Spain (region of Valencia, Murcia and Andalucia); it allowed to exploit the natural monopoly derived from pedoclimatic conditions, thus creating an economy, which would not be reproducible in northern European areas where citrus fruits are traditionally exported.

On foreign markets citrus fruit positions itself as an expensive and exotic commodity, which obtains immediate success in a world which had known industrial revolution and, for this reason, could express an attitude to the consumption of discretionary goods. Therefore, the citrus sector did not emerge as a surplus of demand from local markets, on the contrary, it was stimulated by the demand from capitalist cities.

The history of citrus crops cannot be analyzed through the dialectic "use value exchange value", which postulates first a production for the consumption, next a surplus for the local market, and finally the production for wider markets. (Lupo, $p$. 85, 1990).

As early as the second half of the nineteenth century, citrus fruits cultivation was the most profitable in Europe (Lupo S., 1990, Bevilacqua P. 2000). Citriculture initially established itself in Sicily, thanks to Arab irrigation and cultivation techniques, first in the limited and closed spaces of the giardini ${ }^{20}$ and then spreading in the spaces

\footnotetext{
${ }^{20}$ In Sicily and Calabria, the citrus grove, initially enclosed by walls, is called a giardino (garden) highlighting both its meaning in the Arab culture as a place of beauty and pleasure, and the contrast of the green and luxuriant interior with the arid and barren exterior of the latifundia landscape (Lupo, p. 6 and 7, 1990)
} 
outside the inhabited centers.

The transition to citriculture represents, still today, one of the most expensive cultivation operations. Initially, it was not the members of the peasant class or small owners who started it, but landowners who had capital to invest and resources, allowing them to wait 5 years for fruiting. The willingness to make such a risky and long-term investment was naturally determined by the strong income obtainable, much higher than in any other agricultural activity. This a peculiarity, destined to last over time, which characterised the nineteenth-century situation in approximately the same terms as that of the following century (Lupo S., p.81, 1987).

\subsection{Citrus as a commodity and the birth of the mafia, a hypothesis}

Recently, Dimico, Isopi, and Olsson (2017) have noted that the birth of the mafia coincided with the economic boom in international citrus demand, following the discovery that citrus fruits cured scurvy.

This upheaval of Sicilian agriculture took place in a context where the land patrimony had begun a process of dissolution, and where the law and the state had a weak role. These circumstances increased the demand for protection of this new commodity from the risks of predation. Operating in an environment with a weak rule of law, the mafia protected citrus production from predation and acted as intermediaries between producers and exporters (Ibidem p. 1083).

In their study they found that during the citrus growing boom, in the second half of the 19th century, there was a strong correlation between citrus fruit production areas for export - a significant and profitable production of to be protected - and criminal events. The criminal events are related to the original data from a parliamentary inquiry in 1881-1886, the Damiani Inquiry, on Sicilian towns. They show that the mafia presence is strongly related to the production areas of oranges and lemons; rather than being a consequence of a more generalized demand for protection, resulting from the fragmentation of large properties following the Napoleonic reforms, and the Bourbon-era land reform (1816-1860) as in Bandiera 0. (2003): the Sicilian geographical areas in which criminal events increased are those of citrus fruit production, and not the whole territory which was subjected to reforms.

\subsection{Current citriculture}

Currently, the citrus sector is a strategic sector for the southern Italian regions, especially for Sicily and Calabria which represent $80 \%$ of the total national area 
cultivated with citrus fruits. Italy is, after Spain, the European country with the largest area dedicated to the production of citrus fruits. The Italian citrus growing represents $28.4 \%$ (equal to 146.132 ha) of the total area and $24.2 \%$ ( 2.586 .507 tons) of the total production in Europe. $22 \%$ of the entire Italian citrus production is represented by clementines and Calabria, with $62 \%(16,164$ ha) of the total Italian area dedicated to its cultivation, produces $69 \%(437,800$ tons) of the total production (Ismea, 2019 and MIPAAF-ISMEA, 2020).

The citriculture plays a strategic role in the economy of Southern Italy, one of its most important attributes being the close link between citrus fruits and the territories of production.

Among the 19 citrus fruits to which the EU has recognized the PDO and PGI designation, 12 are Italian, distributed between Sicily, Calabria, Puglia and Campania. Two PGI and one PDO denominations are recognized for Calabrian citrus fruits, two PDOs, one of which is currently undergoing the procedure of recognition. 


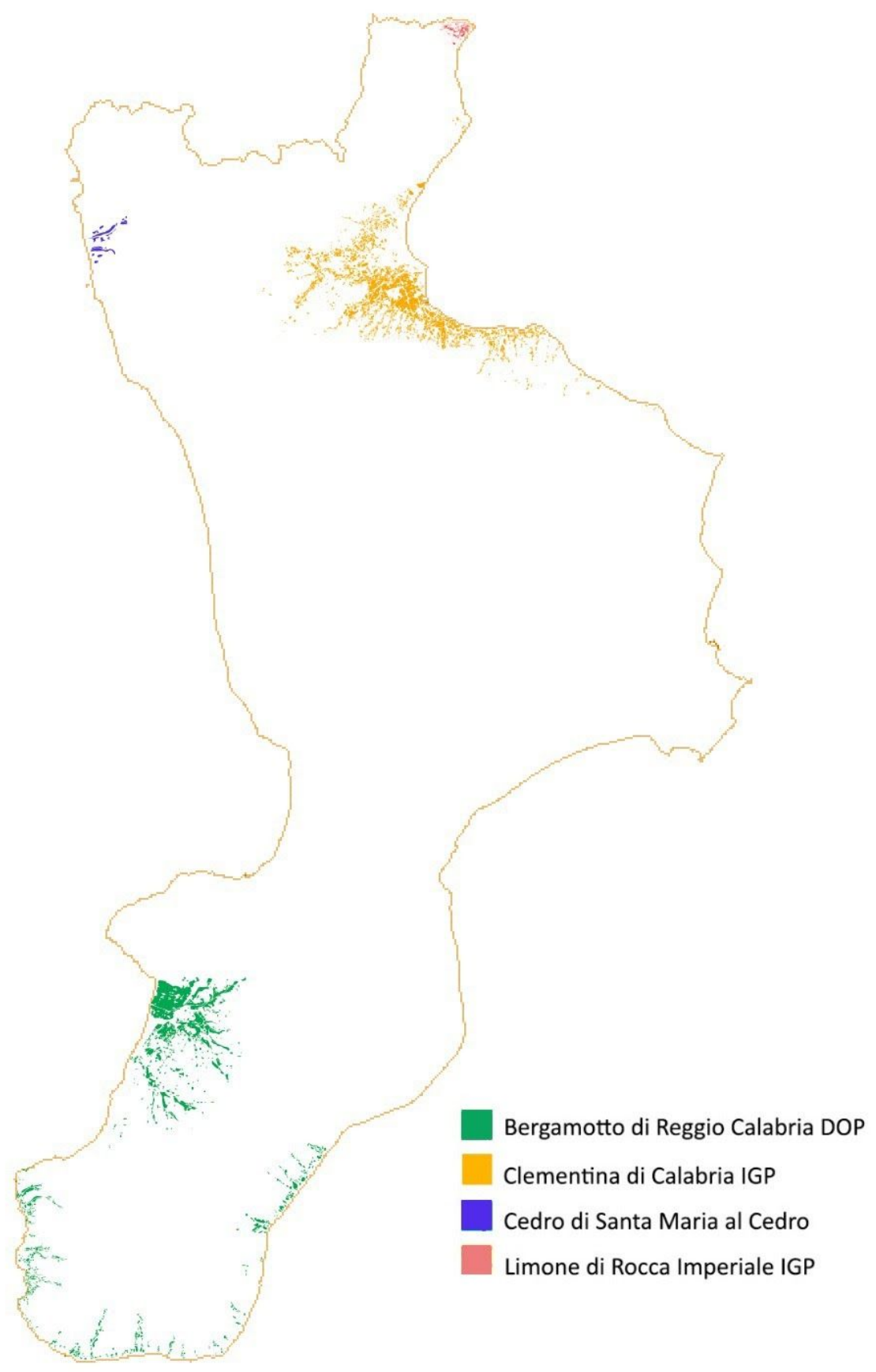

Figure 6 Landscape map of the PDO and PGI citrus fruits of Calabria. Calabria Region Geoportal data 2014, data processing by the author.

The protection of Calabrian clementines with the PGI label "Clementine IGP di Calabria", whose production mainly coincide with the sibaritide territory, is significant of the strong dependence of this citrus fruit on the production area ${ }^{21}$,

\footnotetext{
${ }^{21}$ In addition to giving specific indications regarding the production processes and the geographical limits of the production areas, the guidelines of the "Clementine IGP di Calabria" consortium in the municipalities of the three coastal plains indicate the specific characteristics of the soils, such as medium-textured soils with a silt and clay content less than $60 \%$, and a limestone content of no more than $15 \%$.
} 
along with the peculiar relevance in terms of local economy.

The EU labels represent a competitive factor for local agricultural communities, as they contribute to the protection of biodiversity and ecosystems, the maintenance of human settlements and the development of territories.

The entire production process of Clementine di Calabria PGI under the organic regime appears to have the best yield in terms of revenues, and the lowest impact on energy consumption and $\mathrm{CO} 2$ emissions. This is due to the use of two alternative production methods - conventional and integrated pest management methods ${ }^{22}-$ in the 3 main production areas of the region (Falcone et al, 2020).

The most sustainable aspect of this production method is mainly represented by the exclusion of synthetic products from the production process. The less advantageous production method is the integrated pest management method which, despite its higher production costs compared to the other two production strategies, does not give proportionally higher revenues.

In order to underline the importance of the citrus sector for the region, it should be noted that the only Calabrian company listed on the stock exchange is an agri-food citrus company, Agrumaria Reggina Bevande, that is a "Calabrian SME specialized in basic ingredients for citrus fruit drinks. The figures speak for themselves - about 75\% of the turnover achieved outside the national borders" (www.ilsole24ore.com).

The Calabrian citriculture ranks third in the coastal plains - Sibari, Lamezia and Gioia Tauro, which represent the best areas from the point of view of land use and accessibility. In these areas a quarter of the marketable regional agricultural production is made.

22 Organic farming is characterized by the use of organic fertilizers, the biological control of pests and mechanical operations. At a local level, integrated farming is regulated by specific procedural guidelines describing the most appropriate cultivation techniques for several crops. It combines the best of modern tools and technologies with traditional practices. Conventional farming allows the use of all chemical products authorized by European and national regulations. 


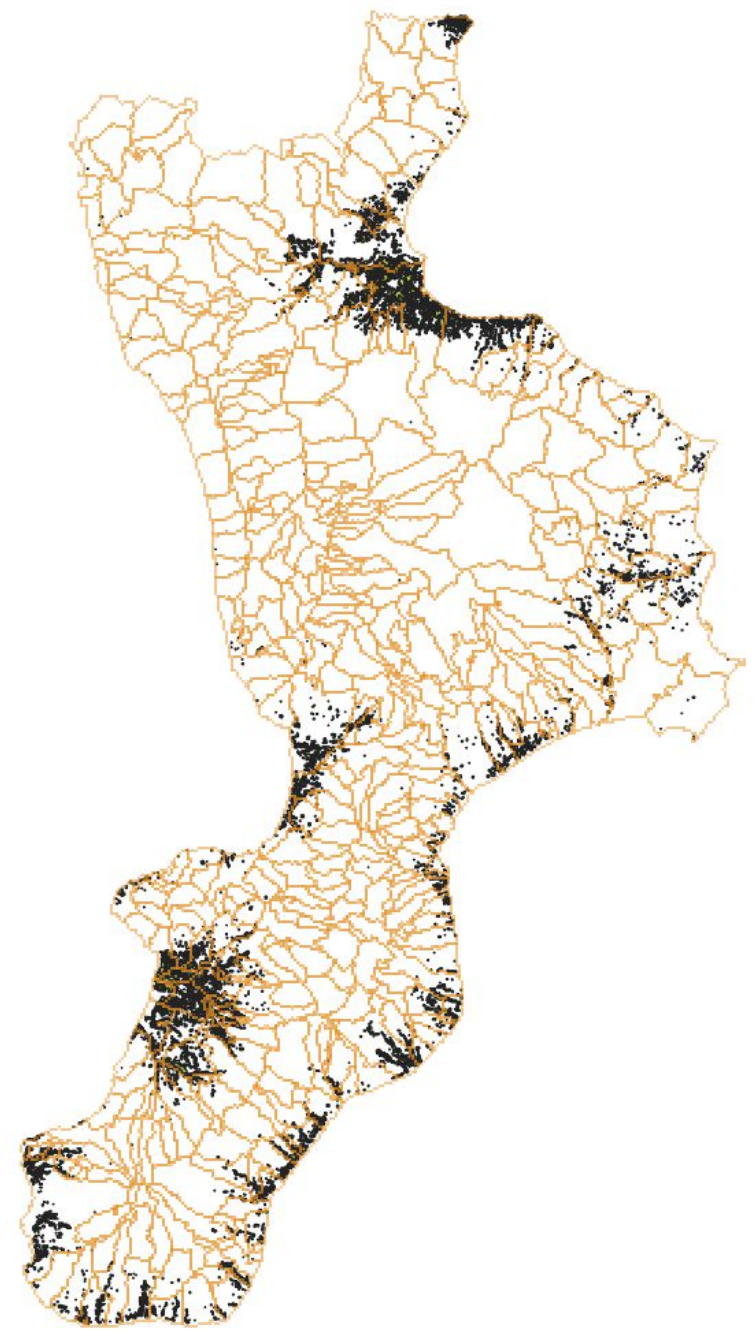

Figure 7 Citrus fruits land cover, municipal boundaries cartographic base, 2014. Calabria Region Geoportal data 2014 processing by the author

Unlike other areas where the transition to citrus has been made as a result of top-down subsidy policies - which often resulted in the opaque area of the clientele system (exchanging political favours and interception of subsidy-related financial flows) - the conversion to clementine in the Sibari Plain took place following strategies of production and market advantages (Cavazzani A. Sivini G, p. 8 and 9, 1997). The turn to the clementine cultivation as a territorial vocation shows that, since the framework of the same economic phenomenon can be reached through different premises and strategies, it would be desirable to use different intervention policies. 


\subsection{The turn to the organic production}

The increasing interest towards organic productions is due, on the one hand, to the growing attention towards healthy products, and on the other hand, to the global goal to make agricultural production more sustainable, in relation to the strong relationship between agricultural production and environment.

In Italy, the incidence of the organic citrus area on the total citrus area is particularly high, reaching 25\% (Sinab, 2019). In 2019, the organic area of small citrus fruits (clementines and mandarins) is 10,039 ha, which corresponds to $28 \%$ of the total area of citrus fruits grown organically in Italy.

Italy is currently the leading nation in Europe with a citrus area twice as high as that of Spain, the leading European citrus producer.

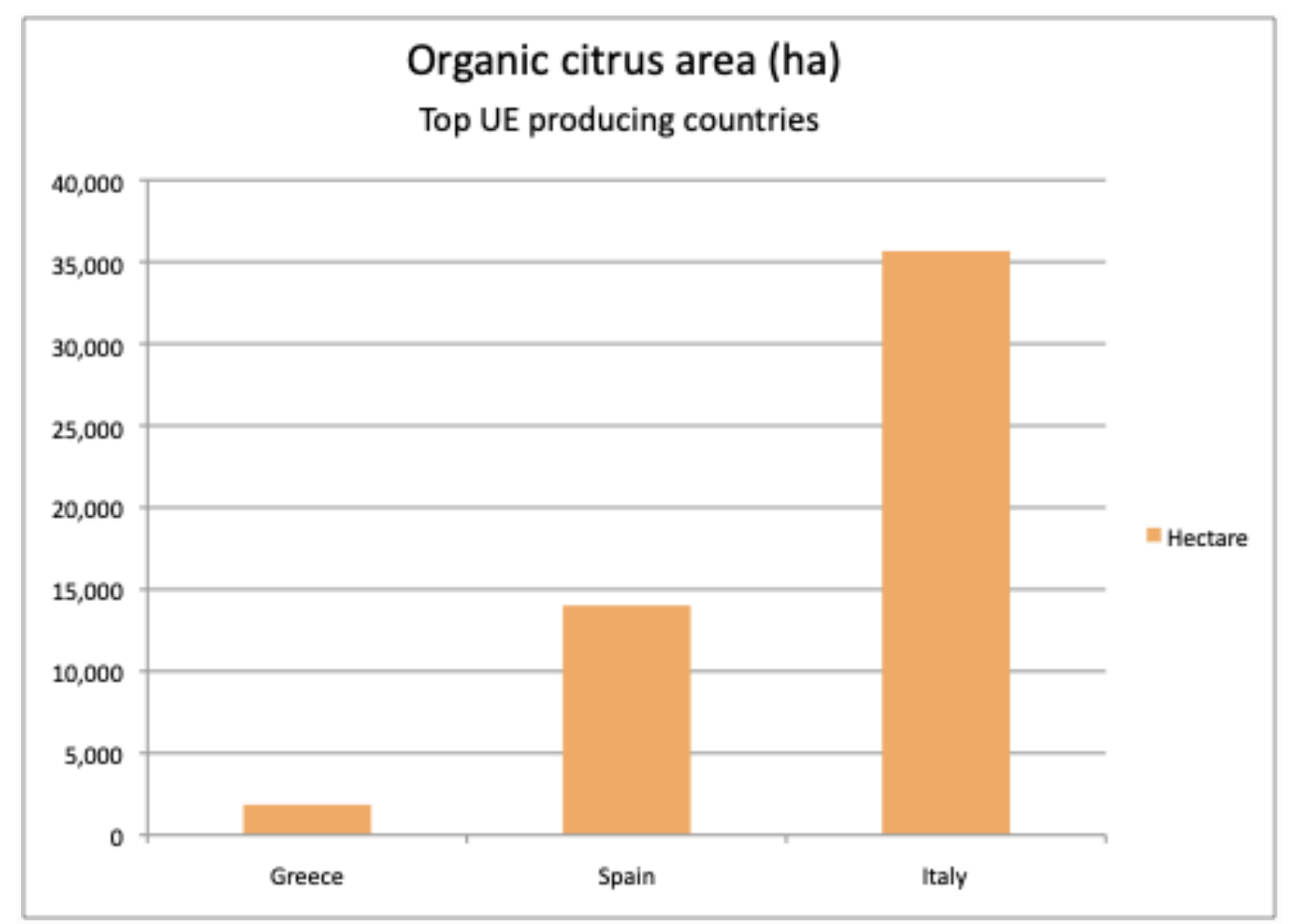

Figure 8. Organic citrus area. Eurostat data, processing by the author (2018).

The success of organic farming is to be attributed to the relative simplicity of citrus cultivation under organic regime, to the concentration of production in southern Italian regions, which are characterised by fewer phytosanitary problems thanks to their drier climate, and to the low profitability especially for part-time farms with family labor which often find it convenient to secure a certain income from the Community Agricultural Plans (CAP) premiums through the conversion to organic 
farming (MIPAAF-ISMEA, p . 29, 2020).

Despite the extensive spread of cultivated land according to organic regulations, mainly stimulated by incentives to producers, and although there is no official data, there has not been a substantial increase in terms of certified and marketed organic production. It is assumed that the premiums insured by the CAP have been an extra income for the companies, rather than representing a real and more profitable conversion of production methods (Ibidem, p. 30, 2020).

In Calabria the area of citrus fruit grown organically corresponds to 11,733 ha (Sinab, 2019). It is the area cultivated with clementines that has recorded the largest percentage increase in organic production (SINAB - ISMEA Bio Report in figures 2020).

\subsection{The citrus production chain}

The world of citrus fruit production is a complex and articulated world, in which many professional figures operate. Alongside the figures of globalised modernity, there are traditional figures from the rural world. Following the paths of the supply chain means reconstructing a journey between very distant clusters which are brought together thanks to citrus fruits.

In the citrus fruit sector it is possible to meet the following structures and professional figures: nurserymen, producers, collectors, commercial intermediaries (mediators), estimators, cooperative, consortium, and/or producers' organization (POs), wholesalers, packaging operators, modern distribution platforms (CeDi) or, alternatively, wholesale fruit and vegetable markets (or agro-food center), large-scale distribution, retailers, consumers.

Alongside the traditional supply chain, short supply chains have recently developed through the Alternative Food Network and direct E-commerce channels.

\section{Citrus growing and irrigation in the Sibari Plain, an inseparable duo}

As early as the mid-19th century, some small and discontinuous plots, islands, have been torn from the marshes and dedicated to valuable crops: vines, gardens, citrus groves (Gambi, p. 468, 1965).

This pioneering citriculture was limited to small plots in the localities of Pendino, Ogliastretti, Morgia, Canalicchio, Vallone Aranci (Brunetti, 1991). 
It was from these small fenced properties that the characteristic Mediterranean garden began in the Sibari Plain - small citrus cultivation enclaves that accompanied the transformation of the territory according to the model of Sicilian gardens. During those years, the cultivation of citrus fruits favoured the increase of the land property value to a much higher extent than with any other types of plant (Lupo S. p. 38, 1990, Bevilacqua P., p. 199, 2000).

During a parliamentary question in 1873 an important citrus exporter from Messina, Carlo Sarauw, affirmed that among the oranges shipped from the port of Messina, at the time dominating the international citrus trade, a part came from Rossano ( $\mathrm{S}$. Lupo, p. 25, 1990). Exports were mainly directed to Russia, Austria, Great Britain and the United States.

At the end of the First World War, after the introduction of land property reforms, the first reclamations and the works to mitigate the flood risk, the population, who for centuries has taken refuge in the molecular settlements of inland areas, began to "migrate to the valley", gradually concentrating on the coastal plain and in the wider river valleys ( O. Petrucci, M. Polemio, 2007).

After the complete reclamation, during the first decade following the Agrarian Reform, a radical transformation of the landscape occured when some large local producers began to replace extensive low-profit arable land with what could be considered a profitable commodity - a part of which P. Bevilacqua (2000) defines the economy of trees.

At the end of the 1980s second crop conversion would have occurred, converting orange to the more profitable and resistant clementine cultivations.

The clementines harvest campaign is concentrated between October and February. The central part of the marketing year, November-December, is characterized by greater price stability, while the beginning and end of the campaign show greater variability [Fig. 10].

The volatility of original prices at the beginning and at the end of the campaign is due to the meteorological variables, and the quantities and fluctuations of the citrus fruits price lists from Mediterranean countries. 


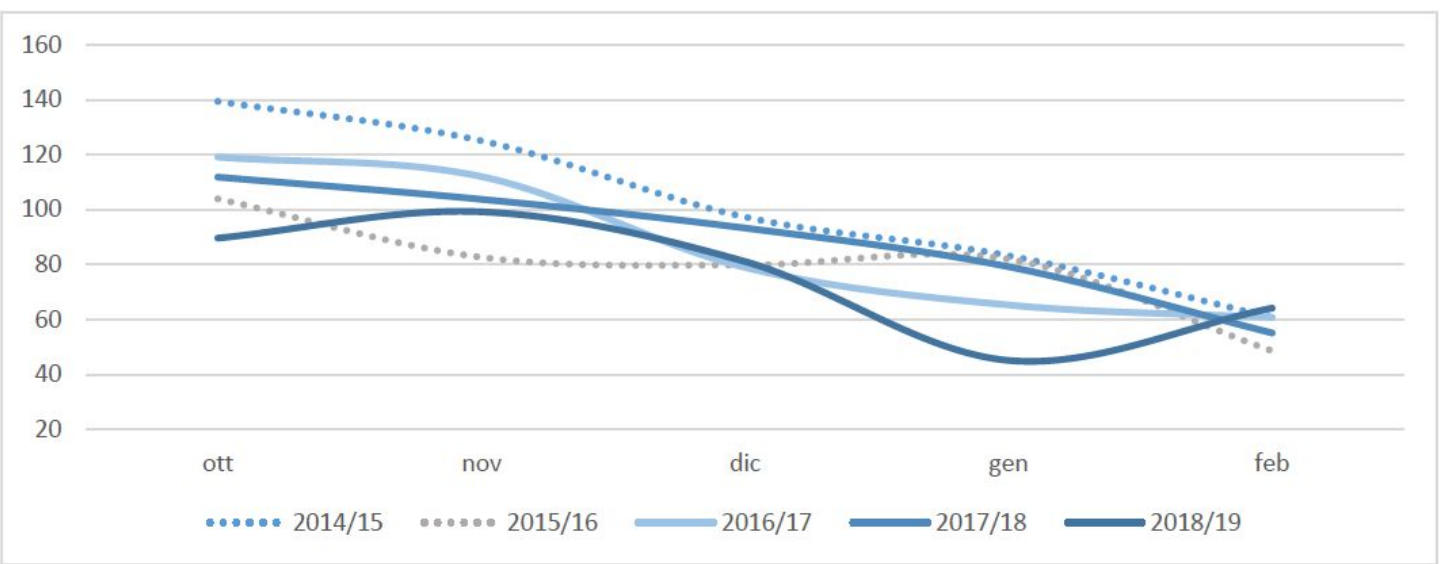

Figure 9. Price index at the origin of clementines $(2010=100)$ Source Ismea (in MIPAAF-ISMEA, p. 45, 2020)

Citrus cultivation is highly dependent on meteorological variables, which affect both quality and quantity; irrigation affects variable costs with a share between $5 \%$ and $17 \%$ (Ismea, 2020). The supply of water and its efficient management for irrigation are crucial factors first of all for the crop yields, product quality, calibers and, ultimately, for price formation.

In the Sibari Plain, the main source of water supply for irrigation should be the water network of the Reclamation Consortium (Consorzio di Bonifica), but its inefficiency has led to the use of individual solutions, such as the private well for groundwater extraction (De Rose and Sivini, p.194, 1997).

For farms and livestock farms spread throughout the area, the simplest, if not the only, solution has often been to build their own wells. The limited extension of consortium irrigation networks, the problems of irregularity in the aqueduct ${ }^{23}$ services $^{-}$ and the succession of increasingly serious drought periods, have further supported the tendency to create autonomous irrigation systems, through conspicuous withdrawals of groundwater (Polemio M. et al. p. 23, 2013).

The consequence is that the number of wells for pumping from underground aquifers, according to approximated lower estimates, net of widespread abuse, went from 500-1000 in the 1970s to 6000 recorded in 2000 (Relazione geologica definitiva Piana di Sibari, 2015).

The solution "each for themselves" represented by wells, is currently the almost obligatory path for the farms which must guarantee the indispensable irrigation of crops. Faced with an original qualitative and quantitative richness of the confined aquifers, the over-pumping of the aquifers is generating salinization effects for the advancement of the sea wedge which slowly compromises the soils of the coastal

${ }^{23}$ The Consortium of Land Reclamation of the Sibari Plain and Media Crati Valley has been in charge without interruption from 1954 to 2010 when it was dissolved and subsequently reorganized in a mini consortium (currently the municipalities of the Sibari Plain are served from the Reclamation Consortium "Consorzio di bonifica integrale dei bacini dello Jonio cosentino"). 
plain reducing their productivity (Relazione geologica definitiva Piana di Sibari, 2015). The necessity to overcome the inefficiencies of the Aqueduct consortium - which generates feedback effects on the quality and quantity of groundwater - implies private investment costs to build wells, along with electricity costs for extraction.

The increasing withdrawals of groundwater to irrigate citrus groves affect the final costs of the product also due to the increasing frequency of climatic stress ${ }^{24}$.

In addition to the costs of building the private water system must be added the costs for irrigation: irrigating through wells costs as high as 10-12 times the cost for irrigation through water from the Consortium. This creates feedback effects, such as the salinization of the aquifers, which slowly compromises the soils and reduces productivity (Petrucci and Polemio, 2013).

The individual solution is used to manage the effects of the dysfunction of the collective water management to the detriment of the consortium collective solution. Whilst providing an immediate advantage for the single, in the longer term the individual solution penalises the local community, causing higher individual and collective environmental costs.

\section{The "unspoken" of the Sibari Plain}

In a territoriale context such as the Calabrian one, it is highly probable that an economic operator will come into contact, by choice or by imposition, with illegal mafia-type networks.

The mafia can either be a sort of "background noise" presence, or have more visible roles; but the illegal dimensions do not constitute a "deviance" from a system of "normal" relationships, rather they represent one of the variables in the process of building social and economic relationships (Barazzetti D., in Dolci Clementine, p. 120, 1997).

The structural presence of organized crime in the Sibari Plain can be traced back to the 70s of the last century, when activities related to agriculture began to arouse interest due to their importance in the local economy.

Between the 70s and 80s of the last century, with the consensus of 'Ndrangheta of Reggio Calabria, the Camorra (mafia-type of Campania Region) took control of the agricultural sector, which was expanding in the Sibari Plain (Ibidem p. 98).

The mafia does not only deal with the classic activities of extortion and protection, but fully enters into the economic and social relations networks.

\footnotetext{
24 The IPPC records a reduction in rainfall and an increase in drought regimes. It also identifies as relevant the impact of agriculture on soil degradation processes (Mirzabaev, A, 2019).
} 
As far as the transactions in the citrus sector are concerned, in those years the Camorra, through its brokers, coercively assigned external traders to producers, who had to cope with a system of bribes to enter the Sibari Plain market (Ibidem p. 106). In the 1980s, mafia control passed to the 'Ndrangheta families who entered the more profitable sector of processing orange fruits into juices, creating a consolidated system of scams to the detriment of the European Union, which in those years gave subsidies to stimulate the processing of agricultural products.

Whereas in the past the mafia in the Sibari Plain even intervened in the shaping of the price of agricultural products, today its role is mainly focused on the nodal points of the agro-food supply chain: on the wholesale markets, where supply is concentrated, and on the trucking sector (Eurispes-Coldiretti, 2019).

Organized crime exploits these sectors to control the transition hubs from production to retail, facilitating anti-competitive behaviors (Eurispes, 2020).

Furthermore, the territories characterised by high-quality productions, with added value provided by brands such as those labelled with geographical indication of origin, are the most permeable to the mafia (Ibidem, 2020).

The success and stability of the mafia model requires the ability to procure the active and/or passive cooperation of social actors, in a system made up of coercion and consent.

At the beginning of the lucrative world of the citrus sector, the mafia began to create a consensus system thanks to a redistribution of wealth ${ }^{25}$ resulting from frauds against other economic operators and public and private entities. Whilst providing Mafia families with economic resources, the long-time tested "services" of

\footnotetext{
${ }^{25}$ Like other power relationships, the mafia relationships have a coercive and consensual character, at the same time, as no power can be exercised without a minimum of consent. In concrete situations, consent and coercion are closely interrelated within a continuum, between the pole of maximum consent and maximum coercion. In concrete cases this also explains the reason why it is so difficult to discern, whether consent is the result of collective manipulation, or whether it is, in fact, the expression of free adhesion. Unlike the individual criminal, Olson noted that the mafia family, since it holds the monopoly on crime in a given community, has a moderately inclusive interest. It bets to a certain extent on the income of the community, thus taking into account - in the use of its coercive power - the interest of the community.

According to Olson, this explains the reason why, in the presence of a criminal group which has managed to settle in a territory and control it effectively, the "subjects" - despite being victims of extortion - end up preferring "such regime to the sporadic robberies of nomadic bandits". In other words, the "sedentary bandit" being the bearer of an inclusive interest in the territory controlled by him - guarantees order and advantages also to the population, so that permanent extortion is perceived far better than a situation of anarchy: " Therefore, we cannot compare him to the wolf attacking the moose, but rather to the breeder who makes sure that his herd is protected and receives the right ration of water" (in Sciarrone, From the global society to local economy, p. 57 and 58, 2002).
} 
guardiania $^{26}$ and caporalato ${ }^{27}$ - which are under the monopoly of the mafia in the agricultural sector - have above all the function of maintaining control of the territory, in competition with the state authority, as well as of strengthening the complex and proven relational system of obligations and exchange.

The shape of both these "services" are evolving: they are still services provided by mafia families, but they take on legitimate appearances through "shell" enterprises, which take the form of cooperatives of workers and security firms (Eurispes-Coldiretti, 2019 and stakeholders interviews)

As we will further discuss in detail, in this and in various other points of the clementine supply chain and networks, the companies linked to the illegal system and the legal ones get confused in a situation of pooling equilibrium, in which it is difficult to distinguish between "healthy" and "sick" economy, that is between "healthy" companies that can to stay on the market thanks to their skills and "sick" companies, these being colluded with organized crime and/or able to withstand competition thanks to incorrect behavior and under the table agreements with public authorities or simple tolerance (Sciarrone, p. 57, 2002).

The large availability of economic resources, as well as the use of violence, allows the mafia to control community activities and influence politics at local and national level. By doing this, it also controls the flows of money destined for welfare, incentives, etc. in order to obtain social consensus and consolidate its power.

The ability to fit into the interrupted points of flows and networks requires that these organizational gaps left by legal, public and private structures are not closed. In order to maintain the control and the appropriation of wealth, it is necessary that these strategic points remain weak or non-existent both in terms of economic and relational resources. It appears that the structural presence of illegal networks, even if it does not enter directly into the citrus market, has an impact by creating obstacles and dysfunctions both at the level of the supply chain, and with respect to the territorial collective services connected to it (cooperatives, transport and logistics, consortium irrigation waters).

\footnotetext{
26 The guardiania is a form of protection-extortion widely practiced by local mafia agents on producers and intermediaries. In the territorial context, it is accepted as inevitable and normal, as it is disguised as a protection and security service for the control of the agricultural fund. Diego Gambetta (1992) says that with the security guard, the mafia privatizes the demand for protection and security, which is a function that should be institutionally ensured by public authorities.

27 The caporalato is an illegal form of recruitment and organization of the workforce, especially agricultural. It uses intermediaries (caporali) who perceive a bribe to illegally hire daily workers - who are not granted the minimum rates of pay - on behalf of the entrepreneur.
} 


\section{Producer enterprises}

The latest available Agriculture Census data (2010) show that the average size of farms in Cosenza province is equal to $4.2 \mathrm{ha}$, given the Italian average size of 7.9 ha. The prevalent size classes of the citrus producing companies in Calabria are small and very small ones - less than 1 hectare and 1-2 hectare and, at the same time, there is a doubling of farms with an area greater than 20 hectares, compared to the previous census.

We can thus underline that this is still the prevailing model for Calabrian agriculture, and that the processes of restructuring and transformation of the productive sector have been less intense than those involving Italy as a whole.

The agricultural units of Calabria continue to be mainly founded on farms in which the tenant directly manages the agricultural activity, that is $96.9 \%$ of the fruit trees companies (Istat, Agriculture Census 1010)

In the 13 municipalities ${ }^{28}$ considered, there are 5.018 citrus producing companies (NACE 01.23$), 3.624$ of which mainly produce clementines, and with regards to the legal form, 4.892 are individual enterprises (Istat, Agricultural Census 1010).

The data from the 2010 Census of Agriculture show a strong discrepancy ${ }^{29}$ with the data of the Chamber of Commerce, according to which in 2019 1,804 individual enterprises and 19 producer cooperatives are registered with NACE code 01.23.

\footnotetext{
28 In 2019 Corigliano calabro and Rossano merged into a single municipality.

${ }^{29}$ One hypothesis is that the citrus production activity may not be the main activity of a tenant. It is therefore "photographed" in the census investigations, but not counted by the Chamber of Commerce as a secondary activity. Another hypothesis on this discrepancy, supported by reports from various operators, is that the owners of small production areas do not register for VAT in order to intercept the money coming from the welfare. Their production is sold through formally registered manufacturing companies.
} 


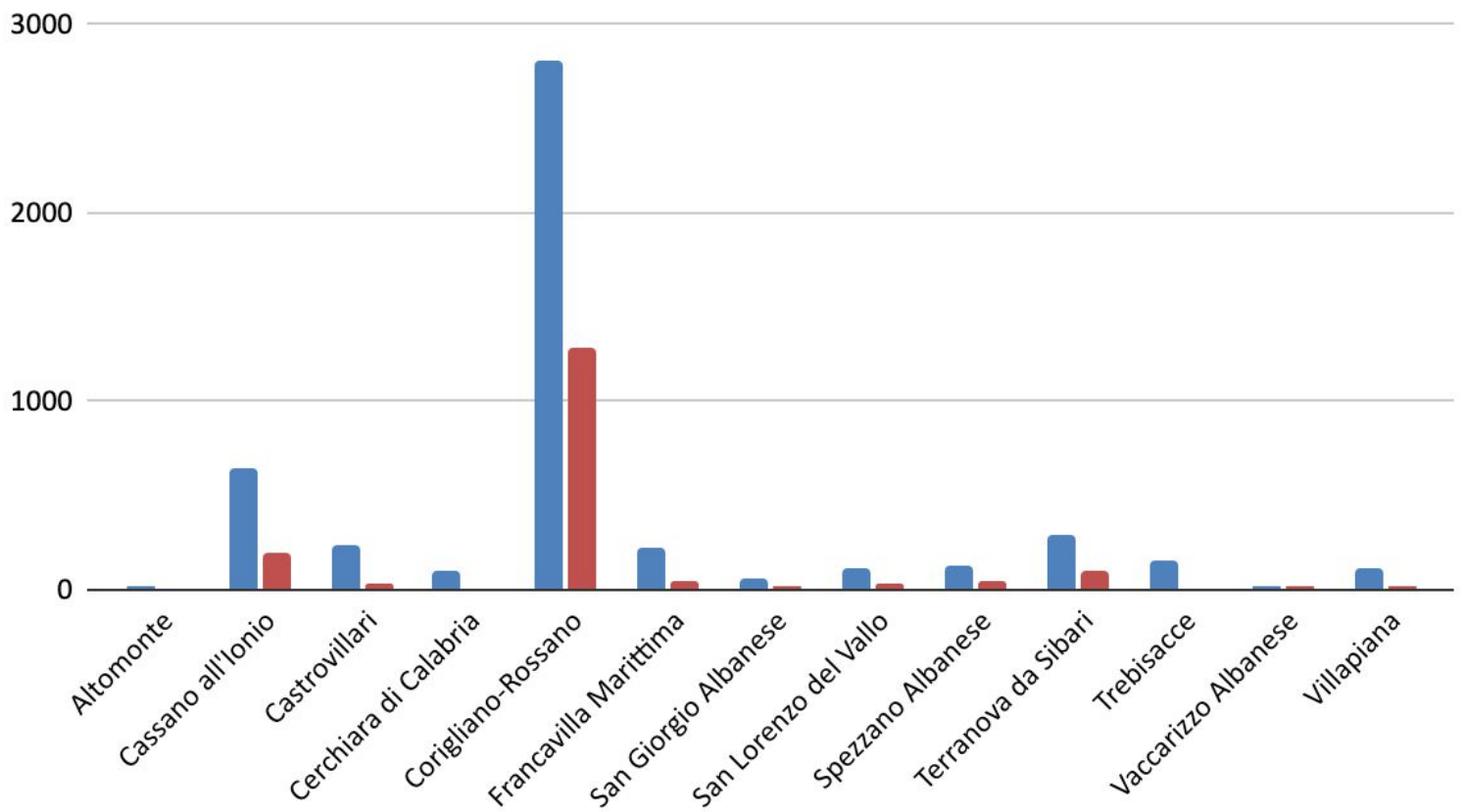

Figure 10 Individual enterprises citrus fruit producers (NACE 01.23), by municipalities. Source: Istat, Agriculture Census 2010 and Italian Business Register of Chamber of Commerce 2019. Data processing by the author.

The strong land fragmentation following the Agrarian Reform is also the consequence of a hereditary distribution of larger funds (Viale, in Dolci clementine, p.31, 1997). Oftentimes the owners of the funds are not actual agricultural entrepreneurs, but people who have other activities (professionals, employees, etc.): they are holders who do not consider agricultural activity as their primary occupation $^{30}$. In some cases, there are "absentee holders" who have opted for family-type organizational solutions, taking advantage of all possible welfare mechanisms and grants available to the sector. The strong discretion of welfare policies has allowed a strong mix between social development and parasitic interests, and between these and the underworld interests (Cavazzani and Sivini, in Dolci clementine, 1997, p. 8). Individual entrepreneurs are considered more vulnerable to intimidation or to the resources offered by criminals (Eurispes, p. 24, 2020). Cooperativism, which is predominant in commercialization activities, is also

\footnotetext{
${ }^{30}$ One respondent reports that "the property characteristics have changed further over the past 20 years. The professionals left the citrus production for various reasons: high costs, or their children were not interested in maintaining the property. The properties were purchased by wholesale traders who are now all in the "Producer Organizations". This change is probably also due to the decrease in social value attributed to owning the "garden". It is no longer felt as a status that confers belonging to a social stratum. The concentration of ownership is also confirmed by the data (Competitiveness of the citrus industry in Italy, 2020).
} 
often used only to access public grants (Petrone, 1995, p. 66 and Zumpano in Dolci clementine, 1997, p. 125). Politics and the mechanism of clientelism are involved too in this sort of "opaque" zone.

With regard to the orientation of companies towards innovation and improvement of cultivation techniques, especially in the past, we can distinguish between the producers oriented to rent-seeking, who are mainly specialized in orange production - which has an outlet in the processing market (low profitability but also low commitment and production costs) - and the market oriented producers, who have a greater citrus specialization in clementines (De Rose and Sivini in Dolci clementine, p. 197, 1997).

\section{The commercialization}

The stable and mostly traditional world of the citrus producers is counterbalanced by the dynamic world of traders, where the wider the organizational structures composing and decomposing and the networks of relationships are, the farther the trader is able to sell citrus fruits. Through citrus commerce, already in the 19th century, the peripheral South of Italy, would create networks from Sicily and Calabria allowing to transport the citrus fruits to the European and American industrial cities in a short time, and resell them at a profit (Lupo S., p. 105, 1999).

Given the narrowness of local and city markets, the citrus fruit trade has therefore always represented a powerful channel for connecting geographically very distant nodes, conveying information, and transferring money. The producers - who are still generally unfamiliar with the world of commerce - in the past were even more excluded than today, especially because information and media were only available to the few. The organizational weakness of a such pulverized production sector with few entrepreneurial motivations, is particularly evident in the commercialization, when the small farmer has to enter a citrus market currently dominated by large-scale distribution, and where the offer is concentrated in a short winter period (October-February). For the producers of the Sibari Plain, the 
competition takes place on a European market dominated by Spain ${ }^{31}$ and with strong price competition from other international players (mainly from other Mediterranean countries). The strong perishable nature of the product and the lack of large neighbouring sales markets deeply affect the rapidity with which the Calabrian clementines arrive on distant markets, national and international ones. The "peripheral" position of the Sibari Plain, rather than because of a geographical reason, but because of inefficient infrastructures and logistics, represents a major competitive disadvantage for exports.

As the Ionian backbone is crossed by a single-track railway line, still without electrification, and the road haulage sector has a low competition regime, the port of Corigliano - an important public infrastructure completely unused for commercial purposes - could instead play a strategic role in the construction of long supply chains, thus allowing important competitive advantages (Caruso and Corrado, 2012).

\footnotetext{
${ }^{31}$ Spain is the world's sixth largest producer of fresh citrus fruits and the world's largest exporter of oranges, mandarins and lemons. $60 \%$ of Spanish citrus production, mainly from the province of Valencia and Castellón, is destined for export, thanks also to the logistics network capable of concentrating the offer and quickly reaching large-scale distribution. Italy and Spain follow two completely different market strategies. On the one hand, Spain is focused on maintaining and increasing its shares on the markets it controls, leveraging on price containment; on the other hand, Italy has a small foreign market niche based on the quality and added value of Made in Italy. Regarding the citrus production of the Sibari Plain, all the interviewees complain about the great difficulty in getting fresh citrus fruits to the markets of northern Europe in a rapid way. Calabrian clementines with the PGI label (2018-2019 + 39\% compared to the previous campaign), must adhere to strict process regulations that allow to obtain a fruit with the highest quality standards in terms of organoleptic qualities, little or no chemical residues on the product. However, its size, smaller than the Spanish clementine, is not what the large-scale retail trade requires for purely commercial reasons, especially for sale in northern Europe.
} 


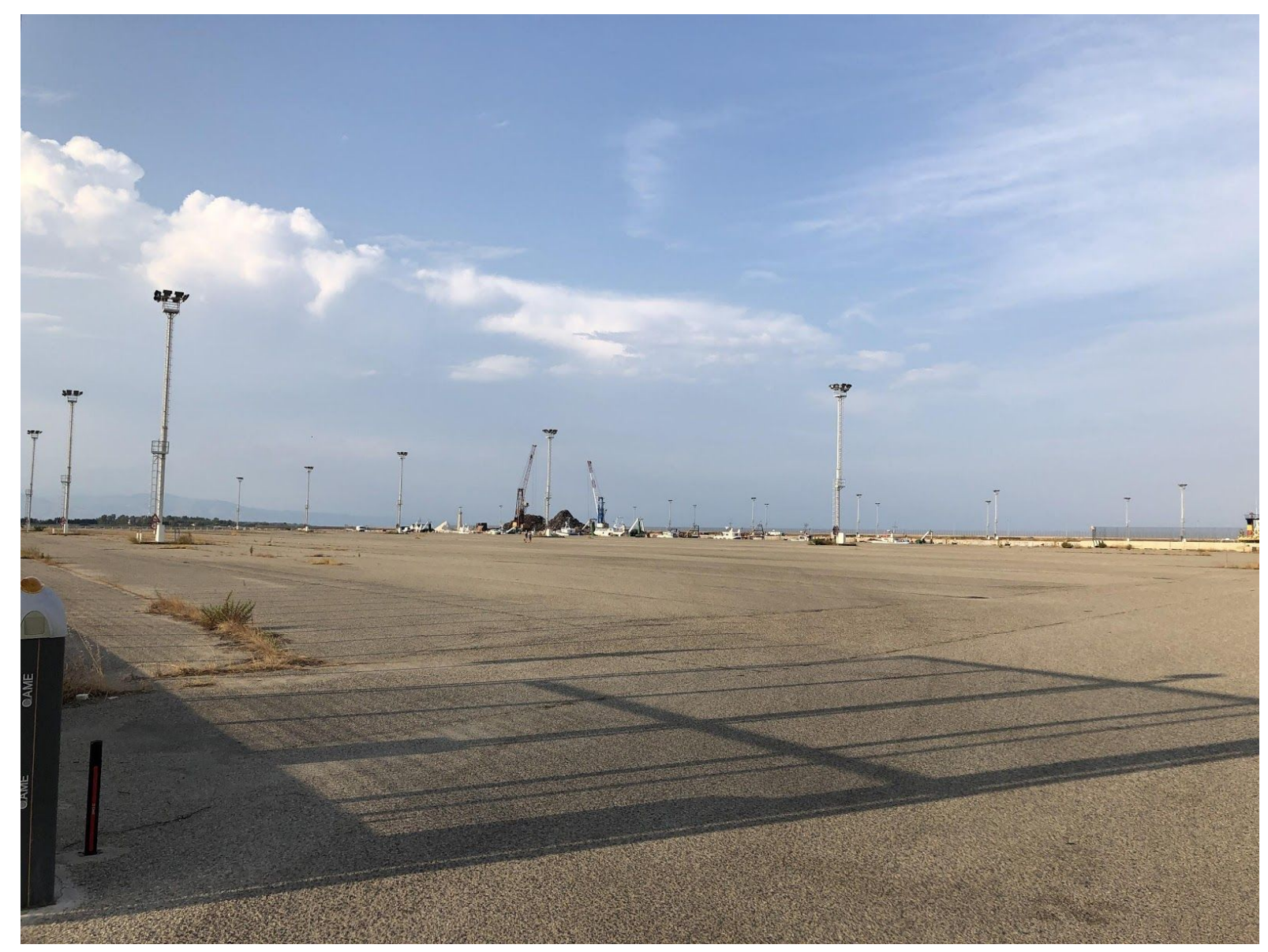

Figure 11 The port of Corigliano in September 2019

In this framework, it is clear that to sell the clementines "well", the mini-fund producers must concentrate their offer. And currently they mainly have two paths: wholesale traders and cooperatives.

\section{Selling to wholesale traders}

In this fragmented reality, the traditional and most practiced method of transfer used by small companies is to sell the product to the wholesale trader - as much as $70 \%$ of the production of clementines is now in the hands of unorganized traders (Alfano F. and Cersosimo D., 2009). The main advantage in choosing this type of intermediation is that the traders take charge of the most expensive part of the activity, the harvest, which accounts for about $90 \%$ of the total labour costs of the producing companies (MIPAAF-ISMEA, 2020). It is the trader who decides the purchase price when the fruits are still on the tree, and being the producer the weakest element of the whole supply chain, rather than "selling well", the trader is concerned with "buying well" (Viale G., in Dolci clementine, 1997). Furthermore, it is the trader who obtains information from cliques outside the production area: he buys from the 
producers, but does not provide them with information on what is required by the markets.

This is a very low-innovation operation, which does not exploit the potential added value inherent in a function that connects distant circles and keeps information flowing. Therefore, the sale to the trader represents a clear economic and managerial break within the same production cycle (Ibidem,, p. 45, 1997).

For the construction of a territorial competitive advantage, a direct involvement of local producers into the organization of relationships with the market should be essential (M. Marini, 2013).

The speculative and low-profile attitude of the traders is also reflected in the export: they maintain irregular and erratic relationships mainly with the undemanding markets of Eastern Europe (Cavazzani and Sivini, in Dolci clementine, p. 11, 1997). Much of the citrus product is intercepted by traders outside the Sibari Plain.

Especially in the past, the sale to the trader was characterised by the distortion operated by the "illegal dimension"32 - the "background noise" pervading local economies in territories controlled by the mafia. External traders accessed local production through a small clan of mediators, some of them contiguous to the dominant mafia clans: this influenced the free dynamics of buying and selling and the formation of prices (D. Barazzetti, in Dolci clementine, p. 106, 1997).

Furthermore, it is precisely through traders that frauds ${ }^{33}$ are committed against producers, and the presence of a conspiracy of silence - the omerta - as well as the lack of transparency in commercial operations, act as a deterrent against any form of legal action: the fear of reacting to prevarications reinforces the possibility of mafia control over the behaviour of individuals and over collective consciousness (Ibidem, p. 107).

\section{The players of private intermediation}

It is around the month of August, when the citrus fruit is still green and has already reached a good size, the figure of the trader begins to appear among the citrus groves. The traders who come first are those from outside the Sibari Plain, such as

\footnotetext{
${ }^{32}$ When the citrus fruit business began to develop in the Plain (1970), first the Camorra (the Giuseppe Cirillo's clan) supported by the local 'Ndranghetiste families, then the local' Ndranghetiste family (Carelli) imposed themselves in the marketing node, thus intercepting the outgoing movements and imposing its traders and a system of bribes (Barazzetti, in Dolci clementine, 1997, p.99).

${ }^{33}$ Furthermore, the cooperatives and POs too are known for fraud, as reported by judicial documents, newspaper articles, stories.
} 
from Puglia or traders referring to the wholesale market of Fondi ${ }^{34}$ (Lazio Region), which is the most important market of Center Southern Italy. Here, they can start to get an idea of how production will be for the subsequent collection campaign.

These traders from outside the Plain are the first to appear because they want to be sure that they have a sufficient quantity of good quality products to sell on wholesale markets or large-scale retail trade. Only later, when the fruits begin to ripen and the producers feel the insecurity of being able to place their production, do the local traders appear in the citrus orchards. The praxis is that the trader looks for the producer and not vice versa.At present, the local traders have decreased their interest in grabbing the best citrus crops because they too are now owners. Generally, these are traders who have invested by purchasing production areas: they have themselves become producers by concentrating fragmented funds. This is the reason why they look for other citrus production to buy only when they estimate that their production is not sufficient for the market's demand. So, they turn to other producers at the moment of the citrus campaign, when those who have ripe citrus fruits on the tree finally resign themselves to low prices. The sale to the trader is made when the fruit is still green on the tree, so it is necessary to estimate the production, which is taken in charge of by the estimator.

The inspection - carried out by two estimators, one hired by the producer and the other by the trader - is followed by the estimates based on evaluations out of 100 trees. Next, the two estimators negotiate the price - the buyer's estimator underestimates production by $30 \%$ to guarantee the trader from the risks associated with the weather or market trends.

At the time of the estimate, the producer knows the price he will receive and, at the time of the contract signature (October), he receives $20-30 \%$ of the agreed amount. The balance is paid between December and February. This payment schedule is highly different compared to selling through the cooperative.

On the contrary, in the sale to the cooperative, the producer has no idea of the price he will receive. The liquidations take place between May and June, thus many months after the end of the citrus campaign which, for the clementine market of the Sibari Plain, ends in February/March at the latest.

As for the harvest - the most expensive phase of the process - in case of sale to the trader, most frequently the trader is responsible for the harvesting costs (the block sale of the product on the tree), but there could also be an agreement with the producer, who accepts to take care of it (sale per kilogram, generally more advantageous for the producer, though little practiced due to harvesting costs

\footnotetext{
${ }^{34}$ Several judicial investigations are carried out into the Mafia infiltrations on the Agri-food wholesale market of Fondi and in the connected road haulage sector.
} 
required to be paid in advance by the producer). With the conferment to the cooperative, the producer is primarily responsible for the collection.

Between the figure of the external trader and that of the producer, there is the mediator, who basically puts the external wholesalers in contact with local producers. There are square mediators and field mediators. The mediator receives $3 \%$ compensation from both the producer and the trader. Oftentimes, these figures are not enrolled in the register of mediators, as they are people who practice this activity with little professionalism and, generally, they do not have a broker licence. It was at this turning point that the mafia played its role (Barazzetti in Dolci Clementine, 1997).

\section{The Cooperatives}

Essential Principles of Co-operative Organizations, based on The Rochdale Principles (1937): 1. Democratic Control 2. Open and Voluntary Membership. 3. Limited Interest On Shares. 4. Return of Surplus To Members. 5. Co-operative Education. 6. Cooperation Among Cooperatives (International Cooperative Alliance, 1966)

\subsection{Introduction of cooperativism in Calabria}

In the Cosenza province, the progressive dissolution of the large latifundia between the first half of the nineteenth century and the First World War evolved into a family-owned peasant property system, which was oriented towards self-consumption and the selling the agricultural surpluses on local markets and workforce on external markets through emigration (Arrighi and Piselli, 1987)

The sale of agricultural products on local markets played a marginal role due to the lack of communication networks, the absence of important centers intercepting the offer, etc.

"The human settlements of some importance, that is the centers which create a significant consumer market and host a certain number of industries for the processing of local agricultural products - and therefore stimulate the vitality of the adjacent areas - are sparse and scarce: this deficiency [...] being a basic reason for the bruttian debilitation (Gambi, 1965).

Rather than the selling, the exchange of both self-consumption products and work services between neighbors was prevalent. Self-sufficiency imposed collaborative 
relationships, which could only be based on the close circles ${ }^{35}$ of kinship, godparenthood $^{36}$ and neighborhood relationships that were further strengthened through exchanges practices (Arrighi and Piselli, 1987, p. 13).

The Agrarian Reform (1950) put established specific bodies in order to promote agricultural development and to create cooperatives and consortia. The beneficiaries of the mini agricultural funds were obliged to enroll in cooperatives or consortia for the following 20 years upon the land assignment (Petrone, p. 66, 1995).

But the exponential growth in the number of cooperatives established in those years and the number of current ones, may not be a good key to understanding the reality of the prevailing behaviour among the tenants of farms.

The cooperatives, created by the reform agencies, often existed only on paper and were created only to access subsidies. The agricultural micro-enterprises continued in their individualistic practices without interacting with the others in the least. The main cause of the failure of the cooperative experiment in the South was that the "top down" policies of obligations and incentives to cooperativism had not considered the scarce or null practices of social interaction outside their own restricted circle. On the contrary, hostility was the prevailing attitude towards anyone who was considered a rival in appropriating what represented the possibility of minimum sustenance (Petrone, 1995).

Although finding the advantages brought by the Agrarian Reform, entrusted to the body Opera Valorizzazione Sila (1948) with the purpose of improving the economic condition of the families and of the region on the whole, Lucio Gambi notes that, in the most prestigious areas, such as the Sibari Plain, there was not that structural improvement, which would have allowed the export of valuable products on domestic and foreign markets (p. 470, 1965).

As a consequence, the tiny companies -which ignore, except in a few rare cases, the cooperative institutions-remain weak in the face of the market and derive less from their heavy work than they should (Ibidem, p. 470).

Basically, the same scenario is repeated in the second half of the 1990s, when the European Union introduced policies aimed at stimulating cooperation at the level of territorial systems between public and private actors. Oftentimes, the appropriation of subsidies is the cause of the phenomenon of ghost cooperatives - cooperatives

\footnotetext{
35 The dispersion of properties, the geomorphology, the swamping and retreat, the precariousness and imperviousness of the communication routes, all played a role in the formation of this type of relationships. The strength of a tie (weak ties) as a combination of services, the amount of time, the intimacy, and the emotional intensity between the subjects (Granovetter, 1973).

${ }^{36}$ The godparenthood (comparaggio) is a system of obligations between people of different families who formalize the figures of godfather, godmother and godchildren, thus creating bonds on the occasion of Catholic ceremonies of baptism, communion, confirmation and marriage.
} 
existing only on paper and that were created only for the purpose of intercepting funds (Capano G. and Marini M., 2005 and Petrone F., 1995).

This hypothesis would seem to be confirmed by the number of cooperatives currently registered in the business register, which were opened between 1989 and 2019 but are now no longer active because they were either cancelled, filed for bankruptcy or were ghost cooperatives. Within the time interval of the dataset considered, 269 marketing cooperative societies (InfoCamere Dataset) have been opened. Out of these cooperatives which were opened over the years, only 35 are currently active.

As reported in literature and in stakeholders interviews, the very few successful cooperative experiences in the Sibari Plain can be traced back to individual charismatic and innovative figures capable of creating aggregation (Petrone F., 1995, Russo A, 2003)

The aim pursued by the policies, in order to compensate for the limits of small peasant properties by forms of aggregate management, although triggering a significant economic growth in the start-up phase of such policies (1951-1973), in a longer term they resulted in failure (Asso P. F., 2020).

\subsection{Concentration of supply: cooperatives for the marketing of citrus fruits}

Given the need for citrus companies to quickly sell all their highly perishable production during the short period of the year in which the entire offer is concentrated, the main advantage of cooperativism in this sector is the security of an ongoing relationship with an organization that will collect all the product and try to get the best possible price on domestic and international markets.

But the small and micro companies (below the size of 5-6 hectares), managed by following local customs, are not particularly interested in investing and innovating in order to have a product which would meet the standards of quality, required by trade cooperatives to attain the standards of large-scale retail trade.

Sometimes the citrus funds belong to "absentee owners", mainly engaged in other professional activities, who consider the giardino an extra activity. These companies, in the marketing phase, turn almost exclusively to the wholesaler, who provides for the harvest - the most expensive part of the entire production process.

On the other hand, joining a cooperative, requires heavy investments both in economic and managerial terms. First of all, the costs of harvesting are in charge of the producer itself; secondly, the cooperative requires innovation and uniformity in 
cultivation practices, therefore the product is required to have certain qualitative and quantitative characteristics, that can only come by following strict disciplinary rules set by technical professionals. Consequently, cooperative associates are mainly owners of medium-large companies, and even if their members include the small ones, these have no relevance in terms of participation (G. Viale, in Dolci Clementine, 1997).

Although clementine fever has transformed the production methods through the use of funds and credit to stimulate varietal and technological innovations, it has not, however, changed the habit of individualistic and autarchic behaviours, nor has it really stimulated collaborative practices.

The cooperatives of the Sibari Plain are very diversified from each other, both in the spirit that animates them and in the strategies (C. Zumpano, in Dolci Clementine, p. 127, 1997).

Basically, we can distinguish between two types of cooperatives: those oriented to the market and profit, and those oriented to rent-seeking through the interception of subsidies and tax benefits. The critical element of associations in the Plain lies in the fact that most of the associated producers are members of cooperatives oriented to rent-seeking, which are closed within a few years. The impact of citrus fruit cooperatives of market-oriented and profit-oriented cooperatives is quantitatively marginal (Ibidem, p. 140). Despite of some virtuous and successful experiences ${ }^{37}$, there are many cooperatives closing within a very few years of activity. For instance, this is shown by the data from the Business Register on cooperatives that open and close after a few years of activity. From the data set of the Chamber of Commerce (active cooperatives NACE 01.61 and 46.31) the average life of a cooperative in the Sibari Plain is 5 years, the modal value is 1 year of life (elaboration on 98 verified cooperatives no longer active). The survival rate and the average size of the corporate legal form are used to measure the solidity of the production system, and therefore the ability to resist criminal pressures (Eurispes, 2020).

The commercialization cooperatives with more than 30 members citrus fruit

37 A great innovator was the landlord called Toscano of Cassano ionico, who had already the leading production structure of the Sibari Plain in the 30s of the 900. He transformed the company from extensive cereal to intensive vegetable, starting to export products to Northern Europe as early as in the thirties of the last century. After the agrarian reform, the son of a farm manager founded the "OSAS fruit and vegetable cooperative of Cassano ionico" - one of the pioneer cooperatives for the whole territory from which OSAS citrus fruit was derived in 1986. In the face of the continuous failure of cooperatives supported by state aid, OSAS managed to stay on the markets thanks to its rigid contractual structure. On the one hand, this allowed recourse to the judicial authority in case of defection, and on the other hand, this structure encouraged cooperation by limiting speculative attitudes. This was a successful method of keeping members linked even in the total absence of a cooperative culture in the territory. (A. Russo, 2013). Another successful experience is that of CORAS founded in 1963 and still active, although with another name and few partners. 
producers are the most long-lived cooperatives (between 15 and 20 years of activity).

Another critical element of cooperativism in the plain, as shown by interviews with operators in the sector carried out between 2016 and 2020, is that the local traders themselves set up cooperatives in order not to carry out mutualistic activities, as prescribed in art. 2512 of the Civil Code, but rather to intercept funds and incentives. There are therefore many critical issues with respect to the management of this organizational model which would seem mostly used to pursue purposes not consistent with the cooperative spirit. This could explain the very high number of cooperatives opened and then quickly liquidated, filed for bankruptcy, closed due to the mafia or dissolved ex officio.

Another aspect is that the cooperatives with the traders at the helm present a vertical and hierarchical organization: they are the ones providing indications to the producer, to whom these become strict obligations he has to follow if he wants to be in the cooperative. This type of management does not favour the growth and awareness of the associate. Unlike horizontally developed networks, the vertical organizations do not favour cooperation (Locke, 1995).

These differences affect productivity in the districts in the long-term (Locke, 1995). What is important is not so much the number and density of associative organizations, but qualitative elements, such as the structure of the networks of which these associations are composed (Granovetter, 2000, in Flora, pp. 375-376, 2008).

Cooperation in the citrus sector of the Sibari Plain occurs almost exclusively for post-harvest activities and for the ones related to the marketing of fresh products, irrilevante è il numero di produttori con NACE 01.23).

As regard to the post-harvest activities and trading of fresh products, 169 first degree cooperatives (2019 data) are registered as active in the Chamber of Commerce, of these, through cross-checks and through direct contact, 139 appear to be inactive (for various orders of causes: filed for bankruptcy, liquidated, in liquidation, dissolved ex officio, dissolved by mafia, ghost and "shell" cooperatives, etc.). It is important to highlight that it is quite common for cooperative properties, offices and factories, to be attacked. The same happens to people with managerial positions ${ }^{38}$.

From the information collected in one-to-one interviews, and from the members' liquidation data provided by some cooperatives it emerges with a preponderance of

\footnotetext{
38 The president of one of the probably active cooperatives, whom I was unable to contact to find out the number of members, I later discovered was killed, presumably at the hands of the 'Ndrangheta, in July 2019. The cooperative is currently not active.
} 
the affiliation by territorial proximity: it is highly probable that a producer of a given municipality is associated with a cooperative of the same municipality. The reason for this is both linked to economic and logistic conveniences, but probably also to familiarity with the context, revealing a possible decisive role of the circles of proximity when choosing which cooperative to join. Another significant fact is the presence, in the same cooperative, of many members belonging to the same family. In the Sibari Plain 30 first-level cooperatives and 5 Producer Organizations (POs) ${ }^{39}$ are active. They associate about 1050 individual producer enterprises.

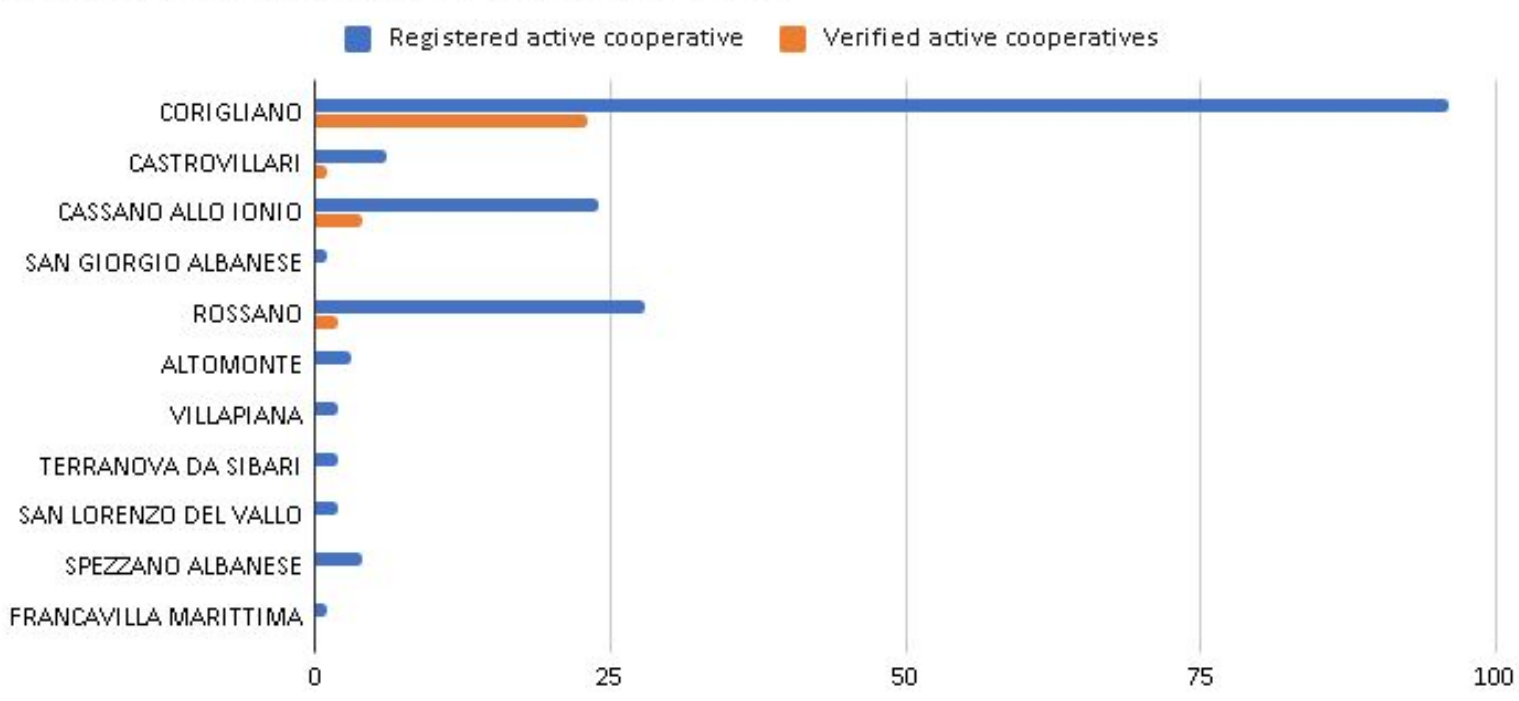

Figure 12. Number of cooperatives active with NACE 01.6 and 46.31 by municipalities. Year 2019. Blue colour are the registered as active in the Camera di Commercio Database, orange color are the verified active cooperatives (Source: Data set Infocamere processing by the author).

\subsection{Associated cooperativism: Producer Organizations (POs)}

A decisive role is played by the Producers' Organizations (POs). It is a form of organization established by the European Commission (2009) in order to stimulate the organization and concentration of the offer to reduce the asymmetry of negotiating power within the agri-food supply chains.

As evidence of how the Italian cooperative system is characterized by a differentiated development in relation to the different geographical location of the companies, although $59 \%$ of the value of fruit and vegetable production is due to the southern regions and $54 \%$ of the POs reside in the same territories, only $32 \%$ of the

39

https://ec.europa.eu/agriculture/producer-interbranch-organisations/producer-organisations-association en 
value marketed by the system organized at national level derives from POs in the South.

On the one hand this happens because in the South there is a good share of production which is not conveyed by the organized agri-food system, and on the other hand, because many farms in the southern regions are associated with POs in the Center-North (MIPAAF-ISMEA, 2020).

As a matter of fact, in the central and southern regions POs did not have the desired development from the point of view of supply aggregation: a high number of organizations often does not correspond to an equally significant level of concentration of production (G. Petriccione et al. , 2012).

The lack of aggregative capacity of the Calabrian POs is well represented by Mipaaf data (2019) on the consistency of POs at national level. The 22 OPs of Calabria associate 4,434 producers. This is a very low consistency when compared with the number of total fruit and vegetable producers, about 100,000 (Istat, 2016). The POs of Calabria also have little interregional aggregative power.

Therefore, it is important to go beyond the mere calculation of the amount of associative organizations in order to have a more accurate picture of the situation and to also understand the economic strategies at the territorial level, by starting to study the characteristics of the networks.

In the national list of fruit and vegetable Producers Organizations, authorized by the Ministry of Agriculture (2019), Food and Forestry, 5 POs are domiciled in the 14 municipalities considered.

The Sibari Plain POs group about 720 producers, both in a direct way (134 individual enterprises), and through 14 first-degree marketing cooperatives, and 2 production cooperatives. Four first-degree marketing cooperatives are associated with POs in the Calabria region with a total of about 160 members; whereas other 4 co-op, with around 170 members, are associated with 3 POs outside the region, one of which is in turn associated with a POA.

\subsection{Members' Perception of Their Participation in the Cooperatives}

In this section, the social actors are considered as single agents who act collectively by creating relational networks in cooperative systems. The characteristics of the individual agents and their perception are not underestimated, on the contrary, they 
are considered foundational of the relational system. The actors model this relational system and they are in turn modeled by it in their behaviors and strategies. Among the studies on the factors influencing cooperation in economic sectors, in addition to the factors related to organizational and economic advantages, particularly important are those related to the members' perception regarding their role within the cooperative governance.

Socio-psychological factors, for cooperative members, seem to be of greater importance than mere economic factors (P. Österberg, J. Nilsson, 2009). Those who decide to become part of a cooperative usually do so not only to have economic and organizational advantages, but also because they believe in the mutual spirit.

The members' perception of participating in the democratic control of cooperatives outweighs all other factors in explaining both the members' cooperative involvement and their confidence in the boards (Ibidem, p.194).

Particularly significant is the perception of the actors involved in the world of cooperatives regarding the governing bodies of cooperatives and the social environment.

Below are reported the interviews with various actors in the world of citrus cooperativism of the Sibari Plain carried out between 2016 and 2020.

\section{Field interviews with various operators}

A common point shared by almost all the interviewees is that, "cooperatives are not cooperatives", the explanation of which is that cooperatives are in reality, "traders disguised as cooperatives". This observation is also reported in literature, articles, etc., and it is important to understand the quality of cooperativism in this geographical area. Cooperativism has not grown as a bottom-up strategy, chosen for the advantages deriving from mutualism. On the contrary, it has grown as an obligation or has been incentivized from top down politics: it has been chosen mainly for the advantages deriving from the appropriation of indirect external resources.

\section{Here are some significant interviews.}

The president of one of the longest-lived co-ops in the area: "Small realities like ours with few associates, easier to coordinate, are better than organizations with many associates like the coop of the 90s (OSAS for example).

So, we are like a family, we coordinate in the morning at 6 on the field and in the evening we meet at the bar to take stock of the day. The payments to the associates 
are different from producer to producer. The producers that follow the regulations, in our case that of an important large-scale retail trade, receive a higher remuneration because, face higher costs in order to meet the required standards However, it is a matter of a few cents of difference per $\mathrm{kg}$, given the very low price that we are paid anyway.

Even those who diversify their production with early and late fruits are liquidated with higher values. We know that in Spain agronomists are in the field, on the contrary, here in Calabria, they are mainly bureaucrats, they give support to elaborate the RDPs (Rural Development Program).

We have no collaborations with research institutions and universities regarding innovation and now also adaptation to climate change. Our production suffers from the aesthetic standards required by the large-scale retail trade: large sizes, colour, etc.

In our territory, the clementines with the PGI label are treated with integrated pest control. For this reason, they have zero residue of chemical products on the skin, superior organoleptic properties, but also a smaller caliber. And this is a message very difficult to pass on to the consumer that on the supermarket counter only sees the size and colour.

Since 2006, the price has been made by the large-scale distribution, not by the fruit and vegetable markets."

A manager of a farmers' confederation: "The price of fruit and vegetables in Italy is made by COOP Italy, and everyone follows. The Cooperatives here are very small, not like in Trentino. My dream is that something like the consortium Melinda (Apple Producers' Consortium of the Trentino Region) will be created here. It is only with large numbers that cooperativism can have strength. The 'Ndrangheta in Calabria is present in the nodal sectors, for example in road transport. "

A producer who is a member of a cooperative: "Everything changed when, to meet the needs of the large-scale retail trade, we started harvesting by box rather than by day.

With the daily harvest, human relationships were established. We would start at sunrise and have breakfast together in the fields, and we would finish working at 12. Nowaday, with the cashier payment, you work in a stressful way from sunrise to sunset. The market demands certain quantities continuously, so our goal is to harvest for 50 continuous days (period of the common clementine), bad weather permitting. We are aware that everything starts from the land - in the warehouses they can't do miracles". 
I had the possibility to follow this cooperative member between September 2016 and the present today, and I think that it was a sort of a pilot case. The story of his experience could be emblematic. He has more than 20 hectares planted with citrus. In September 2016 he was enthusiastic about the cooperative, considered it as a family and had enormous confidence in having precisely chosen the right cooperative, not so much because it allocated its product at an advantageous price, but because of the spirit animating the group.

"We always talk as soon as we arrive in the countryside in the morning, and then in the evening we all gather together, telling each other how the day went and we make decisions together".

This producer is motivated by entrepreneurial spirit, his first and only activity being that of agricultural entrepreneurship. At the same time, he deeply believes in the values and methods of cooperative enterprises. Over time, he began to sell using informal supply chain networks between consumers and producers that can be framed in the context of Alternative Food Networks (AFNs), which is a newly emerging networks of producers, consumers, and other actors that embody alternatives to the more standardised industrial mode of food supply (Murdoch et al, 2000).

He met his customers directly and sensed that organic would be a new opportunity. Its production process was already practically organic, as it was associated with the Clementine di Calabria PGI consortium. Therefore, moving to organic certification did not require great effort. The cooperative he was associated with, however, did not have an organic line and its product was paid as much as that of all the other members who made traditional production. Believing in the cooperative spirit, he asked the board if a new line could be planned within a few years. His proposal was rejected and, deeply disappointed, he decided to leave the cooperative.

Now he has an excellent economic response thanks to direct sales through networks he built by himself, and using online AFNs platforms connecting producers and consumers without intermediaries.

However, he would gladly return to a cooperative if his product were equally valued. The decision to leave the cooperative was therefore due to the perception that his contribution to innovation was not received by the management. This all caused great psychological suffering.

He concluded: "When I entered I was told that we were a family and this has been my perception for several years, but then things have changed. I began noticing that, rather than make the cooperative evolve and innovate as a group of producer members, they were more interested in pursuing individualistic interests. What kind 
of cooperative is the one in which managers say, 'I paid this expense' or 'I made this investment'? But being members of a cooperative means that we all did it. Still, the managers do not seem to be willing to understand this, because they consider the cooperative as their own company!".

The president of a cooperative: "On March 8, 1987 in the Plain there was a historic frost that compromised all orange cultivation. The only fruits that were saved were the clementines, at the time cultivated in very few plots. I am absolutely sure of this, because at the time I was working in a nursery and the following year there was a boom in the demand for rootstocks and a rise in prices. Everything was grafted to clementines and after 5 years, in 1992, everything went into production. In 1998 the saturation of the offer led to a price collapse. A further collapse occurred in 2000-2001 with the changeover to the euro. They demanded a 1:1 exchange rate from 800 lire per $\mathrm{kg}$ to $0.80 € "$.

The president of a cooperative who suffered an attack on the company: "I started very young as an exporter. Now with my export cooperative in Austria, one of the problems is that in the short period of maximum production, from mid-November to mid-January, it is difficult to supply large surfaces with the quantities they need.

There are three market segments: basic, premium and organic. On the first two, the Spanish competition is too strong. On the third, we have no problem getting the price we ask for.

The Spanish product, in which the use of chemicals is not avoided, is large and uniform in calibers (the largest being mainly 1 ), with a harvest lasting basically all year round. Although our product is undoubtedly better than the Spanish one thanks, for example, to its organoleptic characteristics, the absence of chemicals and the privileging of the rhythms of nature, which make our harvesting campaigns much shorter - it is, however, precisely these characteristics which make it less attractive for large-scale distribution. It is also more difficult to communicate our strengths in terms of healthiness and goodness."

When I point out that the Spaniards have a great strength in logistics or in knowing how to concentrate the offer and in creating a system with the institutions, while in Calabria the infrastructures leave something to be desired - for instance, the port of Schiavonea is not active, and as for cooperativism, much exists on paper, but little in practice - he replies that the support of the institutions is not important. It is the Calabrian entrepreneurs who do not know how to be entrepreneurs. 
As for the relationship with the shareholders, he tells me that if there is an expense to be made that he considers right, or if there is a need to make an important decision, he does not listen to anyone because he believes that his partners (the co-op members) do not have the skills to be able to decide. He gives both rewards and punishments: if there is a production to be sacrificed, he also sacrifices his own. He loves the Spaniards as entrepreneurs and for their marketing management, but he would also "send them to prison" for their product. Far from being a natural product, it is only a commodity.

The salesman of a cooperative not associated with a PO: "We export almost everything abroad, mainly to Eastern Europe, but alone, not with a PO. Let's say that the POs are not very happy when a co-op wants to export. For a VAT problem. Coops who want to sell their goods on UE markets through POs are discouraged as the POs should buy the associated Coop including VAT and sell on foreign markets without, as required by art.8 DPR $n$ 633/72. By selling alone we lose $4.1 \%$ of the subsidies that we could have instead by selling through $\mathrm{POs}^{40}$.

This does not help, even if it is true that our lack of willingness to cooperate is atavistic. The members should give all the production to the co-op, but in the years when there is overproduction, it is more difficult to place the product. They all beg me to take their clementines, but in years like this, in which there is little and excellent production, when I call them for the conferment, they are never there, they make up excuses, etcetera and I end up with few quantities of product ".

A producer not associated in a co-op: "I am not part of a cooperative because if I were to be part of it I would pretend to know how my product is sold and I would pretend to take part in the decisions. This should always happen, whether the member owns 1 hectare or 100. But in the local cooperatives, this is not possible. So, having a great product, I can get a good price from the wholesale traders. I am also seeing the possibility of being reached by foreign wholesalers through social networks. As for the advent of clementines in the Sibari Plain, in addition to the historic frost of 1987, there was the concomitance of a virus on young navel orange plants. Furthermore, the spread of this virus gave impetus to convert to clementines."

The president of a cooperative that started exporting clementines to the United Arab Emirates using the port of Gioia Tauro: "If the Port of Corigliano were functioning as for the movement of commercial ships, the whole territorial system would benefit

${ }^{40}$ At the present the problem seems to have been overcome. 
from it".

A co-op president, who had to provide me with some data, told me that at the moment he would not be able to do so, having suffered an arson attack that had destroyed his offices.

\section{Survey}

The questionnaire for the citrus producers of the Sibari Plain was partly filled face to face, and partly online, disseminated between September and October 2020. The sample is random and the number of respondents rather small, therefore the results are only indicators of experiences and perceptions.

Due to the Covid-19 pandemic situation, the scheduled time for the distribution of the face-to-face survey - the most effective way to obtain answers from the stakeholders of this sector - was very short and postponed compared to what was planned.

The survey is addressed to the producers who choose the strategy of selling to the wholesaler, and to those who choose to give their product to a cooperative.

The aim is to understand the reasons behind the choice of one strategy or the other.

Below is the online survey to witch just now replied 55 producers:

https://docs.google.com/forms/d/e/1FAlpQLSf66jwqOvZ9puimTOlu7AwZOigc29MU-T4Jv_Fi 42AWK4XZlw/viewform?usp=sf link

\subsection{The results}

The age group of the prevailing respondents is $40-49$, as regards to the gender, there are only 3 women.
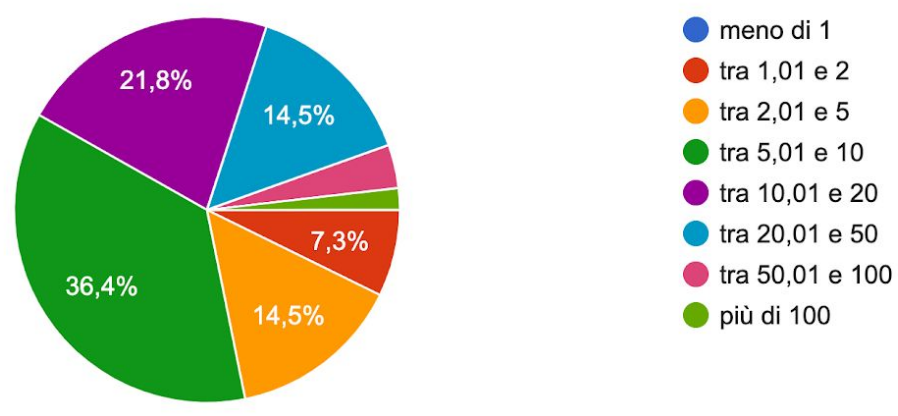
Figure 13 Citrus crop cultivated (ha) from the respondents

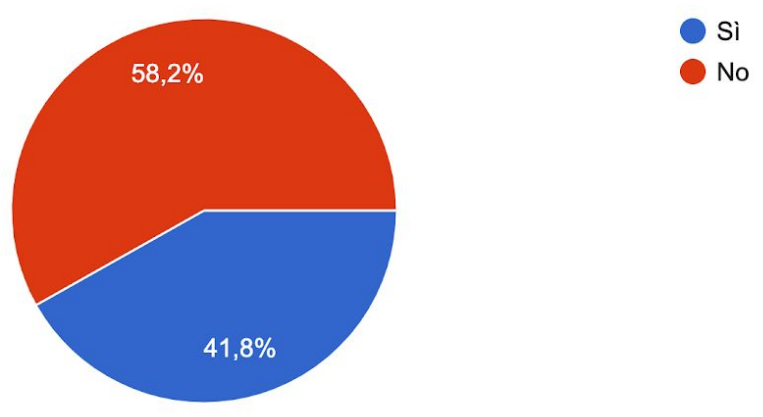

Figure 14 Percentage of members and non-members of a cooperative.

\section{The members}

Among those who replied that they were associated in a cooperative, $70 \%$ replied that they were associated with a first degree cooperative, the remaining with POs and just one with a consortium of organic producers outside the Region. $70 \%$ was associated with a co-op organization of the territory of the Sibari Plain.

Why did you choose to sell your product through a cooperative instead of selling it to a trader?
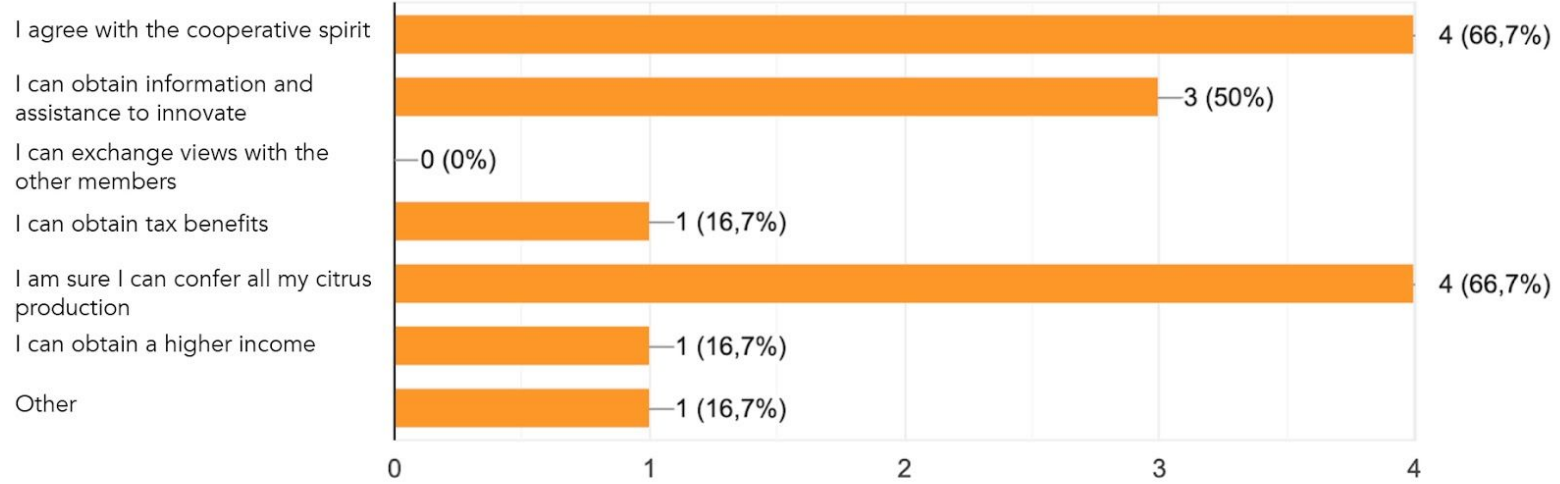

Figure 15 Motivation for those who choose to cooperate rather than selling to wholesale traders.

The main motivation for those who choose to cooperate instead of selling to the trader is, first of all, the withdrawal of all production by the cooperative, and secondly because of their valuing of the cooperative spirit. 
What are the main reasons for choosing the cooperative you are a member of?

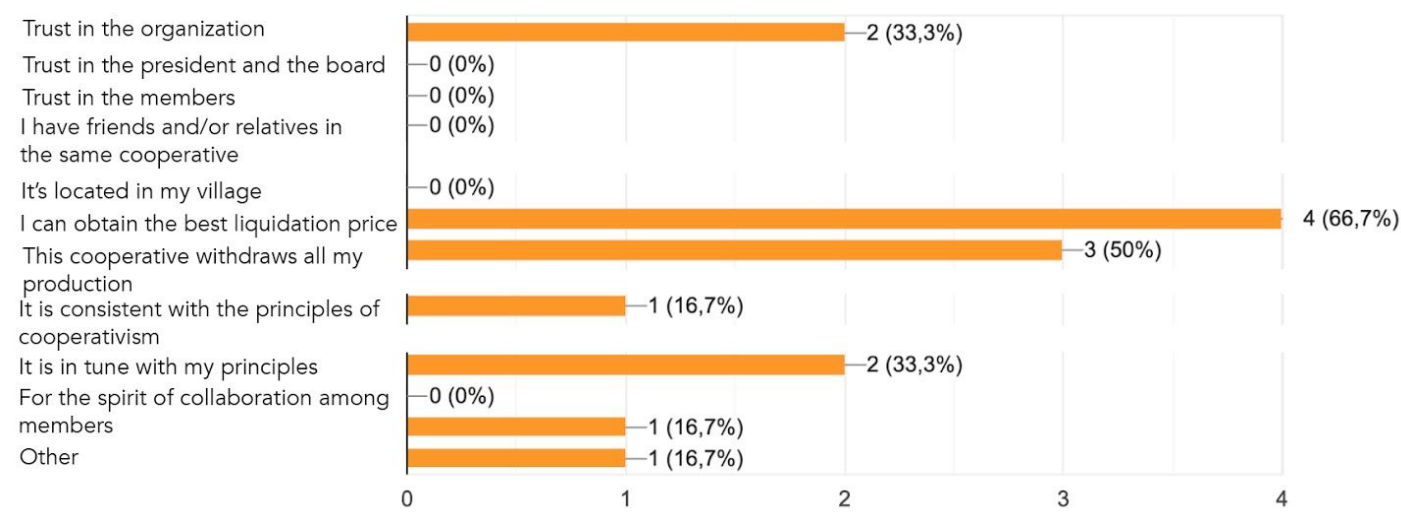

Figure 16 Reason for choosing a specific cooperative

Regarding the choice of a specific cooperative, the overwhelming majority replied that their choice related to the trust in the organization and in the president (no one ticked the answer "trust in the members"), followed by "the safety of the withdrawal of all production" and "obtain information and assistance from the cooperative". Those who are associated are mostly satisfied, but many of the members have been associated in the past with other cooperatives, on average 2 cooperatives in addition to the current one.

The non-members

Who are you generally targeting to sell your citrus fruits?

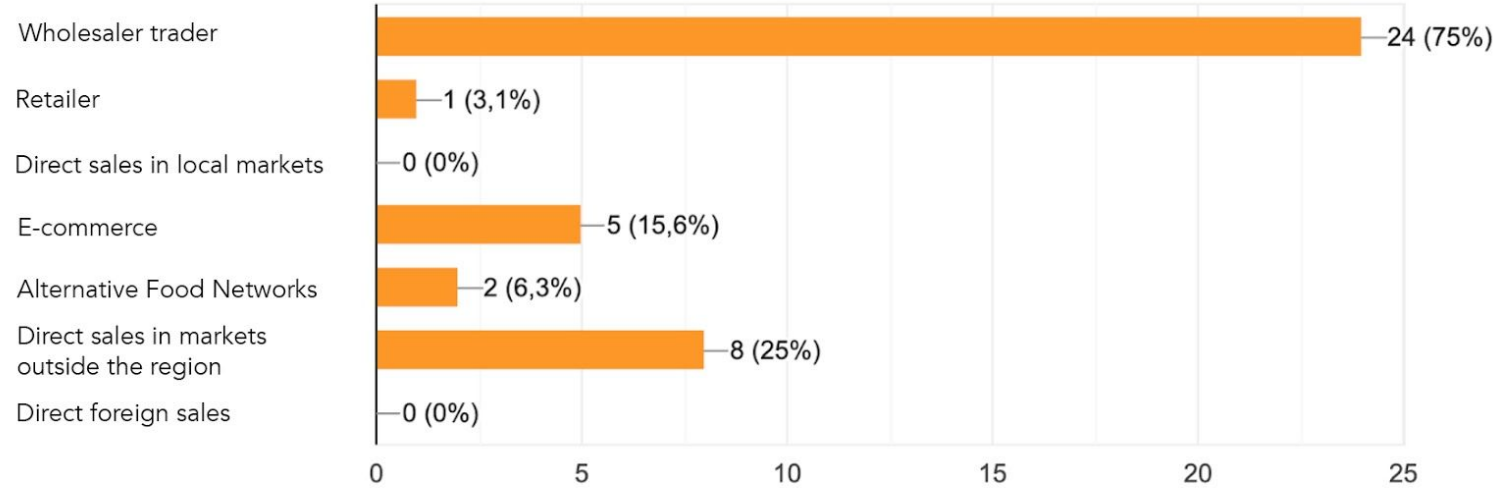

Figure 17 To whom do you sell your citrus fruits? More than one answer ( $\max 3$ ) could be given to these questions. 
Those who are not associated mostly turn to more traditional channels: wholesalers and direct sales to markets outside the region. A good percentage also sells through alternative channels, e-commerce and Alternative Food Networks (AFNs) ${ }^{41}$.

\section{Why are you not a member of a cooperative or a $\mathrm{PO}$ ?}

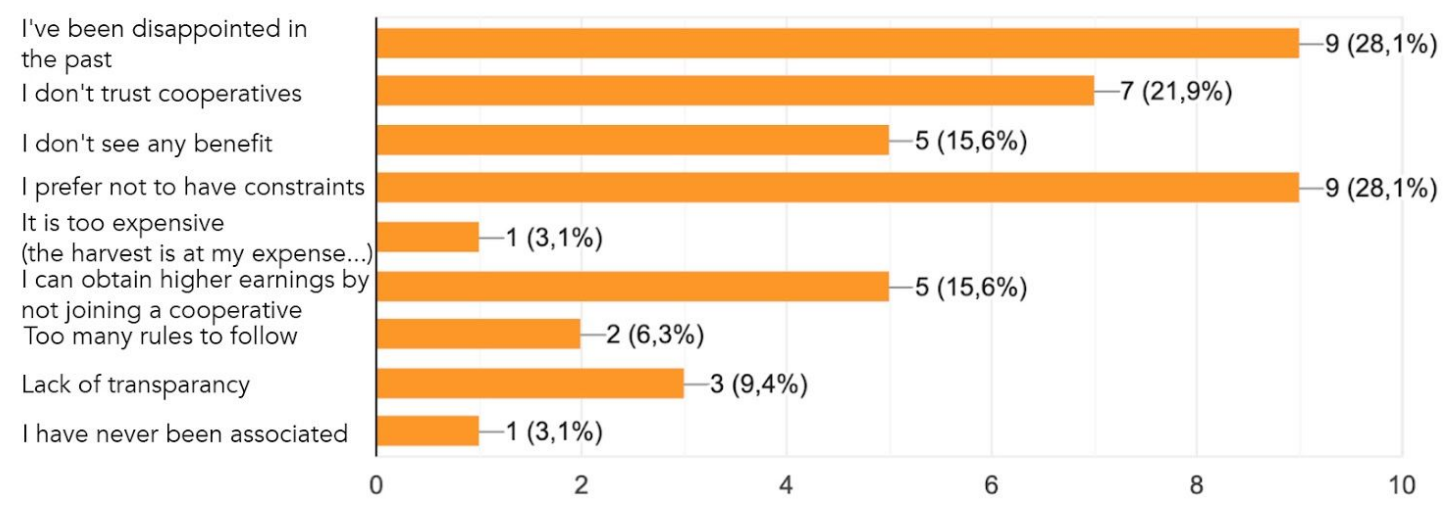

Figure 18 What is the reason why you are not associated in a Co-op or a PO?

For the majority the reasons for the individualistic choice are: the disappointment after being a cooperative member in the past and a pure individualistic choice, lack of trust in cooperativism and having no constraints, never being associated, greater gains. Others link it to the specific weaknesses of local cooperativism: there are no advantages, too expensive because the harvest is borne by the producer, too many rules, little transparency (question 6). $56 \%$ of non-members in the past were members of a cooperative or POs. $92 \%$ of the cooperatives and OPs were in the Sibari Plain. The reason for the abandonment of the cooperative and the consequent individualistic choice was mainly the lack of transparency in the post-harvest (generally because it is believed that favoritism is made), followed by the disappointment of expectations.

It is interesting to note that when asked "Would you return to a cooperative if you did not encounter the problem you described?" $70 \%$ said yes.

\footnotetext{
${ }^{41} \mathrm{~A}$ note on the 2020-2021 campaign. There is an exponential increase in online citrus fruit sales platforms in December 2021. Presumably, the causes are the following: effects of the crisis due to the Covid-19 pandemic, production of citrus fruits with small calibers (prevalence of 3, 4 and 5) due to the prolonged summer drought and the difficulty to market them through large-scale distribution and, finally, to adverse weather events at the beginning of the harvesting campaign of the common clementine, which saw between $20-30 \%$ of the production of this variety damaged. However, even in the case of sales through e-commerce channels, there is a strong fragmentation of the offer that replicates what happens in traditional marketing.
} 
When asking the question "Would you choose a cooperative or OP outside the Sibari Plain, provided that it meets the requirements you consider important?", the majority replied no.

\section{Interviews and questionnaire: the "something" in the cooperating}

Those who are currently in the cooperative feel very and quite satisfied (70\%), but it is also true that $80 \%$ have changed cooperatives several times and that $40 \%$ of those who are now not in the cooperative have previously been, $90 \%$ of these have been members in a cooperative in the Sibari Plain.

Many of those who abandoned cooperativism would return to cooperate if the problems were eliminated (mainly due to non-payment of the right liquidation and non-transparent management).

They would not leave local cooperatives in exchange for higher product liquidation, so profitability seems not to be a crucial factor. On the contrary, the territorial factor and transparency are. The fact that the members attach strong importance to their participation in the democratic governance system has the practical implication that cooperatives should spend resources to create well-functioning member democracy (Österberg et al. p. 12, 2007).

From an organizational point of view, the cooperativism in the studied territorial system seems to be a form of organization as well as ephemeral and volatile, used only for the purpose of obtaining some kind of advantage: profits, subsidies, etc. Normally for a smaller circle of people. The majority of cooperatives seems to be run by former traders who consider the cooperative type of organization as a form of advantage for their activities. Over time, many of these traders have also become owners of important production areas.

This suggests that the choice of the cooperative model is mainly attributable to obtaining fiscal and economic benefits.

From the face-to-face interviews and the surveys responses, it emerges that the producers consider not so much the economic advantage, but rather the withdrawal of all production and the transparency as the characterizing elements of the cooperative choice. If the members have had a chance to express their minds, they may support a decision that is at odds with their wishes, provided that they get credible explanations (Österberg et al. p. 12, 2007) 
The continuous failures of the cooperatives, the short duration of life, the connection of many of them with the opaque system and the frequency of cooperative changes by the producers suggest a continuous disappointments in the local cooperative model.

In general, the failure of the cooperative system can be traced back to the defections of the members. In this case of study, it could be confirmed that the cooperative strategy, at the territorial level, has never really taken off.

The recurring disappointments made the producers feel that it was the form of cooperative organization in their territory which had failed. The most frequent comments are "There are no real cooperatives" and "They are all the same". Nevertheless, searching for cooperative networks outside the territory appears to be an irrelevant strategy.

The cooperative model would seem to be a model of economic organization in which strictly economic material factors are not so decisive.

In order to answer the question "Why did things go so differently in Spain?", Garrido S., Planas J. and Sabio A. (2006) analyze experiences of cooperativism in the Spanish, European and extra-European agricultural sector.

In spite of the more or less large differences between the different geographical areas and between the purposes according to which farmers associate in a cooperative (credit, sale or production of agricultural products, purchases, etc.), the authors highlight a number of examples which trace the strategies of collaboration or desertion, not only to economic benefits, but probably to a "something" (an algo) concerning social and political factors related to different contexts.

In all probability, this "something" was related to factors of a "social" and "political" nature, which are actually very difficult to separate from the "economic" factors: the structure of ownership, the forms of land exploitation, the ability of the rural world to punish governments through the ballot box, the desire on the part of certain political forces to use the cooperative movement to recruit votes, the cooperative state policy (Ibidem, p. 615, 2006)

In the Sibari Plain, the two cooperative experiments considered unanimously successful and represented by the cooperatives OSAS and CORAS (Petriccione 1995, Zumpano in Dolci clementine, 1999, Russo, 2014 e Marini M., 2013), were activated by well-respected local professionals who assumed the function of charismatic leaders.

These probably represented the function of activating agents of cooperation and of dispersed or latent potentialities in the territory (Hirschman A., 1970), but in the long term, with the disappearance of the founders, the aggregative capacity of these organizations lost its strength. 
In this territorial context, the only market incentives to promote the offer concentration through cooperatives are probably distorted and, as they are implemented, they do not represent the appropriate tool to facilitate the overcoming of cooperation dilemmas.

It would also seem that as the leader figures disappear, the started virtuous processes dissolve themselves. We can argue that trust refers to the leader, rather than to the organizational form of cooperativism (prevalence of the answers to the questionnaire related to trust in the president and in the organization). Although charismatic leaders can activate latent cooperative capacities, these alone are not able to transform mental, behavioural and relational models.

On the other hand, the mechanisms of defection by the members seems to be equally strong. When they are unaware about the price formation methods and the functioning of sale markets, they feel "authorized" to sell their citrus production to the traders. The reason behind this behaviour is that they perceive the price obtained by the cooperatives too low and motivated by elements consistent not with the market situation, but rather related to favouritism towards other members.

The opacity of the whole system means that in the campaigns of overproduction the cooperative can make choices regarding the contribution of its members, and those who are excluded turn to the traders. On the other hand, in the campaigns when there is little production, the cooperatives must turn to non-associated producers.

It would seem that the improvement of E-commerce for agri-food, along with the strong push following the Covid-19 pandemic, are marking a turning point with regard to the marketing of citrus fruits through Alternative Food Networks (Osservatorio Smart Agrifood, 2020).

\section{The role of available social capital}

The social actor and his economic actions can be understood only starting from his roots in the structure of the social networks that surround him (M. Granovetter, 1985).

It is assumed that the agents involved in the network of relationships that are established between producers and marketers of citrus fruits of the Sibari Plain, traders or cooperatives, are immersed in a system of convictions and habits, which draw on the specific territorial social capital and, in turn, reproduce it. 
Social capital is a neutral resource that facilitates any manner of action, but whether society is better off as a result depends entirely on the individual uses to which it is put (Foley MW, Edwards B. 1997).

According to this point of view, the economic agent acts within a framework of broader rationalities than those referring to self-interest, this being a result of a more complex set of social and environmental interdependencies and benefits.

The hypothesis is that cooperativism - a strategic factor for the marketing of fresh citrus fruits - is not merely one of the many forms of entrepreneurial management, but rather one of the structural dimensions of the social organization of a territory.

As a matter of fact, social capital, that is the network of relationships that binds individual and collective subjects, available in a given territory and at a given moment, can favour or hinder cooperation, trust, civic awareness, the openness to innovation and ultimately local development (C. Trigilia, 1999).

By adopting the approach so far followed the purpose is to highlight the importance of the study of the territorialization processes in the construction of social capital and economies: the territory as an original system of natural and anthropic interdependencies influencing the development processes.

Given the peripheralization of the territory in question (G. Arrighi F. Piselli, 1987), greater evidence was given to the strong endogenous environmental and social constraints, the ability to respond and adapt to the specific local context, also with respect to external constraints and conditioning.

The territory, in this case, appears as a complex system with its own identity following its original development dynamics. The territorial system is also considered as an open system that maintains two-way relationships with the external environment. These relationships are characterized by links and constraints weaker than those that occur within the narrow territorial circle.

Therefore, what kind of relationship can exist between the evolution of the specific territory and the social capital available for local development, and especially for the cooperation between citrus fruit companies in order to commercialize the product outside the local market?

There is a large body of theoretical and empirical literature which states that collective action, in business and other social areas, depends on the amount of accumulated social capital (Putnam, 1993A and 1993B, Fukuyama 1995, Helliwell 1996, etc.).

Belrtán Tapia (2012) underlines how, in agriculture, if there are no previous experiences of collaboration, for example for common pastures or water for irrigation, it becomes very difficult to build a cooperative culture. In the territory 
under examination, the lack of long-term sharing of these practices could have prevented the premises for this process of collective learning.

The top-down economic policy strategy, first implemented with the Agrarian Reform and then continued with community policies in support of agriculture in Southern Italy, proved to be a distorting factor, both because it did not really take into account the comparative advantages of Southern Italy and its institutional fragility (Asso, 2020), and because it attempted to change the economy without changing society (Zamagni, 1978).

In the case of the specific territory, the support measures given over a long period of time, through national and EU policies, to local development projects - with the purpose of establishing strategic networks of associations to obtain better performances on the markets - show their inadequacy.

The support of cooperativism through subsidies has not caused a concentration of supply through Cooperatives and OPs.

In Calabria, the weakness of this sector can be found in the following aspects:

- a high number of cooperatives and commercialization POs does not correspond to a high number of associates (Out of the 1800 citrus producers of the Sibari Plain registered with the Chamber of Commerce or more likely, of the about 5,000 surveyed by Istat in the Agriculture Census 2010, only about 1050 confer their citrus fruits to local cooperatives or POs;

- compared to the 22 fruit and vegetable POs active in Calabria in 2017 (MIPAAF) the average marketed value per PO is low (9 million euro in Calabria);

- the regional share of fruit and vegetable production at basic prices marketed through POs is very low (19\% in Calabria);

- most of the 22 POs have a turnover of less than 10 million euros and therefore do not significantly affect the aggregation of the offer and the enhancement of production (MIPAAF-ISMEA, 2020).

\section{Social Network Analysis (SNA)}

In recent times, the SNA perspective has been applied to the study of social capital. The starting point for the choice of this type of analysis is given by the consideration that the individual agents - the citrus producers - act within a specific social dimension provided with what we can call territorial social capital. This relational dimension concretises itself in the network which, in the case of the clementine 
supply-chain, involves at various levels citrus producing companies, first degree trading cooperatives, Producer Organizations (POs) and finally Associations of Producer Organizations (APOs).

In this work we observe the patterns developing when the citrus producers choose allocation strategies for their product.

What has been reported in the literature and what has emerged in the field research validate the importance of the role played by relational structures in economies in which, in the face of strong production dispersion, the concentration of supply takes on a strategic value. In this case the SNA appears to be a suitable tool to represent and analyze the social network, i.e. the relational lattices created by a set of actors with a specific social capital. Through the agents' social action network structures are formed, which in turn influence the individual agents as well as the social structure as a whole. The relational structures and the agents that compose them are cause and effect at the same time.

First of all, there is the local dimension of companies producing citrus fruits characterised by an "individual enterprise"42 legal form (NACE 01.23): they have the possibility to choose whether to commercialize their production through local Cooperatives (out of the 14 municipalities considered) ${ }^{43}$, local POs or from outside the territory, or individually, basically through single traders.

\section{Synthesis framework}

\begin{tabular}{|c|c|c|c|c|c|c|}
\hline $\begin{array}{l}\text { Individual } \\
\text { enterprises } \\
\text { (citrus } \\
\text { producers) } \\
\text { NACE } 01.23 \\
\text { ISTAT } \\
\text { Agriculture } \\
\text { Census } \\
2010\end{array}$ & $\begin{array}{l}\text { Cooperatives } \\
\text { (citrus } \\
\text { producers) } \\
\text { NACE } 01.23 \\
\text { Infocamere } \\
\text { Dataset }\end{array}$ & $\begin{array}{l}\text { Cooperatives }^{44} \text { : } \\
\text { post-harvest } \\
\text { activities } \\
\text { NACE } 01.61 \text { and } \\
\text { fruit wholesale } \\
\text { NACE } 46.31 \\
\text { Infocamere } \\
\text { Dataset }\end{array}$ & $\begin{array}{l}\text { POs Sibari Plain } \\
\text { Infocamere } \\
\text { Dataset and } \\
\text { MIPAAF }\end{array}$ & $\begin{array}{l}\text { POs } \\
\text { Calabria } \\
\text { MIPAAF } \\
\text { Dataset }\end{array}$ & $\begin{array}{l}\text { OP Italy } \\
\text { MIPAAF } \\
\text { Dataset }\end{array}$ & $\begin{array}{l}\text { AOP } \\
\text { Italy } \\
\text { MIPAAF } \\
\text { Dataset }\end{array}$ \\
\hline 4892 & 11 & 30 & 5 & 4 & 3 & 1 \\
\hline
\end{tabular}

\footnotetext{
42 The cooperativism in the production phase is very small. Some production cooperatives have been counted as the number of their members when they join marketing or PO cooperatives. The cooperative of OSAS Ortofrutticola producers, which is one of the longest-lived co-op and with the most number of members (130 associated citrus producers), has been included within the OP Sibarit. Both follow a strategy different from that of the other organizations in the territorial context.

${ }^{43}$ There is no official information about the producers associated with marketing cooperatives outside the territorial context in question. From the interviews carried out to dozens of participants in the supply chain, it is common opinion that they are a small number. Out of all the producers interviewed, only one producer is associated with a Sicilian cooperative for the marketing of her product.

${ }^{44}$ These co-ops are classified according to a generic NACE code of post-harvest and marketing of fresh fruit, but the selected ones market only, or to a prevalent extent, citrus fruits. In addition, the information on the shareholders relates only to citrus fruit companies or cooperatives.
} 
The empirical part of the work was carried out through documentary sources, telephone and face-to-face interviews and field research. The latter was carried out in 4 different periods.

Field research turned out to be a key tool, and, in a certain way, also an obligatory way both to rebuild the circles of the members of the individual cooperatives (the numbers of members is not as reported by public data), and to obtain a clear picture of the truly active cooperatives, given the strong discrepancy between official and real data.

For the cooperatives and POs of the 14 municipalities, the database of the Chamber of Commerce (Infocamere-DB Tolomeo) was chosen because it contained qualitative information (names, addresses, year of opening, social capital, production value, revenues or losses).

Field research and direct contacts (visits, telephone and e-mail) were also crucial to know the number of associates of cooperatives and POs which only receive citrus fruits, and to know whether and to which PO they are associated with.

Among the 30 marketing cooperatives active in the Sibari Plain, 6 of these, which group a total of 116 members, are not associated with any PO. They therefore appear as isolated nodes. If we consider the citrus producers companies (Istat 2010 census data set) as the main scenario, the isolated nodes become the total of producer companies not associated at any level, therefore about 3,800 producers.

The tool which has been used to study these networks of relationships between the agents of the cooperative market of clementines is the Social Network Analysis (SNA): at the basis of this theoretical-methodological perspective there is the recognition that the causal engine of what the actors do, believe or feel resides in the relationship models between the actors themselves, caught in a specific context (Salvini, 2005).

\subsection{Results}

In recent years the application of complex networks to multidisciplinary fields is strongly increased (Dorogovtsev and Mendez, 2003), specifically also to economic applications (Schweitzer, 2009). This instrument is very useful when a system is composed of many units connected in a non-trivial way, so that a complex topology emerges. For the year 2019, a list of 30 active cooperatives is provided. For 22 of them, their POs are also provided.

Within the framework of the local cooperative structure we can distinguish the POs SIBARIT and COAB, the members of which are not marketing cooperatives. The first 
one owns one producer's cooperative of 130 members (OSAS Agrumaria) as a partner, while the second one owns 116 individual citrus producers companies.

This allows to properly define a bipartite network consisting of two kinds of nodes: cooperatives and POs. A link exists between a cooperative and a PO if that cooperative belongs to that PO. Projecting the network to the space of cooperatives allows to define a second network, in particular, an undirected binary network where two cooperatives are connected if they belong to the same PO (Peltomaki and Alava, 2006; Sneppen et al., 2004; Guillaume and Latapy, 2004).

\section{Bipartite Network}

In the bipartite network two kinds of nodes are defined: cooperatives and POs. A link exists between a specific cooperative and a specific $P O$ if that cooperative belongs to that PO. In Figure 19 and Figure 20, the bipartite networks are represented: in Figure 19 the size of cooperative nodes is proportional to the number of members, while in Figure 20 the size represents the production value. In both cases, the figures in the top panels clearly identify two layers in a three-dimensional representation (3D view). Each layer is a subspace: the top layer is POs space, while the bottom layer is the cooperative space. The bottom panels are instead planar representations (2D view) of the respective graphs reported in the top panels. The two cooperatives with largest production value adhere to two POs outside the Sibari Plain, even if one of them is still in the same province (Rocca Imperiale in Cosenza Province and Battipaglia in Salerno Province), whereas two strategies are more common among the cooperatives of Corigliano: most of them belong to OP POMEZ or APOA BRUZIA, both based in the Sibari Plain, forming two cliques as evident in the next paragraph. At the same time other cooperatives from Corigliano Calabro seem instead to use a very diversified approach in choosing their POs outside the province, even in Northern Italy. The two cooperatives from Rossano join the APOA Bruzia OP, while the three cooperatives from Cassano diversify their affiliation to POs. 

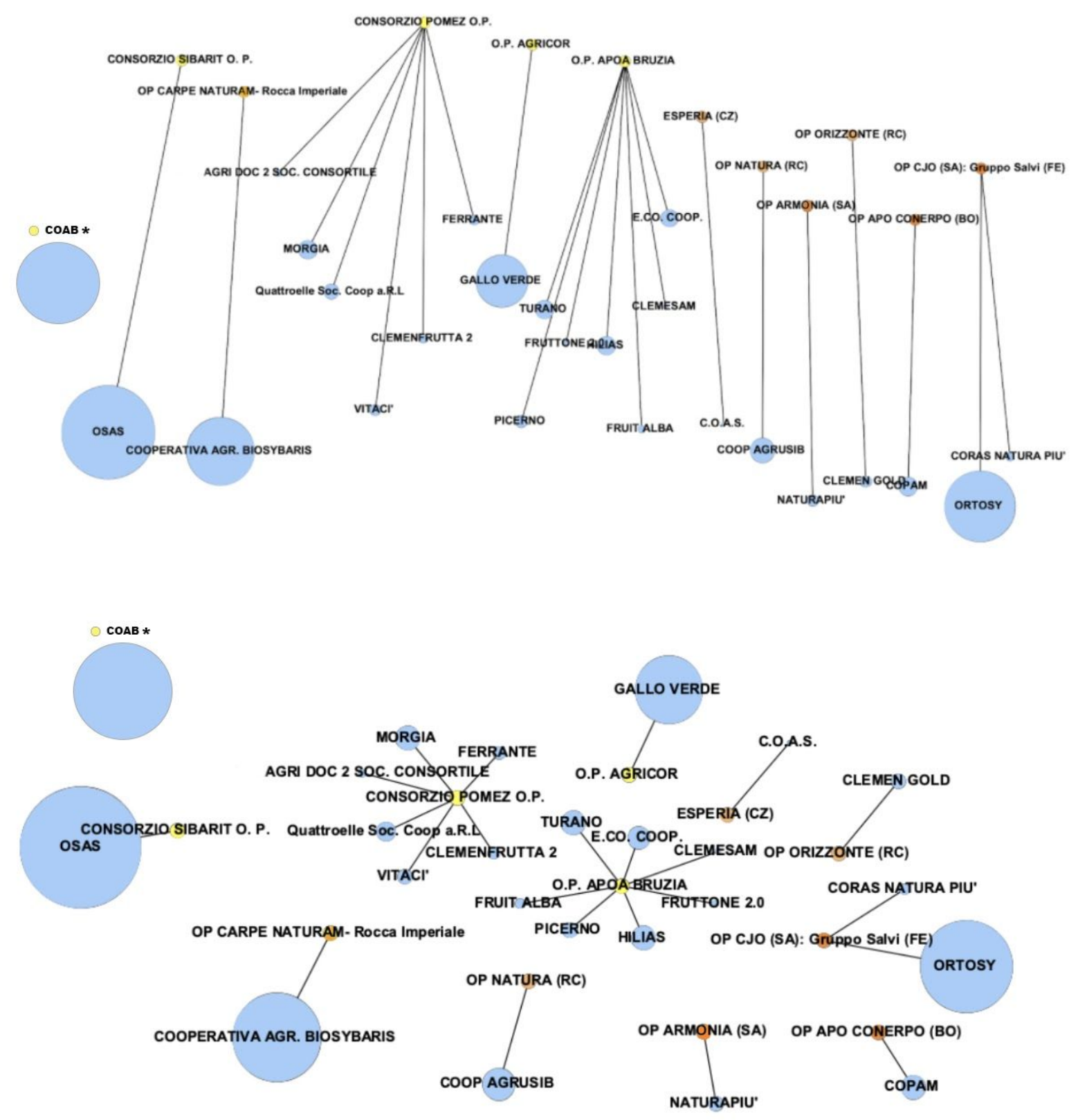

Fig. 19 Bipartite Graph including 23 cooperatives belonging to an POs and 11 POs: 3D view (top) and 2D view (bottom). The color of nodes represent their location. The blue circles are the cooperatives. Their size represents the number of members. The yellow circles represent POs in the Sibari Plain, the orange circle Calabria region, and the red circle outside the Calabria region. *COAB is a PO of the Sibari Plain whose partners are individual companies producing citrus fruits ** OSAS is a producer's Cooperative. 

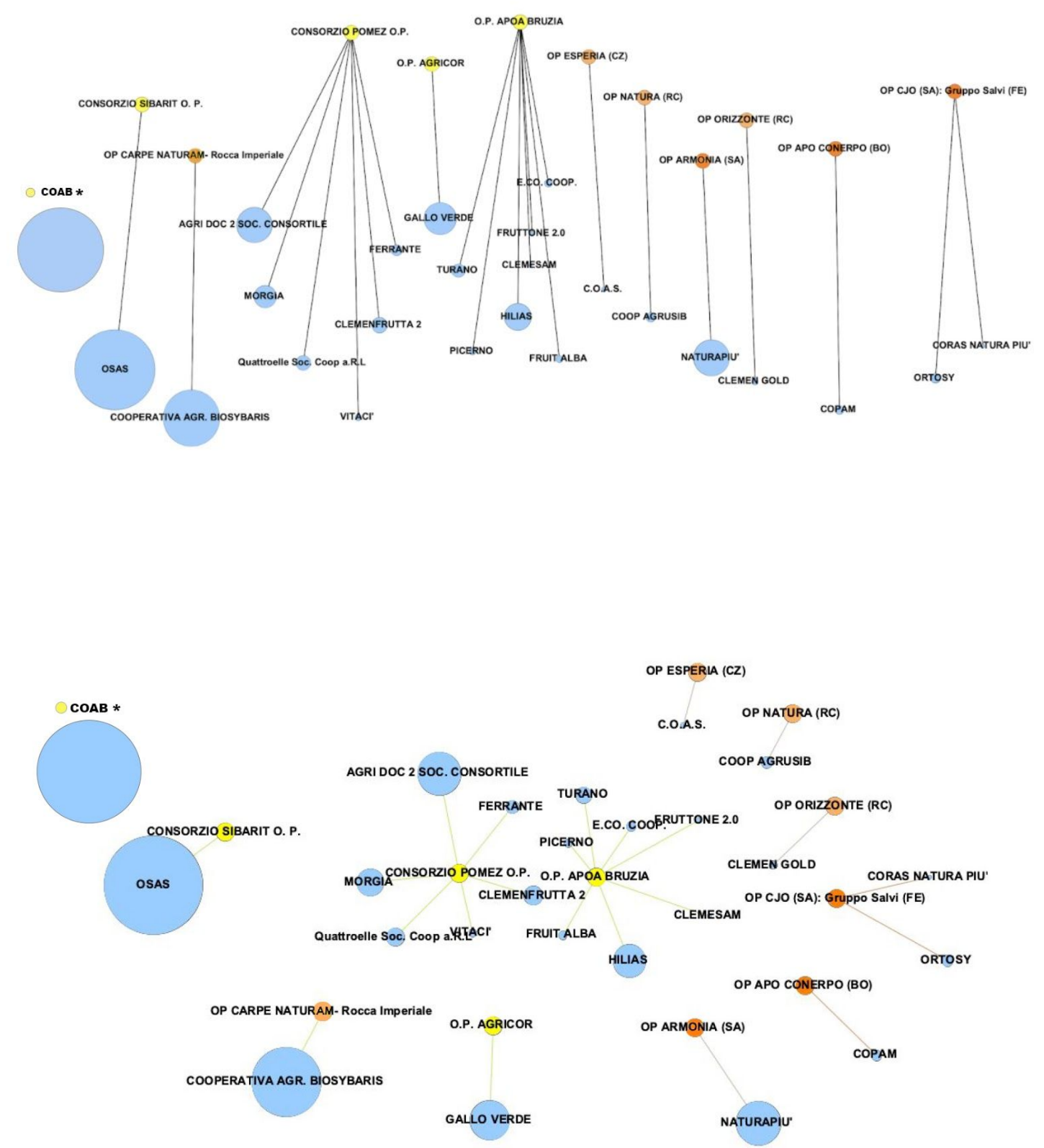

Fig. 20 Bipartite Graph including 22 marketing cooperatives and one producers cooperative belonging to a PO and 13 POs: 3D view (top) and 2D view (bottom). The color of nodes represents their location. The blue circles are the cooperatives. Their size represents the production value. The yellow circles represent POs in the Sibari Plain, the orange circle represents Calabria region, while the red circle represents the outside of the region. ${ }^{*} \mathrm{COAB}$ is a PO of the Sibari Plain whose partners are individual companies producing citrus fruits. ${ }^{* *}$ OSAS is a producer's Cooperative 


\section{Projected network}

The projection of the bipartite network on the space of cooperatives allows to define a second network, consisting of only one kind of node, specifically cooperatives. In this network, two cooperatives are connected if they belong to the same PO. This network is both undirected and binary (no weight can be associated with the link; only a dummy variable is used to indicate if the link exists or not). Because of the definition, we expect the emergence of cliques (fully connected subgraphs), one for each group of cooperatives belonging to the same PO and disconnected nodes (cooperative belonging to POs different from those chosen by the rest of cooperatives of our set).

In Figure 21 the projection of the bipartite network in cooperative space is shown. As expected, it consists of cliques and disconnected nodes. The two cliques correspond, respectively, to cooperatives belonging to OP APOA Bruzia, and to those belonging to OP POMEZ. The disconnected nodes are the cooperatives belonging to POs different from any other POs of the dataset.

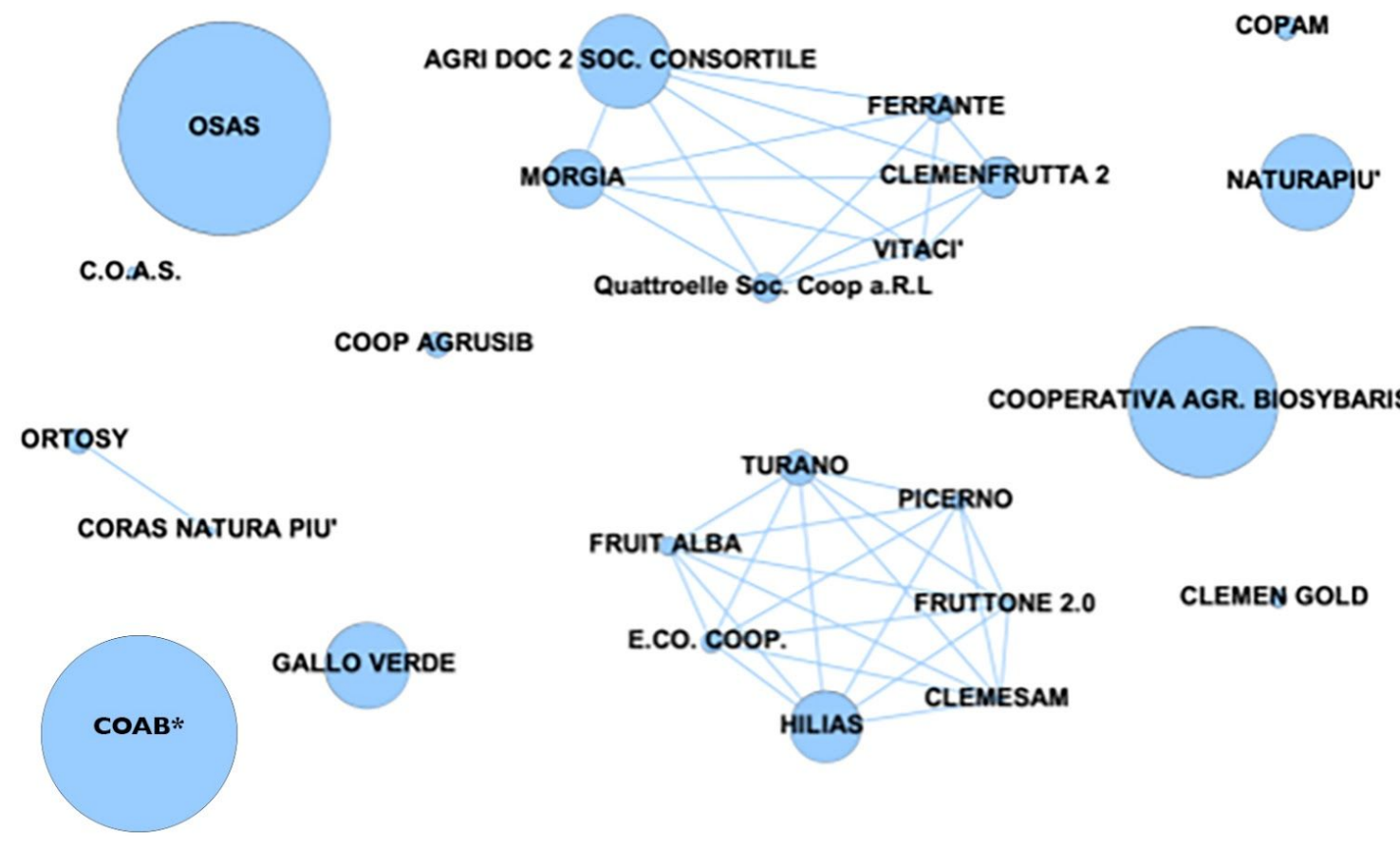

Figure 21 Network of cooperatives. Two cliques emerge: one for cooperatives belonging to APOA Bruzia, one for OP POMEZ. The size of nodes represent the production. *COAB is a PO of the Sibari Plain whose partners are individual companies producing citrus fruits** Osas is a producer's cooperative.

It is worth to notice that the most productive cooperatives are outside the emerging cliques, so they have a diverse strategy in choosing their POs. 


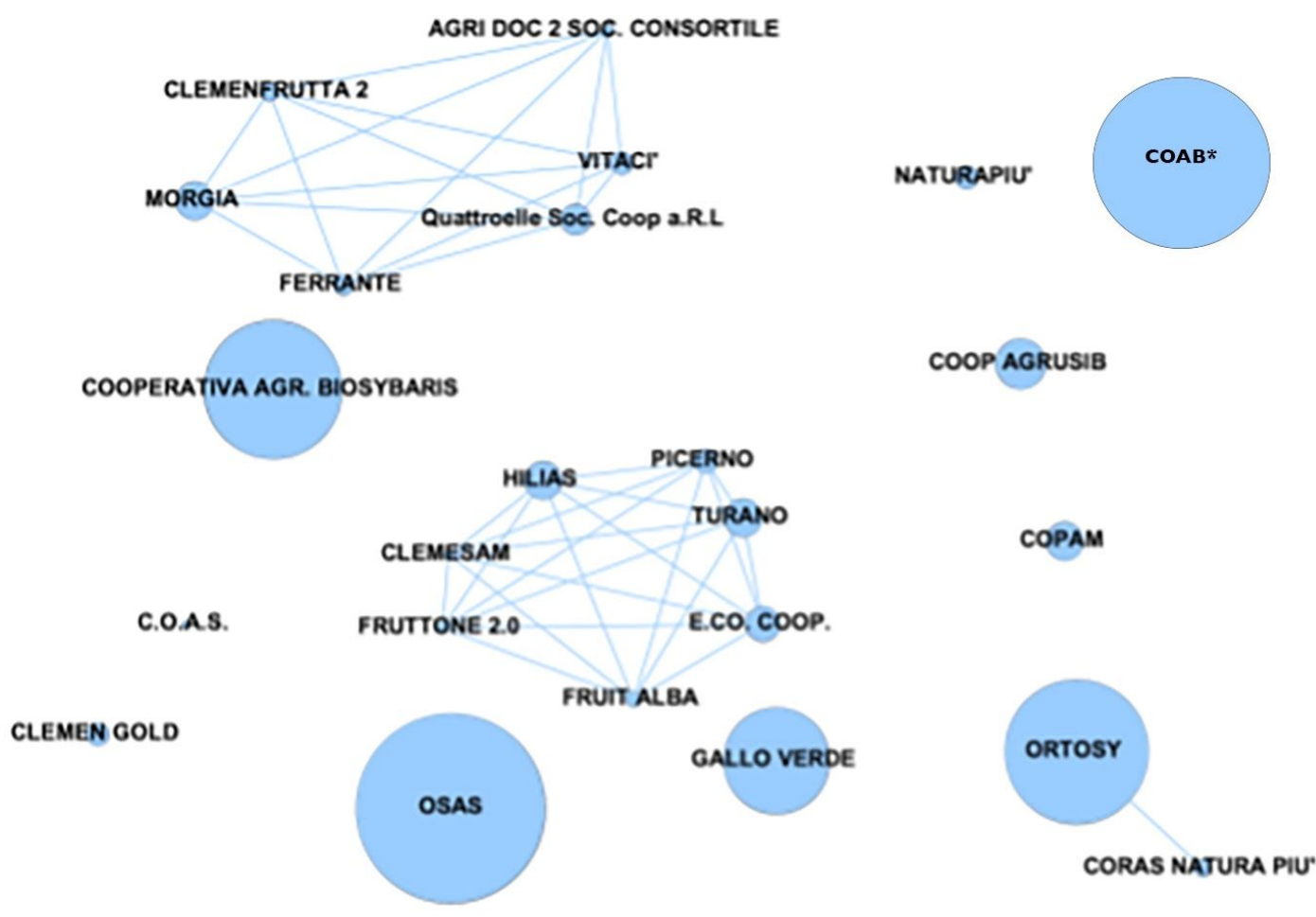

Figure 22 Network of cooperatives. Two cliques emerge: one for cooperatives belonging to APOA Bruzia, one for OP POMEZ. The size of nodes represent the number of members.

In Figure 22 the same figure is reported but the size is now proportional to the number of members. The largest cooperatives do not aggregate to common POs. They act more independently of each other. It is very interesting to observe that cooperatives belonging to the same PO are mainly from the same municipality, so personal acquaintance is highly probable. But also diversification emerges because both cliques arise from Corigliano cooperatives.

\subsection{Discussion of results from network analysis}

We can summarize the following conclusions

- The two first level cooperatives with largest production value adhere to two cooperatives outside the Sibari Plain, thus suggesting a correlation between performance/health of the cooperative and the geographical distance of POs.

- the most productive cooperatives are outside the emerging cliques, so they have a diverse strategy in choosing their POs. 
- the structures of two POs (Sibarit and COAB) highlight two different strategies.

- two strategies are more common from cooperatives of Corigliano: they mainly chose OP POMEZ or APOA Bruzia, forming two cliques.

- cooperatives belonging to the same PO are mainly from the same municipality (Corigliano), so personal acquaintance is highly probable.

- a certain diversification (like a split in cooperatives' choices) also in Corigliano emerges because both cliques arise from Corigliano itself.

- other cooperatives from Corigliano Calabro seem to use, instead, a very diversified approach in choosing their PO. 


\section{Conclusions}

By adopting the multidisciplinary approach, we wanted to highlight the importance of territorialization processes in the construction of social capital and economies, for the purpose of supporting the hypothesis that economic actions can be better understood in a framework of a broader rationality than that of self-interest attributed to homo oeconomicus. The territory was considered as a complex geographic reality, the result of specific interdependencies between environmental, socio-cultural and political factors that influence the dynamics of development. In-depth knowledge of the territorial context was a prerequisite for the study of the specific milieu and the specific dilemmas of collective action.

In the light of the specific territorial social capital, the different rationality of an agent defined as homo geographicus has emerged: an actor who can behave very differently from the way they are supposed to behave according to economic orthodoxy.

Given the peripheralization of the territory in question, within the work a greater emphasis was given to the endogenous social and environmental aspects, and to the ability to respond and adapt to the specific local context with respect to external constraints. By bearing this in mind, we did not neglect the analysis of the presence of the mafia phenomenon, which pervades the territory and branches out in the economies until it replaces the State in the control of certain functions, and in the appropriation of certain services in a quasi-monopoly regime.

In this perspective, the economy of clementines and the networks that are developed for their marketing have been read as embedded in the relational system of the specific territory. Therefore, the hypothesis is that cooperativism - a strategic factor for the marketing of citrus fruits - not only is one of the many forms of entrepreneurial management legal form, but also one of the structural dimensions of the social organization, strongly conditioned by the specific social capital.

With reference to the citrus fruit market, it was highlighted that the weakness of the territorial system in question is mainly found in the management of resources and collective services, in which collaborative behaviors are strategic. An expression of this weakness are both the infrastructural networks (seaport, railway, Reclamation consortium) and the relational networks between citrus fruit producers and cooperatives.

Social Network Analysis, applied to the dataset of first-degree commercialization cooperatives and to hierarchically higher-degree marketing cooperatives (POs), has proved to be a useful tool for representing and analyzing the characteristics of 
cooperative networks within the territory. The results of the network analysis, as well as the face-to-face interviews, seem to confirm the initial hypothesis, i.e. that the economic actor acts within a framework of rationality, in which the relational resources contained in the territorial social networks play an important role in the framework of cooperation and in designing the topology of emerging cliques.

This trend is observed when first-level cooperatives choose to associate with hierarchically superior organizations such as Producer Organizations.

Although better performances appear to correspond to the cooperatives that associate with POs outside the local circles, only $25 \%$ of the first-level cooperatives associate with POs outside the Sibari Plain. Weakness in concentrating supply through cooperatives - only $20 \%$ of producers are associated in some form - and the inability to build long lattices - only $5 \%$ of total clementine production is exported are a disadvantage to local producers both in terms of revenues and of competition with Spain and North African countries on foreign markets.

The ability to concentrate supply to create long networks is a crucial element both to be able to confer all the production in citrus campaigns - where there is over-production and internal markets become quickly saturated - and to obtain higher revenues. Faced with a strong dispersion of production, the concentration of supply therefore assumes a strategic value. The lack of organizational transformation of the sector, evidenced by the scarce collaboration, and the reduced density and length of the analyzed networks, especially in times of crisis, is a penalizing factor.

In particular, producers operating outside the cooperation networks could be the most fragile in dealing with the repercussions of increasing competitiveness and the effects of the ongoing climate crisis.

In conclusion, it could be interesting to compare the results emerged from this research experience with those of the territories with similar economies, but whose territorialization dynamics have followed different paths and outcomes.

The citrus economy characterising the coastal plain of the Province of Castellón appears to be the most directly comparable.

This is where the European largest production of clementines takes place (Generalitat Valenciana, 2019) and where the cultivation areas, huertas, are irrigated by canalized waters governed by long-life institutions, comunidad de regantes. These institutions were considered as one of the successful examples of collective natural resources management by Nobel Prize winner Elinor Ostrom in Governing the Commons (1990). 


\section{References}

AA. VV, Osservatorio della cooperazione agricola italiana, Rapporto 2017

AA.VV. Piano Strutturale Associato" (PSA) della Sibaritide, 2011

AA.VV. Sinab, Bio in cifre, Roma, 2018

AA. VV., Relazione geologica definitiva Piana di Sibari, 2015

Afan De Rivera C., Considerazioni su i mezzi da restituire il valore proprio a' doni che ha la natura largamente conceduto al Regno delle Due Sicilie, 3 Volumi, Napoli: Stamperia del Fibreno, 1832-1842

Alfano F. e Cersosimo D., Imprese agricole e sviluppo locale. Un percorso di analisi territoriale, Quaderni gruppo 2013, Edizioni Tellus, Roma

Arrighi G. and Piselli F., Capitalist Development in Hostile Environments: Feuds, Class Struggles, and. Migrations in a Peripheral Region of Southern Italy, in Review. Fernand Braudel Center, pp. 649-751, 1987

Arrighi G. and Piselli F., Il capitalismo in un contesto ostile, Donzelli: faide, lotta di classe, migrazioni nella Calabria tra Otto e Novecento, Roma, 2017

Asso P. F., New perspectives on old inequalities: Italy's north-south divide, Territory, Politics, Governance, 2020

Bandiera O., Land Reform, the Market for Protection, and the Origins of the Sicilian Mafia: Theory and Evidence, Journal of Law, Economics, and Organization 19, no. 1, pp. 218-44, 2003

Barábasi A-L., Link, La scienza delle reti, Einaudi, Torino, 2002

Bertalanffy von L., La teoria generale dei sistemi. Fondamenti, sviluppo, applicazioni, Mondadori, Milano 2014

Bowles S. Gintis, H., Social Capital and Community Governance, The Economic Journal, Volume 112, Issue 483, November, Pages F419-F436, 2002

Bellotti P. et al., La Piana di Sibari (Cosenza). Reciproche influenze tra variazioni morfologiche e popolamento, in Agri Centuriati, pp. 73-99, N. 3, 2006

Bellotti P. et al, Insediamenti umani in un paesaggio in evoluzione: interazione uomo-ambiente nella piana di Sibari (Calabria ionica), Quaternario Italian Journal of Quaternary Sciences 22 (1), pp. 61-72, 2009

Beltrán Tapia F.J., Commons, Social Capital and the Emergence of Agricultural Cooperatives in Early 20th Century Spain, European Review of Economic History, pp. 511-528, Oxford University Press, 2012

Bevilacqua P., Breve storia dell'Italia meridionale: dall'Ottocento a oggi, Donzelli, Roma 1993 Bevilacqua P., Storia del territorio o romanzo della natura?, Rivista Meridiana, n. 2, pp. 189-201, 1988

Bevilacqua P., Tra natura e storia, Ambiente, economie, risorse in Italia, Donzelli, Roma, 2000 
Bevilacqua P. and Placanica A. (a cura di), Storia d'Italia. Le regioni III: La Calabria, Einaudi, Torino, 1985

Bevilacqua P. and Rossi-Doria M., Le bonifiche in Italia dal '700 a oggi, Laterza, Bari, 1984

Biagianti I., La legislazione sulle bonifiche nell'Italia unita, in Rivista di storia dell'agricoltura, a. XXVII n. 2 (luglio-dicembre), pp. 231-249, 1987

Brunetti, D.: Cronotassi dell'agricoltura e della bonifica nella Piana di Sibari, Arti grafiche Joniche, Corigliano Calabro (CS), Italy, 1991

Capano G. e Marini M., Le trasformazioni dell'agricoltura della Calabria contemporanea, in A. Placanica (a cura di), Storia della Calabria Moderna e Contemporanea, Roma, 2005

Caruso F. S., Corrado A, Crisi e migrazioni nel Mediterraneo. I casi del Poniente Almeriense e della Piana di Sibari, in AgriregioniEuropa, anno $8 n^{\circ} 31,2012$

Cavazzani A. e Sivini G. a cura di, Arance amare. La crisi dell'agrumicoltura italiana e lo sviluppo di quella spagnola, Rubbettino, Soveria Mannelli, 1997

Cavazzani A. e Sivini G. a cura di, Dolci clementine. Innovazioni e problemi di un'agricoltura sviluppata. La Piana di Sibari, Rubbettino, Soveria Mannelli, 1997

Cersosimo D. a cura di, Una politica economica per la Calabria. Valori, strutture, attori, Rubbettino, Soveria Mannelli, 1996

Coleman J. S., Foundations of Social Theory, Cambridge, Harvard University Press, 1990.

Coleman J. S., Social Capital in the Creation of Human Capital, The American Journal of Sociology N. 94, The University Chicago Press, 1988

D'Amaro F., Acqua e potere. Istituzioni, mercato e abuso delle risorse irrigue. Palermo e Valencia (XX secolo), Tesi di Dottorato Università La Sapienza, Roma, Anno Accademico 2011-2013

Dematteis G., Le metafore della terra. La geografia umana tra mito e scienza, Feltrinelli, Milano, 1985

Dimico, A., Isopi, A., \& Olsson, O., Origins of the Sicilian Mafia: The Market for Lemons, The Journal of Economic History, 77(4), 1083-1115, 2017

Dorogovtsev, S.N. and Mendez J.F.F, Evolution of networks, Oxford University Press,

Eurispes, Indice di permeabilità dei territori alla criminalità organizzata, Eurispes, Roma, 2020

Eurispes - Coldiretti, Agromafie, terzo rapporto sui crimini agroalimentari in Italia, Minerva, Bologna, 2019

Falcone, G. et al.; M. Energetic and Economic Analyses for Agricultural Management Models: The Calabria PGI Clementine Case Study. Energies 2020, 13, 1289

Federico G., Breve storia economica dell'agricoltura, II Mulino, Bologna, 2009

Federico G., Ma l'agricoltura meridionale era davvero arretrata?, in Rivista di Politica Economica, pp. 317-340, 2007

Federico G., A Capital Intensive Innovation in a Capital-Scarce World: Steam-Threshing in 19th Century Italy, Advances in Agricultural Economic History, n. 2, 2003c, pp. 75-114

Flora A., Lo sviluppo economico: i fattori immateriali, nuove frontiere della ricerca, Franco Angeli, Milano, 2008 
Foley MW, Edwards B., Escape From Politics? Social Theory and the Social Capital Debate. American Behavioral Scientist;40(5):550-561, 1997

Fukuyama, F., Trust: the social virtues and the creation of prosperity, New York: Free Press, 1995

Gambetta D., La mafia siciliana. Un'industria della protezione privata, Einaudi, 1992

Gambi L., La Calabria, Utet, Torino, 1965

Garrido S., Plenty of trust, not much cooperation: social capital and collective action in early twentieth century eastern Spain, European Review of Economic History, Volume 18, Issue 4, Pages 413-432, November 2014

Garrido, S.; Planas, J. e Sabio, A., Asociacionismo y cooperativismo agrario: España en el contexto europeo, Historia Agraria, Revista de Agricultura e Historia Rural, 40, pp. 609-619, 2006

Governa F., La dimensione territoriale dello sviluppo socio-economico locale: dalle economie esterne distrettuali alle componenti del milieu, in Rappresentare i luoghi, metodi e tecniche, Alinea Editrice, Firenze, 2001

Governa F., Il milieu urbano, l'identità territoriale nei processi di sviluppo, Franco Angeli, Milano, 1997

Granovetter M., Struttura sociale ed esiti economici, in Stato e Mercato, n. 72, 2004

Granovetter M., The Impact of Social Structure on Economic Outcomes, Journal of Economic Perspectives-Volume 19, Number 1-Winter Pages 33-50, 2005

Granovetter M., The Strength of Weak Ties, American Journal of Sociology, Vol. 78, No. 6., May, pp 1360-1380, 1973

Granovetter M., Economic Action and Social Structure: The Problem of Embeddedness, American Journal of Sociology, vol. 91, no. 3,, pp. 481-510, 1985

Guillaume J.L. and Latapy M., Bipartite structure of all complex networks, Inf. Process. Lett., 90 (5), 2004

Hirschman A. O., 1970. Exit, Voice, and Loyalty: Responses to Decline in Firms, Organizations, and States. Cambridge, Massachusetts: Harvard University Press, 1970

Laursen, K., Masciarelli, F., Prencipe, A. , Trapped or spurred by the home region? The effects of potential social capital on involvement in foreign markets for goods and technology, Journal of International Business Studies, 43, 783-807, 2012b

Lazega E., Réseaux sociaux et structures relationnelles, Presses Universitaires de France PUF, Paris, 1998

Legambiente, Ecomafia 2017. Le storie ei numeri della criminalità ambientale in Italia, Edizioni ambiente, Milano, 2017

Locke, E. A., Motivation through conscious goal setting, Applied \& Preventive Psychology 5:117-124, Cambridge University Press, 1996

Locke, E. A., Beyond determinism and materialism, or isn't it time we took consciousness seriously?, Journal of Behavior Therapy \& Experimental Psychiatry, 26, 265-273, 1995

Lupo S., II giardino degli aranci. II mondo degli agrumi nella storia del mezzogiorno, Marsilio Editori, Venezia, 1990, 
Lupo S., Tra società locale e commercio a lunga distanza: la vicenda degli agrumi siciliani, Rivista Meridiana, N.. 1, MERCATI, pp. 81-112, 1987

Maggioli M., Dentro lo Spatial Turn: luogo e località, spazio e territorio, Semestrale di studi e ricerche di geografia, N. 2, 2015

Magnaghi A (a cura), Rappresentare i luoghi. Metodi e tecniche, Alinea, Firenze 2001

Marcianò C. e Palladino M., Analisi del capitale sociale in I distretti rurali in Calabria aspetti teorici, metodologici ed applicativi, a cura di Gulisano G. e Marcianò C., pp. 247-280 Editrice KALiT, Reggio Calabria, 2008

Marini M., Note metodologiche sullo studio di un caso di sviluppo locale, Atti conferenza Aisre, Palermo 2013

Marshall A., Scritti sull'economia cooperativa, II Mulino, Bologna, 2014

MIPAAF-ISMEA., La competitività della filiera agrumicola in Italia, 2020

Mirzabaev, A., et. al., Desertification, In Climate Change and Land: an IPCC special report on climate change, desertification, land degradation, sustainable land management, food security, and greenhouse gas fluxes in terrestrial ecosystems, In press., 2019

Murdoch, J., Marsden, T., \& Banks, J., Quality, nature, and embeddedness: Some theoretical considerations in the context of the food sector, Economic Geography, 76, 107-125, 2000

Nicoletti L., Uno spazio per città medie e "micropoli". II caso della Calabria, in Itinerari di ricerca storica XXVII n.1, 2013.

North, D. C., Institutions, Institutional Change and Economic Performance, Cambridge: Cambridge University Press, 190

Olson M., Potere e mercato. Regimi politici e crescita economica, Università Bocconi Editore, Milano, 2001

Österberg P. \& Nilsson J. Members' perception of their participation in the governance of cooperatives: the key to trust and commitment in agricultural cooperatives, in Agribusiness, 25: 181-197, 2009

Ostrom E., Governare i beni collettivi, Marsilio, Venezia, 2006

Peltomaki M. and Alava M., Correlations in bipartite collaboration networks, J. Stat. Mech., P01010, 2006

Petriccione G. e Solazzo R., Le Organizzazioni dei produttori nell'agricoltura italiana, in Agriregionieuropa anno $8 n^{\circ} 30,2012$

Petrone F., Agrumicoltura e cooperazione. Studio di un caso calabrese, Rubbettino, Soveria Mannelli, 1995

Petrucci O. and Polemio M., Flood risk mitigation and anthropogenic modifications of a coastal plain in southern Italy: combined effects over the past 150 years, in Natural Hazards and Earth System Sciences pp.361-373, Copernicus Publications on behalf of the European Geosciences Union, 2007

Petrusewicz M., Latifondo: economia morale e vita materiale in una periferia dell'Ottocento, Marsilio, Venezia, 1989

Piselli F., Capitale sociale: un concetto situazionale e dinamico, in Stato e Mercato n. 57, 1999 
Placanica A., Storia della Calabria dall'antichità ai giorni nostri, Donzelli, Roma, 1999

Polemio M. et al., La risorsa idrica. Sfruttamento, depauperamento dei serbatoi sotterranei e utilizzo razionale nel caso della Calabria, Rendiconti Accademia Nazionale delle Scienze detta dei XL, L'acqua in Calabria: risorsa o problema?, pag. 11-29, 2013

Prigogine I, La fine delle certezze. Il tempo, il caos e le leggi della natura, Bollati Boringhieri, Torino, 2014

Putnam RD., The Prosperous Community: Social Capital and Public Life, The American Prospect (13) :35-42, 1993

Raffestin C., Per una geografia del potere, Unicopli, Trezzano S/N, 1981

Rose R., Getting Things Done In An Anti-Modern Society: Social Capital Networks in Russia, in Social Capital, a multifaceted perspective, edited by Partha Dasgupta, Ismail Serageldin, The International Bank for Reconstruction and Development/THE WORLD BANK, Washington D.C., 2000

Rossi Doria M., Dieci anni di Politica agraria nel mezzogiorno, Laterza, Bari, 1958

Rossi Doria M., Struttura e problemi dell'agricoltura meridionale, in Riforma agraria e azione meridionalista, Edagricole, Bologna, 1956

Russo A., Il caso di studio: dall'impresa cooperativa al distretto produttivo locale, Atti conferenza Aisre, Palermo, 2013

Russo A., Dallo sviluppo della cooperazione allo sviluppo attraverso la cooperazione, in Stato e Mercato, 101 p. 259-287, 2014

Sack R. D., Homo Geographicus: A Framework for Action, Awareness, and Moral Concern, Johns Hopkins University Press, 1997

Sabatini F., Il capitale sociale nelle regioni italiane: un'analisi comparata, Rivista di Politica Economica, SIPI Spa, vol. 99(2), pages 167-220, April-Jun, 2009

Salvini A. a cura di, L'analisi delle reti sociali, risorse e meccanismi, Ed. Plus, Pisa University Press, Pisa, 2005

Sciarrone R. a cura di, Mafie del nord: Strategie criminali e contesti locali, Donzelli, Roma, 2019

Sciarrone R., 'Ndrangheta: A reticular organization, in The 'Ndrangheta and Sacra corona unita, 2014, pp. 81-99, Cham:Springer,, 2014

Sciarrone R. a cura di, Alleanze nell'ombra. Mafie ed economie locali in Sicilia e nel Mezzogiorno, Donzelli, Roma, 2011

Sciarrone R., Le mafie dalla società locale all'economia globale, in Rivista Meridiana, N. 43, 2002

Sciarrone R., Il capitale sociale della mafia. Relazioni esterne e controllo del territorio, Quaderni di Sociologia, 18, pp. 51-72, 1998

Schweitzer, F., Fagiolo G., Sornette D., Vega-Redondo F., Vespignani A., White D.R., Economic Networks: The New Challenges, Science, 24 July 2009, Vol. 325, No. 5939, pp. 422-425, 2009

Sneppen K., Rosvall M. and Trusina A., A simple model for self-organization of bipartite networks, Europhys. Lett., 67 (3), pp. 349-354, 2004 
Sokol M., Economic Geographies of Globalisation, Edward Elgar Publishing, Cheltenham, 2011

Trigilia, C., Why the Italian Mezzogiorno did not achieve a sustainable growth: Social capital and political constraints, in Cambio. Rivista Sulle Trasformazioni Sociali, 2 (4), 137-148, 2016 Trigilia C., Capitale sociale e sviluppo locale, in Stato e mercato, N.3, pp. 419-440, 1999 Trigilia C., Le condizioni "non economiche" dello sviluppo: problemi di ricerca sul Mezzogiorno d'oggi, in Rivista Meridiana, n. 2, 1988.

Turco A., Verso una teoria geografica della complessità, Unicopli, Milano, 1988

Uzzi B., The Sources and Consequences of Embeddedness for the Economic Performance of Organizations: The Network Effect, American Sociological Review, 61(4), 674-698, 1996 Vallega A., La Regione, sistema territoriale sostenibile. Compendio di geografia regionale sistematica, Mursia, 1995

Zamagni V., (1978). Industrializzazione e squilibri regionali in Italia. Bilancio dell'età giolittiana, II Mulino, Bologna, 1978

\section{Consulted websites}

agriregionieuropa.univpm.it/

http://agroambient.gva.es/va/

www.britannica.com/

www.cbjoniocosentino.it/

www.eurostat.eu

www.fao.org

geoportale.regione.calabria.it/opendata

www.inea.it

www.istat.it

www.mipaaf.it

www.oced.org

www.osservatori.net/it/ricerche/osservatori-attivi/smart-agrifood

www.sinab.it/

www.registroimprese.it/

ww.treccani.it/enciclopedia 
